\title{
Kryokonservierung von \\ Bullensperma in kleinen Volumina
}

\author{
Dissertation \\ zur Erlangung des Doktorgrades \\ der Fakultät für Agrarwissenschaften \\ der Georg-August-Universität Göttingen
}

vorgelegt von

Marlene Sophie Strothmeyer

geboren in Göttingen

Göttingen, Mai 2013 
D 7

1. Referent: Prof. Dr. Christoph Knorr

2. Korreferent: Prof. Dr. Detlef Rath

Tag der mündlichen Prüfung: 16. Mai 2013 
Für

Mathilda Sophie

und Leopold 
Abkürzungsverzeichnis ix

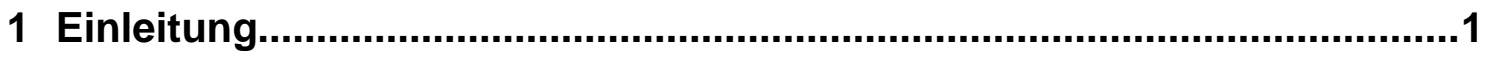

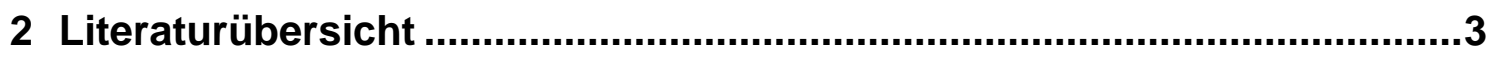

2.1 Physiologie des Spermientransports durch den Uterus .........................

2.1.1 Spermientransport im weiblichen Genitaltrakt...........................4

2.1.2 Kapazitation und Akrosomreaktion .....................................6

2.2 Zusammenhang zwischen Fruchtbarkeitsvorhersage aufgrund von Spermaqualitätsuntersuchungen und der Fertilität ..........................8

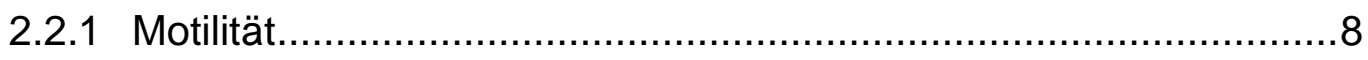

2.2.2 Morphologie .............................................................. 12

2.2.3 Durchflusszytometrische Spermabeurteilung ......................... 14

2.3 Kryokonservierung von Bullensperma ........................................... 17

2.3.1 Auswirkungen der Kryokonservierung auf die Spermienintegrität 17

2.3.2 Kompensierbare und nicht kompensierbare Spermienmängel....20

2.3.3 Einfluss des Auftauprozesses ...............................................21

2.3.4 Kryokonservierung kleiner Zellmengen bzw. Volumina...............22

2.3.5 Alternativen zur Tiefgefrierung von Bullensperma in Straws ........24

2.4 Minimierung der Spermienzahl zur Nachkommenerzeugung ...............27

2.5 Intrauterine und intracornuale Besamung .......................................29

2.6 Spermien- und Gametentransfer in den Eileiter...............................31

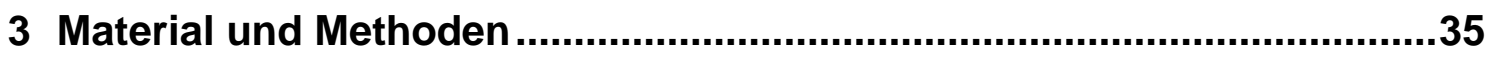

3.1 Wiederkehrende Arbeitsschritte ................................................. 36

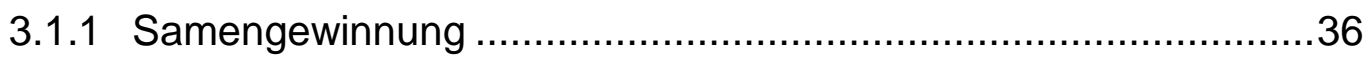

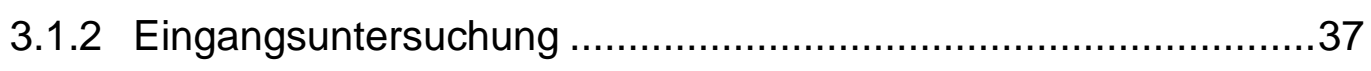

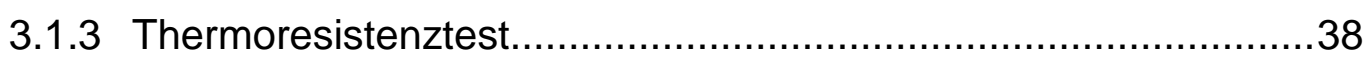

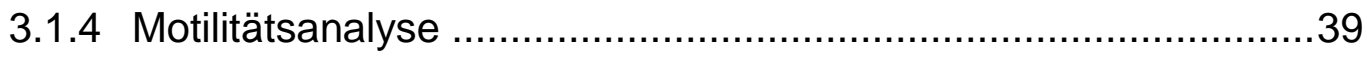

3.1.5 Morphologische Untersuchung ......................................... 39

3.1.6 Durchflusszytometrische Untersuchungen .............................40

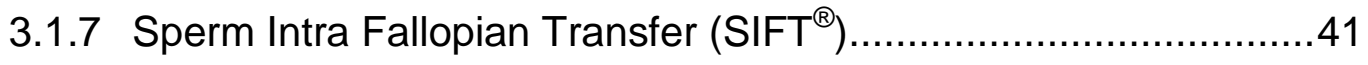

3.1.8 Entwicklung eines Nanostraws und dessen Handhabung............44

3.1.9 Sperma-Sexing .............................................................. 45

3.2 Versuch 1: Screeningversuche zur Entwicklung eines angepassten

Kryokonservierungsprotokolls mit einer volumen-reduzierten

Spermaportion im Nanostraw ..................................................4 47

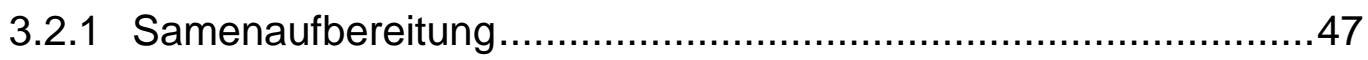

3.2.2 Kryokonservierung der Spermien..................................... 48

3.2.3 Auftauen der Spermien ................................................ 50 
3.3 Versuch 2: Qualitätsüberprüfung der in Versuch 1 entwickelten Kühlkurve und der tiefgefrorenen Spermien im Nanostraw mittels etablierter

Laborverfahren .51

3.3.1 Spermatologische Qualitätsanalyse ..................................51

3.3.2 Kryokonservierung der Spermien......................................51

3.3.3 Auftauen der Spermien ...................................................51

3.4 Versuch 3: SIFT $^{\circledR}$ mit Frischsamen (gesext) ................................. 52

3.5 Versuch 4: Besamungsversuch SIFT ${ }^{\circledR}$-Tiefgefriersperma .....................54

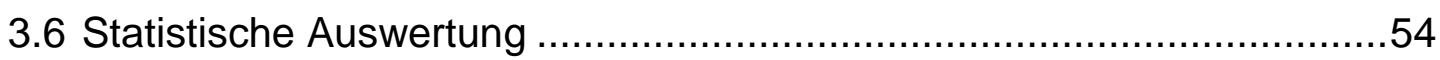

4 Ergebnisse. .56

4.1 Versuch 1: Screeningversuche zur Entwicklung eines angepassten Kryokonservierungsprotokolls mit volumen-reduzierten Spermaportionen im Nanostraw. .56

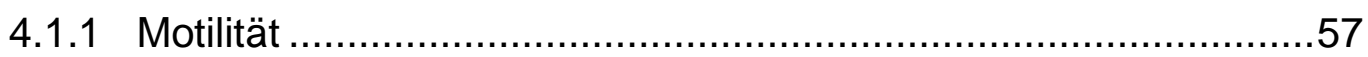

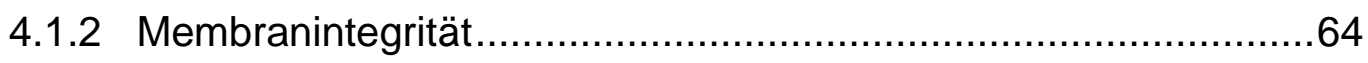

4.1.3 Morphologie ................................................................. 65

4.2 Versuch 2: Qualitätsüberprüfung der in Versuch 1 entwickelten Kühlkurve und der tiefgefrorenen Spermien im Nanostraw mittels etablierter Laborverfahren ......................................................................68

4.2.1 Auswertung der spermatologischen Qualitätsparameter.............68

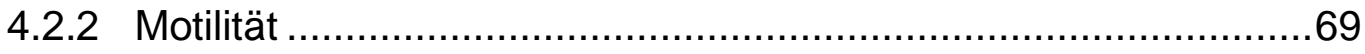

4.2.3 Membranintegrität..................................................... 73

4.2.4 Morphologie .............................................................. 75

4.3 Versuch 3: SIFT mit Frischsamen (gesext) .................................. 78

4.3.1 Trächtigkeitsergebnisse der Färsen ....................................78

4.3.2 Trächtigkeitsergebnisse der Kühe ....................................... 80

4.4 Versuch 4: Besamungsversuch SIFT ${ }^{\circledR}$ - TG-Sperma ...........................82

4.4.1 Trächtigkeitsergebnisse der Färsen ..................................82

4.4.2 Trächtigkeitsergebnisse der Kühe..................................... 83

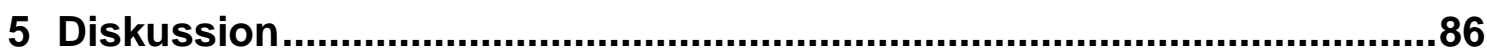

5.1 Laboruntersuchungen....................................................... 87

5.1.1 Versuch 1: Screeningversuche zur Entwicklung eines angepassten Kryokonservierungsprotokolls mit einer volumenreduzierten Spermaportion im Nanostraw . .87

5.1.2 Auftauen der Nanostraws.

5.1.3 Versuch 2: Qualitätsüberprüfung der in Versuch 1 entwickelten Kühlkurve und der tiefgefrorenen Spermien im Nanostraw mittels etablierter Laborverfahren..................................................92

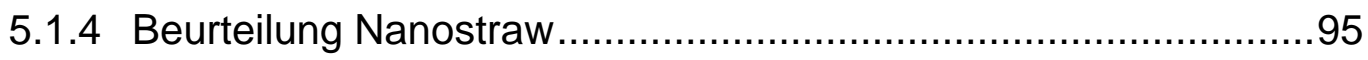


5.2 Einsatz von Sperma aus Nanostraws für SIFT ${ }^{\circledR}$ .97

5.2.1 Versuch 3: Besamungsversuch $\mathrm{SIFT}^{\circledR}$ - Frischsamen (gesext) ....97

5.2.2 Versuch 4: Besamungsversuch SIFT ${ }^{\circledR}$ TG-Sperma .....................99

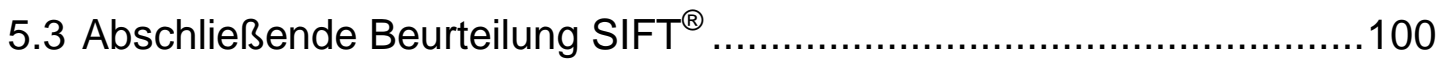

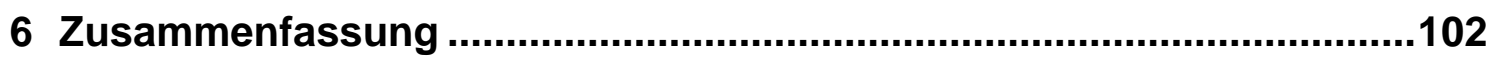

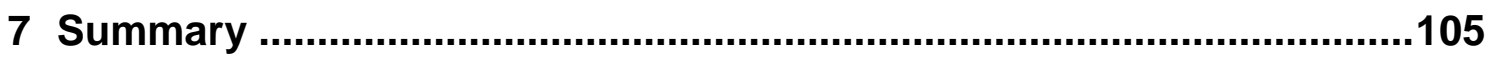

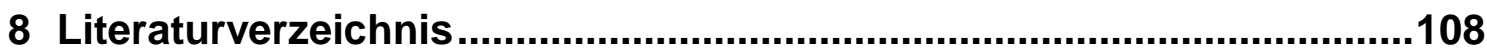

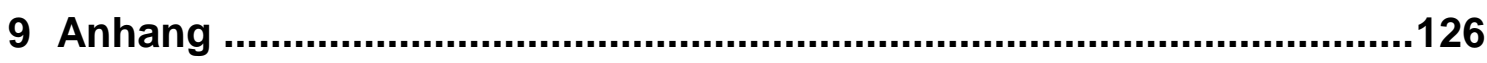

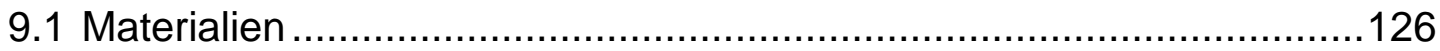

9.2 Zusammensetzung der Verdünner ................................................126

9.3 Parametereinstellungen CASA (Version 12 IVOS, Hamilton .................128

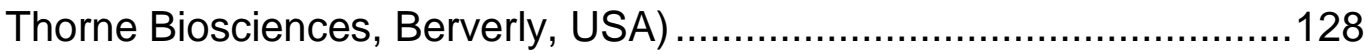

9.4 Parametereinstellungen Durchflusszytometer (FACScan $\odot$, .................129

Becton, Dickinson, Biosciences, Heidelberg, Deutschland) .................129

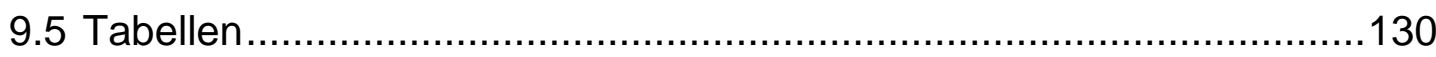

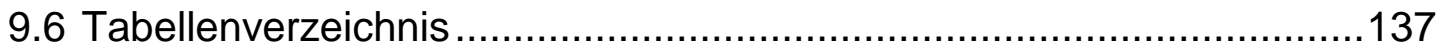

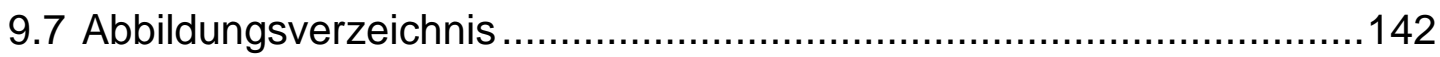

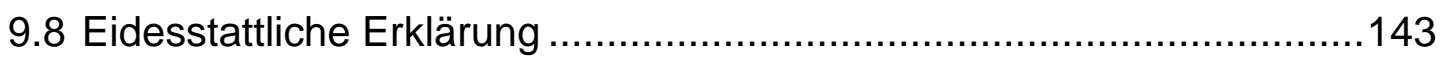

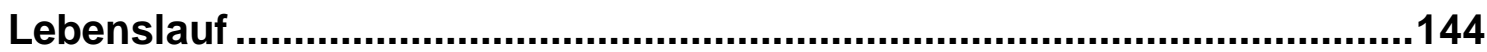




\section{Abkürzungsverzeichnis}

\begin{tabular}{|c|c|}
\hline ALH & Amplitude of Lateral Head Displacement \\
\hline ATP & Adenosintriphosphat \\
\hline BCF & Beat Cross Frequency \\
\hline BSA & Bovines Serum Albumin \\
\hline BSP & Bovines Seminal Plasmaprotein \\
\hline $\mathrm{Ca}$ & Kalzium \\
\hline $\mathrm{CaCl}$ & Kalziumchlorid \\
\hline CASA & Computer Assisted Sperm Analysis \\
\hline DFI & Defragmentationsindex \\
\hline DMSO & Dimethylsulfoxid \\
\hline DNA & Deoxyribonucleic acid \\
\hline EDTA & Ethylendiamintetraessigsäure \\
\hline ER & Endoplasmatisches Retikulum \\
\hline ET & Embryotransfer \\
\hline FACS & Fluorescence activated cell sorting \\
\hline FITC & Fluoresceinisothiocyanat \\
\hline GIFT & Gameten intrafallopian transfer \\
\hline Hsp & Hitzeschockprotein \\
\hline ING & Institut für Nutztiergenetik \\
\hline IVF & In-vitro-Fertilisation \\
\hline IVP & In vitro Produktion \\
\hline KB & Künstliche Besamung \\
\hline LIN & Linearity \\
\hline LSM & Least Squares Mean \\
\hline $\mathrm{LN}_{2}$ & Flüssiger Stickstoff \\
\hline NRR56 & Non-Return-Rate am Tag 56 nach Belegung \\
\hline OPU & Ovum Pick Up \\
\hline PBS & Phosphatgepufferte Salzlösung \\
\hline$P G$ & Prostaglandin \\
\hline $\mathrm{Pl}$ & Propidiumiodid \\
\hline psi & Pound per square inch ( 1 psi $\bumpeq 0,0689$ bar) \\
\hline PSP & Porcines Seminalplasma \\
\hline PTFE & Polytetrafluoroethylen \\
\hline ROS & Reactive Oxygen Species \\
\hline PUFA & Polyansaturated fatty acids \\
\hline SCSA & Spermien-Chromatinstruktur-Analyse \\
\hline SEM & Standardfehler \\
\hline SIFT & Sperm-Intra-Fallopian-Transfer \\
\hline SOD & Superoxid-Dismutase \\
\hline STR & Straightness \\
\hline SZ & Samenzellen \\
\hline$\overline{T G}$ & tiefgefroren \\
\hline TRIS & Tris-Hydroxymethyl-Aminomethan \\
\hline TU & Trächtigkeitsuntersuchung \\
\hline UV & Ultraviolett \\
\hline VAP & Velocity average path \\
\hline VCL & Velocity curve line \\
\hline VSL & Velocity straight line \\
\hline
\end{tabular}




\section{$1 \quad$ Einleitung}

Die künstliche Besamung $(\mathrm{KB})$ ist ein bewährtes und erfolgreiches reproduktionsbiotechnologisches Verfahren bei landwirtschaftlichen Nutztieren. In den 60 iger Jahren des letzten Jahrhunderts stand zunächst die Eindämmung von Deckseuchen mit Hilfe dieser Technik im Vordergrund; heute dient die KB tierzüchterischen Aspekten, die eine zeit- und ortsunabhängige Besamung selektierter Elterntiere ermöglicht (Busch, 2007). Durch die Entdeckung der kryoprotektiven Eigenschaften von Glyzerin beim Tiefgefrieren von Hühnersperma wurde der Grundstein der künstlichen Besamung mit Tiefgefriersperma (TG) gelegt (POLGE ET AL., 1949). Die Entwicklung effizienter Spermakonservierungstechniken macht die instrumentelle Samenübertragung heute in sehr vielen landwirtschaftlichen Nutztierbeständen möglich. Ein Ziel der Besamung ist es, die Ejakulate der männlichen Spendertiere optimal zu nutzen und weibliche Tiere mit möglichst wenigen Spermien zu besamen ohne dabei Einbußen bei der Non-Return-Rate (NRR) zu riskieren (DEN DAAS ET AL., 1998).

Seit der Einführung der genomischen Zuchtwertschätzung im Jahr 2010 werden die Bullen bereits mit Beginn der Geschlechtsreife zur Spermaproduktion eingesetzt. Da Jungbullen deutlich kleinere Ejakulate als Altbullen produzieren, die gleichzeitig erheblich weniger Spermien enthalten, ist eine weitergehende Nutzungsstrategie für Einzelejakulate erforderlich. Tiefgefrorene Spermaportionen enthalten üblicherweise im Schnitt 10-15 x 106 Samenzellen/230 $\mu$ l (CRAMER ET AL., 2009). Die kürzlich am Institut für Nutztiergenetik Mariensee entwickelte Methode SIFT ${ }^{\circledR}$ (Sperm-Intra-Fallopian-Transfer) ermöglicht es, minimale Spermakonzentrationen nicht chirurgisch in den Eileiter zu übertragen. Ein wesentlicher Vorteil der Methode SIFT ${ }^{\circledR}$ ist die Reduzierung des Besamungsvolumens unter Beibehaltung des Volumen-/Mengenverhältnisses.

Zielsetzung dieser Arbeit war es, die in Volumen und Spermienzahl reduzierte Spermaportion neu zu konfektionieren und ein angepasstes Kühl- sowie Gefrierprotokoll zu entwickeln. Dabei sollten vergleichbare Auftauqualitäten wie in einer üblichen Besamungsportion erreicht werden. Die Qualität des Spermas 
wurde dabei sowohl unter Laborbedingungen als auch in Testbesamungen an Einzeltieren überprüft. 


\section{$2 \quad$ Literaturübersicht}

In der Literatur werden Begriffsdefinitionen oft unterschiedlich ausgelegt. Für die folgende Literaturstudie wurden Begriffsdefinitionen festgelegt und darauf zurückgegriffen bzw. korrigiert, wenn die Begriffe in der zitierten Literatur anders verwendet wurden.

1. Befruchtungsrate: beschreibt die Anzahl in vitro befruchteter im Reagenzglas ausgezählter Eizellen.

2. Geschlechtsreife: ist der Zeitpunkt an dem die Fortpflanzungsfähigkeit und somit die Reife, um sich fortzupflanzen, erreicht wurde.

3. Sperma: ist die Befruchtungsflüssigkeit männlicher Tiere, die sich aus Spermien, Epithelzellen, Sekreten der Hodenkanälchen und Seminalplasma zusammensetzt.

4. Spermien: sind die reifen männlichen Samenzellen.

5. Trächtigkeitsrate: gibt den prozentualen Anteil tragender Tiere an den besamten Tieren an.

6. Zuchtreife: beschreibt den Zeitraum in dem ein Tier erstmals zur Zucht herangezogen wird.

\subsection{Physiologie des Spermientransports durch den Uterus}

Für eine erfolgreiche Befruchtung spielen die Vitalität und Funktionalität der Spermien auf dem Weg zur Eileiterampulle eine entscheidende Rolle. Durch eine hohe Vitalität und eine ausreichende Funktionalität werden die Fusion des Spermiums mit der Eizelle und die Entwicklung des Embryos sichergestellt (HAWK, 1983).

Ein Bullenejakulat enthält ca. 5-12 x 109 Spermien, welche beim natürlichen Paarungsakt in das kraniale Scheidengewölbe abgesetzt werden. Die Sper- 
mienzahl reduziert sich auf dem Weg in den Eileiter. Im Uterus beträgt die Spermienzahl noch $10^{6}$ Spermien $/ \mathrm{ml}$, im kaudalen Isthmus $10^{4}$ Spermien $/ \mathrm{ml}$ und in der Eileiterampulle ist sie bereits auf $10^{2}$ Spermien pro Milliliter zurück gegangen (HAWK, 1983; LARSSON, 1988).

\subsubsection{Spermientransport im weiblichen Genitaltrakt}

Damit die Spermien mit der Eizelle fusionieren können, müssen sie vom Ablageort bis in die Ampulle des Eileiters transportiert werden. Dabei müssen sie einen multifunktionellen Selektionsprozess durchlaufen, der sowohl aus mechanischen Barrieren, wie den Krypten und Falten der Zervix besteht, als auch immunologischen und chemischen Mechanismen (Vaginalsekret, Zervikalmukus) unterliegt (TöPFER-PETERSEN UND WABERSKI, 2001). Bei Scheidenbesamern wie dem Rind ist die Zervix das erste Spermienreservoir. Die Drüsen der Zervixschleimhaut produzieren einen Schleim, der geschädigte Spermien, Seminalplasma und Bakterien vorab selektiert (TÖPFER-PETERSEN UND WABERSKI, 2001). Das Spermienreservoir wird in den Zervikalkrypten gebildet. In innen herrscht ein spermienfreundliches Milieu, das eine Migration der Spermien gegen den vaginalwärts gerichteten, spermienfeindlichen Strom des Schleims aus dem Zervixlumen ermöglicht (HAWK, 1987). Bei der KB wird dieses Reservoir umgangen (VISHWANATH, 2003; WENDT, 2007; RATH UND JOHNSON, 2008) und die Spermien werden im kranialen Zervikalabschnitt oder im Uteruskörper abgesetzt.

Das zweite funktionelle Spermienreservoir beim Rind ist der kaudale Isthmus des Eileiters. Die Spermien können dort bis zu 24 Stunden überleben und werden vor Phagozytose und frühzeitiger Kapazitation geschützt (SUAREZ, 2002). Als Voraussetzung für das Überleben gilt die Bindung der Spermien an das Eileiterepithel. Über bovine Seminalplasmaproteine (BSP) an der Oberfläche der Spermien binden diese über Fukoseliganden an die Zilien des Eileiters. Die bovinen Seminalplasmaproteine spielen eine wichtige Rolle bei der Kapazitation, der Akrosomreaktion, der Motilität der Spermien und der Fusion von Spermium und Eizelle (GWATHMEY ET AL. 2003; SUAREZ, 2007). 
Nach KILLIAN ET AL. (1993) geben höhere Anteile der Proteine 26kDa (pl 6,2) und $55 \mathrm{kDa}(\mathrm{pl} 4,5)$ im Seminalplasma Hinweise auf eine bessere Fruchtbarkeit des

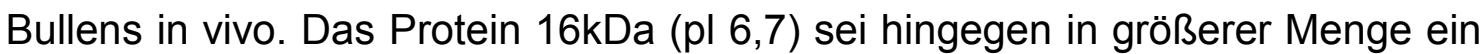
Anzeiger für eine verminderte Fertilität. Es wurde ein Regressionsmodell entwickelt, um anhand der Proteine die Fruchtbarkeit eines Ejakulates vorauszusagen. Dabei zeigte sich ein lineare positive Korrelation $(r=0,89)$ zwischen der tatsächlichen und der vorhergesagten Befruchtungsfähigkeit der Ejakulate aufgrund der genannten Anteile der Proteine (KILLIAN ET AL., 1993). Die Autoren vermuten, dass es sich hierbei um die Phospholipase $A_{2}$ und die heparinbindenden Proteine BSP-A1, BSP-A2 und BSP-A3 handelt, die während der Ejakulation an Cholinphospholipide der Plasmamembran binden und den Cholesterolefflux fördern (KILLIAN ET AL., 1993). Ein weiteres Protein PDC-109 gehört zu der Gruppe der heparin-bindenden Seminalplasmaproteine und bindet während der Ejakulation durch Phospholipidbindungen an die Spermienoberfläche. Gleichzeitig induziert es die Kapazitation (DESNOYERS UND MANJUNATH, 1992; TaleVI Und GualtierI, 2010). Proteine an der Oberfläche des Eileiterepithels, sogenannte Annexine, die eine hohe Affinität zu Heparin aufweisen, wirken als Spermienrezeptoren. PDC-109 bindet an die Fukose am Annexin und so an die Oberfläche des Eileiterepithels (ISHITSUKA ET AL., 1998). Ähnliche Bindungseigenschaften wurden für die Seminalplasmaproteine BSPA3 und BSP30K entdeckt (GWATHMEY ET AL., 2006).

HAWK (1983) vermutete zunächst, dass beim Kaninchen die Spermien in einem ersten initialen schnellen passiven Transport bereits innerhalb weniger Minuten zum Ovidukt gelangen. Die Befruchtungsfähigkeit dieser Spermien wurde jedoch angezweifelt. Als mögliche Ursache für den schnellen Transport wurde die Anregung der Myometriumkontraktion durch den Kopulations- und Inseminationsvorgang vermutet. Vier Jahre später widerlegte HAWK (1987) seine ersten Vermutungen. Er beschrieb, dass befruchtungsfähige Spermien den Eileiter ca. acht Stunden nach dem Deckakt erreichen und dort bis zur Ovulation verweilen. Dabei wird der größte Anteil der Spermien innerhalb von 24 Stunden nach der Befruchtung wieder in die Vagina abgegeben. Der Spermientransport erfolgt durch die Kontraktionen des weiblichen Genitaltraktes (HAWK, 1987). HUNTER (2003) beschrieb, dass Hormone des Seminalplasmas, wie z.B. Prostaglandine, 
die Kontraktion der Uterusmuskulatur und somit den Spermientransport stimulieren (HUNTER, 2003).

Für das Schwein wird vermutet, dass intakte Spermien auch im Uterus gebunden werden, um das Reservoir im Ovidukt für einen längeren Zeitraum zu versorgen (TAYLOR ET AL., 2008). Untersuchungen am Schwein zeigten, dass die Spermien mit den uterinen Epithelzellen interagieren (RODRIGUEZ-MARTINEZ ET AL. 1990). Der Grund hierfür ist jedoch noch weitgehend unbekannt. Eine mögliche Erklärung könnte eine noch nicht abgeschlossene Reifung der Spermien sein, die sich während der Bindung an die Epithelzellen weiterentwickeln können. Die Spermien stehen dem Reservoir im Eileiter so für einen längeren Zeitraum als befruchtungskompetente Spermien zur Verfügung (MÖNCH-TEGEDER, 2011). Nach RATH UND JOHNSON (2008) kann jedoch eine Besamung mit einer

geringeren Anzahl an Spermien dazu führen, dass das Spermienreservoir im Uterus nicht ausreichend aufgebaut wird, wodurch die Zeit für eine erfolgreiche Besamung reduziert wird. Besonders kritisch sei dies zu bewerten, wenn die Lebensfähigkeit der Spermien durch Kryokonservierung und Sortierung des Spermas verringert wird (RATH UND JOHNSON, 2008). SUAREZ (2007) beschrieb zudem eine reduzierte Lebensfähigkeit und Fruchtbarkeit der Spermien durch den flowzytometrischen Sortierprozess. Durch die Belastungen der Spermien kann deren Transport durch den Uterus sowie die Bindung und Entwicklung des Spermienreservoirs eingeschränkt werden (SUAREZ, 2007).

\subsubsection{Kapazitation und Akrosomreaktion}

Im weiblichen Genitaltrakt durchlaufen die Spermien komplexe membranstrukturelle und metabolische Veränderungen bis sie an die Zona pellucida binden, um mit der Eizelle zu fusionieren (AustiN, 1951). Dieser Vorgang wird unter dem Begriff Kapazitation zusammengefasst (AustIN, 1960). Die genauen Abläufe der Kapazitation sind noch nicht im Detail geklärt und können speziesabhängig durchaus unterschiedlich verlaufen. Die Kapazitation ist essentiell für die Befruchtungsfähigkeit, da die Spermien hyperaktiviert werden und somit zur Interaktion mit der Zona pellucida der Eizelle befähigt sind (KLEWITZ, 2009). All- 
gemein werden bei der Kapazitation zu Beginn oberflächenassoziierte schützende Proteine, die sogenannten Dekapazitationsfaktoren entfernt. Dieser Vorgang macht die Spermienmembran durchlässig für lipidbindende Proteine des Eileiters, die einen Cholesterinefflux aus der Plasmamembran bewirken (TÖPFER-PETERSEN UND WABERSKI, 2001). Durch die Umverteilung von Proteinen und Lipiden in der Zellmembran werden lonenkanäle aktiviert und es kommt zum Einstrom von extrazellulären Calziumionen, was zur Phosphorylierung der Proteine führt. Insgesamt kommt es zur Destabilisierung der Zellmembran der Spermien und zu einer Erschöpfung des Metabolismus (TÖPFER-PETERSEN, 2007). Der Eileiter selektiert unkapazitierte Spermien, die durch einen niedrigen Kalziumspiegel und eine geringfügige Tyrosinphosphorylierung von Proteinen der akrosomalen Region des Kopfes charakterisiert sind. Diese Vorgänge werden bei gebundenen Spermien am Eileiter zeitweise unterdrückt. Zum Ovulationspunkt beginnen die Spermien zu hyperaktivieren, lösen sich vom Eileiterepithel und schwimmen auf die Eizelle zu (TöPFER-PETERSEN, 2007).

Die Kapazitation ist Voraussetzung für die Akrosomreaktion. Nachdem das Spermium über Glykoproteine der Zona pellucida gebunden wird, werden entscheidende Signalkaskaden zur Auslösung der Akrosomreaktion im Zellinneren freigegeben (BREITBART, 2003). Eine weitere Induktion der Akrosomreaktion liefert das in der Umgebung der Zona pellucida befindliche Progesteron (FLESCH UND GADELLA, 2000). Die durch die Signalkaskade hervorgerufene Erhöhung der intrazellulären Kalziumkonzentration führt zur Aktivierung der Proteinkinase C, wodurch Proteine aktiviert werden, die das Verschmelzen der Plasmamembran mit der äußeren Akrosommembran bewirken (FLESCH UND GADELLA, 2000; RATHI ET AL., 2003). Vesikel und Poren in der Spermamembran öffnen sich, und es kommt zur Freisetzung der akrosomalen Inhaltsstoffe. Hierauf folgt die Proteolyse der Zona pellucida, wodurch das hyperaktivierte und kapazitierte Spermium in die Eizelle penetrieren kann (TöPFER-PETERSEN, 2007).

Neben der oben genannten Akrosomvorbereitung, können auch autolytische Prozesse Veränderungen des Akrosoms auslösen, die Ähnlichkeit mit der Akrosomreaktion haben (KLEWITZ, 2009). Das Einfrieren der Spermien in flüssigem Stickstoff und das Auftauen der Spermien im Wasserbad bei $38^{\circ} \mathrm{C}$ kann zu einer 
Destabilisierung der Spermamembran führen, wodurch Vorgänge ähnlich der Kapazitation ausgelöst werden. Dadurch wird der Transport der Spermien beeinflusst und es kommt zu einer frühzeitigen Akrosomreaktion (WATSON, 1995; BAILEY ET AL., 2000). BEDFORD (1970) unterscheidet daher zwischen der falschen und echten Akrosomreaktion. Spermien nach falscher Akrosomreaktion sowie vorzeitig ausgelöster echter Akrosomreaktion sind nicht mehr in der Lage, an die Zona pellucida zu binden (FAZELI ET AL., 1997; SPINACI ET AL., 2010).

\subsection{Zusammenhang zwischen Fruchtbarkeitsvorhersage aufgrund von Spermaqualitätsuntersuchungen und der Fertilität}

In der Fachliteratur finden sich sehr unterschiedliche Aussagen über den $\mathrm{Zu}$ sammenhang zwischen den Ergebnissen spermatologischer Untersuchungsmethoden und der Fruchtbarkeit nach Besamung. Eine sichere Aussage anhand der spermatologischen Labordaten über die potenzielle Fruchtbarkeit zu treffen, ist aufgrund der noch nicht vollständig bekannten Faktoren, die zu einer erfolgreichen KB führen, schwierig (DEJARNETTE UND MARSHALL, 2005). Betrachtet man alle Aspekte, die sich auf eine erfolgreiche Besamung und die NRR56 auswirken, machen die Effekte des Bullen und des Ejakulates nur lediglich 0,4\% (Christensen et AL., 2005) bis 1,0\% (StÅlmammar et AL., 1994) aus. Neben Umwelteffekten, Herdeneinfluss und Ausbildungsstand des Besamungstechnikers beträgt die Restvarianz 95\% (CHRISTENSEN ET AL., 2005).

\subsubsection{Motilität}

Die Bewegungsaktivität (Motilität) ist ein wichtiger funktioneller Parameter der Spermien. Die mikroskopische Schätzung der Motilität unter dem Phasenkontrastmikroskop mit einem auf $38^{\circ} \mathrm{C}$ temperierten Heiztisch ist die am häufigsten genutzte routinemäßige Untersuchungsmethode, die einen schnellen Überblick über die Spermienqualität in Bezug auf die Motilität verschafft (WABERSKI UND PETRUNKINA, 2007). Dabei werden die Massenbewegungen (nur bei Wiederkäuern) der unverdünnten Spermien unter dem Mikroskop im Hellfeld bei 100- 
facher Vergrößerung geschätzt und anhand von Mindestanforderungen an die biologische Spermienbeschaffenheit unterteilt. Für die Einzelbewegung werden die Spermien nach vorwärtsbeweglichen, ortsbeweglichen und unbeweglichen Samenzellen unterschieden. Die Untersuchung erfolgt dabei unter dem Phasenkontrastmikroskop bei 200-facher Vergrößerung (WABERSKI UND PETRUNKINA, 2007). Bei der mikroskopischen Motilitätsschätzung handelt es sich jedoch um ein subjektives Verfahren, bei dem die Genauigkeit der visuellen Beurteilung gering ist und das Laborpersonal regelmäßig aufeinander abgestimmt werden muss (WABERSKI UND PETRUNKINA, 2007). Schnellere und effektivere Methoden wie das computerunterstützte Analyseverfahren Computer Assisted Sperm Analysis (CASA) bieten die Möglichkeit einer standardisierten Beurteilung der Bewegungsparameter der Spermien (CHRISTENSEN ET AL., 2005). CASA kann dabei eine große Anzahl von Spermien auswerten und deren Art der Bewegung und Geschwindigkeit messen (WABERSKI ET AL., 1999). Dabei werden die einzelnen Bahnen, die Geschwindigkeit und die Richtung untersucht. Tabelle 1 gibt einen Überblick über die am CASA gemessenen Qualitätsparameter. 
Tabelle 1: Beschreibung der Beurteilung der Spermienbewegung (KATHIRAVAN ET AL., 2011)

\begin{tabular}{|c|c|}
\hline Qualitätsparameter & Definition \\
\hline Motilität & $\begin{array}{l}\text { Gesamtmotilität: Verhältnis der beweg- } \\
\text { lichen Spermien zur Gesamtkonzent- } \\
\text { ration der Spermien in \% }\end{array}$ \\
\hline Progressive Motilität & vorwärtsbewegliche Spermien in \% \\
\hline Velocity straight line (VSL) & $\begin{array}{l}\text { kürzeste Distanz zwischen dem An- } \\
\text { fangs- und dem Endpunkt des Sper- } \\
\text { miums während der Messung geteilt } \\
\text { durch die Dauer der Messung in } \mu \mathrm{m} / \mathrm{s}\end{array}$ \\
\hline Velocity curve line (VCL) & $\begin{array}{l}\text { kurvolineare Geschwindigkeit: kom- } \\
\text { plette vom Spermium zurückgelegte } \\
\text { Distanz geteilt durch die Dauer der } \\
\text { Messung in } \mu \mathrm{m} / \mathrm{s}, \mathrm{VSL}<\mathrm{VCL}\end{array}$ \\
\hline Velocity average path (VAP) & $\begin{array}{l}\text { zurückgelegte Distanz des Spermiums } \\
\text { geteilt durch die Dauer der Messung } \\
\text { auf einer geglätteten Bahn in } \mu \mathrm{m} / \mathrm{s} \text {, } \\
V S L<V A P<V C L\end{array}$ \\
\hline $\begin{array}{l}\text { Amplitude of lateral head displacement } \\
(\mathrm{ALH})\end{array}$ & $\begin{array}{l}\text { seitliche Auslenkung der Spermien- } \\
\text { köpfe in } \mu \mathrm{m}\end{array}$ \\
\hline Beat cross frequency (BCF) & Frequenz der Pendelbewegung in $\mathrm{Hz}$ \\
\hline Straightness (STR) & STR = VSL/VAP x 100 in \% \\
\hline Linearity (LIN) & LIN = VSL/VCL x 100 in \% \\
\hline
\end{tabular}


Mehrere Autoren sehen dieses Analyseverfahren als effizientes objektives Instrument zur Erfassung der Fruchtbarkeitsparameter an. Sie stellten in ihren Untersuchungen positive Korrelationen zwischen die im CASA gemessenen Motilitätswerte nach dem Auftauen und der Trächtigkeitsraten fest (FARRELL ET AL., 1998; JANUSKAUSKAS ET AL., 2001; CHRISTENSEN ET AL., 2005). Dabei variieren die Korrelationen zwischen der Spermienmotilität und der Fruchtbarkeit zwischen 0,15 und 0,83 (STÅLhAMmAR ET AL., 1994). KOZUMPLIK UND SOSNOVA (1985) erzielten in einem Feldversuch mit 10682 Erstbesamungen die höchsten Trächtigkeitsraten, wenn die eingesetzten Besamungsportionen im Thermoresistenztest nach zwei Stunden noch mehr als $40 \%$ vorwärtsbewegliche Spermien aufwiesen. Diese Aussage konnten VIANNA ET AL. (2009) nicht bestätigen. Nach 4920 Erstbesamungen stellten sie keinen Zusammenhang zwischen der im Thermoresistenztest gemessenen Motilität und der Fruchtbarkeit fest. Dabei erreichten Spermien, die nach fünfstündigem Thermoresistenztest keinerlei motile Aktivität mehr zeigten, immer noch Trächtigkeitsraten von $66 \%$. Besamungsportionen mit einem Anteil motiler Spermien von über $40 \%$ erzielten eine Trächtigkeitsrate von 63\% (VIANNA ET AL., 2009). Selbst in standardisierten Verfahren wie der Messung des Parameters Linearity im CASA sind schwankende Korrelationen bezüglich der Befruchtungsfähigkeit der Spermien von $r^{2}=0,45-0,63 \mathrm{zu}$ verzeichnen (ZHANG ET AL., 1998; JANUSKAUSKAS ET AL., 2001). Werden hingegen mehrere Parameter der Motilität, wie z.B. die Linearity und Straightness, mit der Fruchtbarkeit verglichen sind stärkere Korrelationen von $r^{2}=0,68-0,98$ zu finden (FARRELL ET AL., 1998).

Die folgende Tabelle 2 zeigt eine Übersicht von Studien, die sich mit Korrelationen der in vitro gemessenen Spermienmotilität am CASA und der visuell unter dem Mikroskop in vivo gemessenen Fruchtbarkeit beschäftigten. 
Tabelle 2: Korrelation der am CASA bzw. subjektiv unter dem Mikroskop gemessenen Motilität und der Fruchtbarkeit in vivo

\begin{tabular}{|c|c|c|}
\hline Methode & Korrelation (r) & Autoren \\
\hline Subjektiv & 0.21 (Trächtigkeitsrate) & $\begin{array}{l}\text { (BRAHMKSHTRI ET AL., } \\
\text { 1999) }\end{array}$ \\
\hline CASA & $\begin{array}{l}0,34 \text { (Motilität) } \\
0,89 \text { (Motilität aus } 5 \text { Motilitätseigenschaf- } \\
\text { ten) }\end{array}$ & (FARRELL ET AL., 1998) \\
\hline $\begin{array}{l}\text { CASA } \\
\text { Subjektiv }\end{array}$ & $\begin{array}{l}0,53-0,57 \text { (Motilität) } \\
0,66-0,67 \text { (Motilität) }\end{array}$ & $\begin{array}{l}\text { (JANUSKAUSKAS ET AL., } \\
\text { 2001) }\end{array}$ \\
\hline Subjektiv & 0,55 (Motilität) & (KJAESTAD ET AL., 1993) \\
\hline Subjektiv & 0,04 - 0,21 (Motilität) & $\begin{array}{l}\text { (SODERQUIST ET AL., } \\
\text { 1991) }\end{array}$ \\
\hline $\begin{array}{l}\text { CASA } \\
\text { Subjektiv }\end{array}$ & $\begin{array}{l}0,43 \text { - 0,61 (Motilität) } \\
0,52 \text { - 0,59 (Motilität) }\end{array}$ & $\begin{array}{l}\text { (JANUSKAUSKAS ET AL., } \\
\text { 2003) }\end{array}$ \\
\hline
\end{tabular}

\subsubsection{Morphologie}

Die morphologische Untersuchung der Spermien unter dem Mikroskop ist eine weitere von der Motilitätsbewertung unabhängige Methode zur Beurteilung der Spermienqualität. Die gesamtmorphologische Untersuchung erfolgt mikroskopisch am fixen Präparat. Dabei werden 200 zuvor durch z.B. eine Forum-ZitratLösung immobilisierte Spermien unter einem Phasenkontrastmikroskop mittels Ölimmersion bei 800 -facher Vergrößerung hinsichtlich des Vorhandenseins von Kopfkappen-, Kopf-, Hals-, Verbindungsstück- und Endstückveränderungen untersucht (Tabelle 3) (WEITZE, 2001). 
Tabelle 3: Morphologische Untersuchungsklassifikation (WEITZE, 2001)

\begin{tabular}{|c|c|}
\hline Parameter & Definition \\
\hline Kappenveränderungen & $\begin{array}{ll}\text { - } & \text { Abgelöst } \\
\text { - } & \text { Deformiert } \\
\text { - } & \text { Persistierendes } \\
& \text { Akrosomgranulom } \\
\text { - } & \text { geschwollen }\end{array}$ \\
\hline Kopfveränderungen & $\begin{array}{ll}\text { - } & \text { deformiert } \\
\text { - } & \text { morphologische Abweichungen } \\
\text { der Kopfform }\end{array}$ \\
\hline Halsveränderungen & $\begin{array}{ll}\text { - } & \text { Plasmatropfen } \\
\text { - } & \text { Halsbruch }\end{array}$ \\
\hline Verbindungsstückveränderungen & $\begin{array}{ll}- & \text { Deformiert } \\
- & \text { Plasmatropfen }\end{array}$ \\
\hline Haupt- und Endstückveränderungen & $\begin{array}{ll}\text { - } & \text { Schleifenform } \\
\text { - } & \text { Plasmatropfen } \\
\text { - } & \text { Aufgerollt } \\
\text { - } & \text { Um den Kopf gerollt } \\
\text { - } & \text { abgeknickt }\end{array}$ \\
\hline Mehrfachmissbildungen & - Missbildungen \\
\hline
\end{tabular}

Morphologische Spermienveränderungen können primäre, sekundäre und tertiäre Ursachen haben. Erstere entstehen während der Spermatogenese im Hoden. Dazu zählen Missbildungen des Kopfes sowie Formabweichungen des Mittelstücks und des Schwanzes. Primäre Veränderungen werden für die Fertilität des Vatertieres als schwerwiegend angesehen (WABERSKI UND PETRUNKINA, 2007). Sekundäre Missbildungen entstehen im Verlauf der Nebenhodenpassage. Hierbei handelt es sich um abgelöste Kopfkappen, Halsbrüche, Plasmatropfen sowie Formabweichungen des Schwanzes (WEITZE, 2001). Tertiäre Veränderungen entstehen nach der Samengewinnung und Untersuchung durch äußere Einflüsse. Hierzu zählen Kopfkappenablösungen, Schwanzschleifen und Halsbrüche (WEITZE, 2001). 
Nach Untersuchungen von PHILLIPS ET AL. (2004) ist die morphologische Qualitätsbeurteilung eine wichtige Methode zur Vorhersage der Fruchtbarkeitsaussichten. BARTH ET AL. (1992) zeigten in ihren Untersuchungen, dass Spermien, deren Köpfe in der postakrosomalen Region extrem verschmälert sind, eine signifikant geringere Fertilität in vivo aufweisen. GARNER (1997) sahen die morphologischen Untersuchungen mittels Mikroskop als zu subjektiv und zeitaufwendig an. Die neue, innovativere und effektivere Messmethode anhand des Analyseverfahrens CASA sollte diese ersetzen. Bisher stehen jedoch keine automatisierten Analysesysteme für morphologische Parameter zur Verfügung und es wird routinemäßig noch die subjektive Qualitätsbeurteilung mit Hilfe des Mikroskops angewendet.

\subsubsection{Durchflusszytometrische Spermabeurteilung}

Die Befruchtungskompetenz eines Spermiums ist von der funktionellen und morphologischen Integrität der Plasmamembran abhängig (WABERSKI UND PetrunKINA, 2007). Eine objektive Methode zur funktionsabhängigen Qualitätsbeurteilung der Spermien gelingt mit Hilfe der Flowzytometrie. Diese Methode bietet die Möglichkeit mit einem hohen Maß an Reproduzierbarkeit Standardisierung und Genauigkeit vieler tausender Zellen zu beurteilen (WEITZE, 2001). Anhand der durchflusszytometrischen Spermabeurteilung kann die Membranintegrität der Spermien anhand der SYBR14/Propidiumjodid (PI)-Färbung gemessen werden (GARNER ET AL., 1994). CHRISTENSEN ET AL. (2004) entwickelten eine modifizierte und kostengünstige Form dieser Messung, den FACSCount (ChRISTENSEN ET AL., 2004). In einem stichprobenartigen Versuch mit 157 Bullen (114 Holstein- und 43 Jerseybullen) wurden 44946 Erstbesamungen durchgeführt. Dabei konnten die Autoren eine positive Korrelation der NRR56 zur Membranintegrität im nativen Zustand $(r=0,409)$ und nach dem Auftauen $(r=$ 0,506) feststellen. Sie schätzen die Beurteilung der Spermienmebranintegrität anhand der Durchflusszytometrie als einzige aussagekräftige Methode zur Bestimmung der Befruchtungsfähigkeit der Spermien nach dem Auftauen ein (Christensen et AL., 2011). 
Eine weitere Methode der Messung der Spermaqualität anhand der Durchflusszytometrie ist der Spermienchromatinstruktur-Assay (SCSA-Test). Der Zustand des Spermachromatins spielt bei der Befruchtung und embryonalen Entwicklung eine wichtige Rolle (AMBROGI DE ET AL., 2006).

Fertile Spermien besitzen bekannte und unbekannte Eigenschaften, die die Befruchtung beeinflussen (DEN DAAS ET AL., 1998). Daher kann eine Besamung durchaus fehlschlagen, obwohl bekannte Faktoren für eine erfolgreiche Befruchtung sprechen. Sollten andererseits schon anhand der Qualitätsbeurteilung der Spermien große Mängel auftreten, ist eine Trächtigkeit nicht zu erwarten (DEJARNETTE UND MARSHALL, 2005). Spermatologische Beurteilungen der Spermien werden standardmäßig von den Besamungsstationen durchgeführt, um qualitativ geringwertige Ejakulate vor dem Einfrieren zu selektieren und durch die Verarbeitung zu stark geschädigte Portionen von der Besamung auszuschließen. Für gesextes Sperma wurden zum Beispiel von RATH ET AL. (2009) anhand von Messungen der Motilität im CASA, der Fluoreszenz-Analyse und der morphologischen Beurteilung Richtwerte entwickelt. Eine Übersicht ist in Tabelle 4 dargestellt.

Ein Thermoresistenztest simuliert die Körpertemperatur und somit die thermischen Belastungen für Spermien im Reproduktionstrakt. Dabei werden die Spermien direkt nach dem Auftauen über 6 Stunden bei $37^{\circ} \mathrm{C}$ inkubiert, um nach 0, 3 und 6 Stunden Rückschlüsse auf die Qualität des Ejakulates zu ziehen (MüLLER, 2000). Mehrere Autoren sehen den Thermoresistenztest als Möglichkeit die Aussagekraft bezüglich Motilität, Membranintegrität und Morphologie auf das potentielle Befruchtungspotential eines Ejakulates zu erhöhen (MüLLER, 2000; DeJARNETTE UND MARSHALL, 2005).

Für eine erfolgreiche Besamung wäre in Zukunft die Entwicklung eines Modells nötig, das die Umwelteffekte durch den Bullen und den Techniker mit einbezieht, um einen Teil der 95\%igen Restvarianz zu erklären (CHRISTENSEN ET AL., 2005; BERRY ET AL., 2011). 
Tabelle 4: Grenzwerte für die Qualität sortierter Spermien (NACH RATH ET AL. 2009)

\begin{tabular}{|l|c|}
\hline Mikroskopische Beurteilung & Minimalanforderung \\
\hline Einzelspermienbeweglichkeit (in \%) & $\geq 50$ \\
\hline $\begin{array}{l}\text { Motiliät im Thermo-Toleranz-Test nach } \\
6 \text { Stunden (in \%) }\end{array}$ & $\geq 2$ \\
\hline $\begin{array}{l}\text { Anzahl lebender Spermien } \\
\text { (Mio./Straw) }\end{array}$ & $\geq 70$ \\
\hline Fluoreszenz-Analyse & $\geq 90$ \\
\hline Syto17/ FITC-PNA intakt (in \% ) & $\leq 5$ \\
\hline Sortierreinheit (in \%) & $\leq 5$ \\
\hline Defragmentationsindex & $\leq 20$ \\
\hline Morphologische Beurteilung & \\
\hline Spermienkopfveränderungen (in \%) & \\
\hline Kopfkappenveränderungen (in \%) & \\
\hline Gesamtmorphologische & \\
\hline
\end{tabular}




\subsection{Kryokonservierung von Bullensperma}

Ejakulate werden beim Bullen mittels künstlicher Scheide gewonnen. Die anschließende Ejakulatverdünnung und Samenkonservierung sind essentielle Verarbeitungsschritte für die Herstellung von tiefgefrorenen Samenportionen des Bullen. PHILLIPS (1939) entdeckte die protektive Eigenschaft von Hühnereidotter zur Erhaltung und Haltbarmachung der Spermienfruchtbarkeit. Bis heute stellt Eigelb den weltweit am häufigsten verwendeten biologischen Zusatz in der Kryokonservierung boviner Ejakulate dar (MousSA ET AL., 2002). Einen weiteren Durchbruch in der Tiefgefrierung von Sperma erzielten POLGE ET AL. (1949), die die kryoprotektiven Eigenschaften von Glyzerin beim Tiefgefrieren für Hühnersperma entdeckten. Erstmals wurde 1951 ein Kalb nach Besamung mit tiefgefrorenem Bullensperma geboren. Schnell etablierte sich das Verfahren und wird heute routinemäßig eingesetzt (CURRY, 2000; SWELUM ET AL., 2011).

\subsubsection{Auswirkungen der Kryokonservierung auf die Spermienintegrität}

Nach der Verdünnung wird das Ejakulat auf 4 bis $5^{\circ} \mathrm{C}$ heruntergekühlt. Die Abkühlung minimiert den Stoffwechsel der Spermien, wobei dieser Prozess nicht zu schnell erfolgen darf. Eine zu rasche Abkühlung induziert Veränderungen in der Plasmamembran und erhöht die Membranpermeabilität (ANDRABI, 2009). Kalzium wird vermehrt ins Zellinnere der Spermien aufgenommen, wodurch Vorgänge einer verfrühten Kapazitation ausgelöst werden (WATSON, 2000). Zudem kommt es aufgrund des herabgesetzten Fruktose- und Sauerstoffabbaus sowie einer reduzierten ATP-Synthese zu Energieverlusten in der Zelle und folglich zu einer Abnahme der Motilität (VISHWANATH UND SHANNON, 2000). DHAMI ET AL. (1992) untersuchten den Effekt der unterschiedlichen Abkühlraten von $10^{\circ} \mathrm{C}$ auf $5^{\circ} \mathrm{C}$ über $5,30,60$ und 120 Minuten im Vergleich zu 120 Minuten von $28^{\circ} \mathrm{C}$ auf $5^{\circ} \mathrm{C}$ auf die Motilität und Membranintegrität von Bullenspermien. Sie zeigten, dass Sperma bereits nach 30 -minütiger Abkühlung bei $10^{\circ} \mathrm{C}$ erfolgreich eingefroren werden kann (DHAMI ET AL., 1992). 
Der Tiefgefrierprozess hat für Spermien eine Belastung und Schädigung der Zellstrukturen zur Folge, woraus eine erhöhte Desintegration der Akrosom- und Plasmamembran sowie verringerte Motilitätswerte nach dem Auftauen resultieren (WATSON, 1995). Trotz eines guten Einfrierprotokolls überlebt häufig nur die Hälfte der kryokonservierten Spermien nach dem Auftauen (CURRY, 2000). In einer Studie von SHANNON UND VISHWANATH (1995) wurde bovines Frischsperma mit einer Motilität von $80 \%$ und TG-Sperma mit einer Motilität von $40 \%$ für einen Besamungsversuch genutzt. Die Besamung mit 2,5 x $10^{6}$ Frischspermien ergab vergleichbare Trächtigkeitsraten zu den Portionen mit $20 \times 10^{6}$ TG-Spermien (68,1\% bzw. 67,6\% tragende Tiere). Als Folge der durch die Kryokonservierung bedingten Schäden wird daher die Anzahl der Spermien pro Portion soweit erhöht, dass vergleichbare Trächtigkeitsraten erreicht werden können (VISHWANATH UND SHANNON, 2000).

Während des Einfrierprozesses kommt es bei Temperaturen von unter $0^{\circ} \mathrm{C}$ zum Gefrieren der extrazellulären Flüssigkeit. Die damit verbundene Zunahme der Elektrolytkonzentration im extrazellulären Medium führt zu einer verstärkten osmotischen Dehydration der Spermien. Ursache hierfür sind die Kristallisation des reinen Wassers bei Temperaturen unter dem Gefrierpunkt und die damit verbundene Konzentrationserhöhung der gelösten Stoffe im Restwasser (WABERSKI UND PETRUNKINA, 2007). Das Wasser in der Zelle verlässt entsprechend des osmotischen Gradienten die Zelle. Die Dehydration hängt von der Abkühlungsrate und der Wasserdurchlässigkeit der Membran ab. Eine langsame Einfrierkurve sorgt für eine langsame Dehydration der Zelle, eine schnelle Gefrierkurve hingegen führt dazu, dass das Wasser die Zelle nicht schnell genug verlassen kann und es möglicherweise zu einer intrazellulären Eiskristallbildung kommt (WABERSKI UND PETRUNKINA, 2007). Das Volumen der flüssigen Substanzen in der Zelle vergrößert sich und somit erfolgen Zell- und Membranschäden. Einer der wichtigsten technischen Durchbrüche des Einfrierprozesses war die Entdeckung der Schutzwirkung des Glyzerins (PoLGE ET AL., 1949). Es verringert den Anteil des ungefrorenen Wassers bei beliebigen Temperaturen und verringert somit die osmotische Dehydration der Zelle in Folge der Abnahme der Elektrolytkonzentration (BAILEY ET AL., 2000; HOLT, 2000A; SWELUM ET AL., 2011). 
Durch das Einfrieren und Auftauen von Spermien entstehen freie Sauerstoffradikale (ROS) (BILODEAU ET AL., 2000). ROS sind Radikale, die sehr reaktionsfreudig und kurzlebig sind, da sie mehrere ungepaarte Elektronen aufweisen. Sie nutzen als Reaktionspartner Lipide und Proteine an der Membran des Spermiums, um durch die Aufnahme eines zweiten Elektrons eine chemisch stabilere Form einzugehen (AITKEN ET AL., 1989). Unter biologischen Rahmenbedingungen werden ROS von Leukozyten und von abgestorbenen Spermien produziert (GARRIDO ET AL., 2004). Da die Membranen von Säugetieren einen hohen Anteil an ungesättigten Fettsäuren (PUFA) aufweisen, kommt es bei einem Überschuss von ROS zur Lipidoxidation, welche die Plasmamembran der Spermien schädigt. Die Folge sind morphologische Veränderungen sowie eine reduzierte Motilität der Spermien (SIKKA, 1996; BANSAL UND BILASPURI, 2010; BuCAK ET AL., 2010). MAMmOto ET AL. (1996) zeigten bei der Maus, dass ein Überschuss an ROS zu oxidativem Stress führen kann; die Folge sind verringerte Motilitäten, reduzierte Oozyten Penetrationsraten sowie eine Blockierung der Fusion von Spermium und Eizelle (BANSAL UND BILASPURI, 2010). Nach SIKKA (1996) ist die reduzierte Motilität durch den Verlust von intrazellulärem Adenosintriphosphat (ATP) zu erklären, wodurch es zu Schädigungen am Axonem des Spermienschwanzmittelstücks kommt. Mehrere Studien haben aber auch gezeigt, dass freie Sauerstoffradikale einen positiven Effekt auf die Befruchtungsfähigkeit der Spermien haben können. Sie spielen eine wichtige Rolle während der Kapazitation, der Akrosomreaktion, der Hyperaktivierung und der Penetration der Zona pellucida ( AITKEN, 1995; BANSAL UND BILASPURI, 2010).

Die Ergänzung des Verdünnermediums mit Antioxidantien (AO) stellt das Gleichgewicht zwischen ROS und Antioxidantien zum Teil wieder her und kann die Spermien vor Schäden durch ROS schützen. Antioxidantien wirken als Radikalfänger und inaktivieren den Überschuss an ROS (BANSAL UND BILASPURI, 2010). NACH BUCAK ET AL. (2010) verbessern Antioxidantien die Motilität, die Membranintegrität und schützen vor Beeinträchtigungen des Spermienchromatins. GROSSFELD ET AL. (2008) stellten eine Übersicht der Antioxidantien auf und zeigten den positiven Einfluss der Antioxidantien im Verdünnungsmedium auf die Qualität tiefgefrorener und wieder aufgetauter Spermien verschiedener Spezies. 


\subsubsection{Kompensierbare und nicht kompensierbare Spermienmängel}

Es wird zwischen kompensierbaren und nicht kompensierbaren Spermienmängeln unterschieden (SAACKE ET AL., 2000).

Mängel, die an einzelnen Spermien vorkommen und durch andere Samenzellen im Ejakulat weitgehend ausgeglichen werden können, so dass eine maximale Befruchtungsfähigkeit der Besamungsportion erhalten bleibt, sind kompensierbar. Betreffen die Mängel allerdings numerische und strukturelle DNA-Schäden, die zwar die Befruchtungsfähigkeit der Spermien nicht einschränken, jedoch zu schlechten embryonalen Entwicklungsraten führen, sind sie nicht kompensierbar (WABERSKI ET AL., 1999). Morphologisch normal erscheinende Spermien werden am ehesten als Kandidaten für nicht kompensierbare Schädigungen angesehen, denn sie initiieren zwar die Befruchtung, aber die Embryonalentwicklung wird meistens in der präimplantatorischen Phase abgebrochen. WABERSKI ET AL. (1996) beobachteten beispielsweise nach intrazervikaler Besamung mit geringen Spermienmengen beim Schwein einen höheren Anteil degenerierter Embryonen und nicht befruchteter Oozyten, was einen Verdacht auf nicht kompensierbare Mängel an den Spermien aufkommen ließ. Aufgrund der numerischen und strukturellen DNA-Schäden können nicht kompensierbare Spermienschädigungen durch eine Erhöhung der Inseminationsdosis nicht zu einer Steigerung der Fruchtbarkeit beitragen (SCHWARTZ ET AL., 1981).

„Klassische“ Missbildungen sowie mangelnde Vorwärtsbeweglichkeit der Samenzellen gelten als kompensierbare Eigenschaften. Samenzellen, die diese Art von Mängeln aufweisen sind nicht in der Lage, die Selektionsmechanismen im weiblichen Genital zu überwinden und die Oozyte zu befruchten (BEßELING, 2001). Spermien, deren Membran geschädigt wurde, die also frühzeitig kapazitiert sind, können zudem Abwehrreaktionen im weiblichen Genitaltrakt der Epithel- und Immunzellen auslösen, was wiederum einen weiteren negativen Einfluss auf die Befruchtung nach sich ziehen kann (ZERBE ET AL., 2003).

Bei einer ausreichenden Besamungsdosis sind tertiäre Schäden durch den Gefrierprozess kompensierbar. Somit liegt die Inseminationsmenge von Tiefgefriersperma über der von Frischsperma (JOHNSON, 1985). Durch die Schäden der Kryokonservierung ist die verkürzte Lebensdauer der Spermien im weibli- 
chen Genitaltrakt stark verschlechtert, was ebenfalls die Befruchtungsfähigkeit und somit den Befruchtungserfolg vermindert (PURSEL ET AL., 1978). Zudem sind Spermien, die kompensierbare Schäden durch die Kryokonservierung erlitten zwar befruchtungsfähig, die physiologische Passage durch den Uterus können sie jedoch nicht mehr ausreichend vollziehen (HOLT, 2000B). Eine laparoskopische Besamung könnte dabei den Weg der Spermien verkürzen und folglich trotz der Spermienmängel zu besseren Fruchtbarkeitsergebnissen führen.

\subsubsection{Einfluss des Auftauprozesses}

Der Auftauvorgang ist genauso bedeutend für den Erhalt der Befruchtungsfähigkeit der Spermien wie der Einfriervorgang (CHANDLER ET AL., 1984). Die ursprüngliche Abkühl- und Einfrierrate hat einen wesentlichen Einfluss auf das dazugehörige Auftauverfahren. Beim Auftauen sind die Spermien einem starken osmotischen Gradienten ausgesetzt, der durch die Verminderung der Salzkonzentration im umgebenden Medium entsteht. Schnelles Auftauen minimiert die Auskristallisation von Wasser und verringert so Membranschäden. Ein langsames Auftauen führt zum Eintritt von Wasser in die Zellen, was starke osmotische Belastungen zur Folge hat (MAZUR, 1984; VISHWANATH UND SHANNON, 2000).

Spermien, die die Kryokonservierung auf $-196^{\circ} \mathrm{C}$ überlebt haben, müssen auch beim Auftauen wiederum den kritischen Temperaturbereich von $-50^{\circ} \mathrm{C}$ bis $-5^{\circ} \mathrm{C}$ durchlaufen. Generell gilt, dass ein schnelles Auftauregime die Membranschäden besser verhindert als ein langsames Auftauverfahren, da das Gleichgewicht im extra- und intrazellulärem Medium schneller wiederhergestellt wird (ANDRABI, 2009). In der Praxis werden Besamungspailletten mit Bullensperma 20 bis 30 Sekunden in einem $37^{\circ} \mathrm{C}$ warmen Wasserbad aufgetaut. DHAMI ET AL. (1992) untersuchten die Motilität kryokonservierter Spermien nach unterschiedlichen Auftauverfahren (60 Sek. bei $40^{\circ} \mathrm{C}, 15$ Sek. bei $60^{\circ} \mathrm{C}, 5$ Sek. bei $80^{\circ} \mathrm{C}$ ). Dabei wiesen Spermien, die 5 Sekunden bei $60^{\circ} \mathrm{C}$ aufgetaut wurden, einen Anteil motiler Spermien von 39,79\% auf. Spermien, die 60 Sekunden bei $40^{\circ} \mathrm{C}$ aufgetaut wurden, hatten einen Anteil von 35,15\%. Der Prozentsatz motiler Spermien 
nach fünfsekündigem Auftauen bei $80^{\circ} \mathrm{C}$ lag bei $38,15 \%$. SUKHATO ET AL. (2001) betrachteten zusätzlich zur Motilität den Anteil membranintakter Spermien. Sie verglichen drei Einfriergeschwindigkeiten sowie eine schnelle $\left(1000^{\circ} \mathrm{C} / \mathrm{min}\right)$ und eine langsame $\left(100^{\circ} \mathrm{C} / \mathrm{min}\right)$ Auftaukurve miteinander. Dabei zeigte sich ebenfalls, dass ein schnelles Auftauen zu besseren Motilitätswerten führte ( $50 \%$ vs. $30 \%)$.

Das Auftauverfahren hängt auch von der Verpackungsart sowie dem Volumen der Paillette ab (CHANDLER ET AL., 1984). Aufgrund des unterschiedlichen Paillettendurchmessers besteht ein unterschiedliches Oberflächen-VolumenVerhältnis, woraus verschiedene Temperaturgradienten im Straw resultieren. Außerdem haben der verwendete Verdünner, die Konzentration des Gefrierschutzmittels sowie die Abkühl- und Einfrierrate einen wesentlichen Einfluss auf das Auftauverfahren (SENGER ET AL., 1983).

\subsubsection{Kryokonservierung kleiner Zellmengen bzw. Volumina}

Eine Alternative zur konventionellen Kryokonservierung kleiner Volumina ist die Vitrifikation. Es handelt sich hierbei um eine schnelle Einfriertechnik, die die Probleme vermindern soll, die durch das konventionelle Einfrierprotokoll entstehen (Weitze und PetRunkinA, 2001). Bei der Vitrifikation werden die Zellen bei einem Temperaturabfall von $1000^{\circ} \mathrm{C} / \mathrm{min}$ und mehr eingefroren, um extrazelluläre und intrazelluläre Eiskristallbildungen zu vermeiden. Hierbei erstarren die Moleküle in zufälliger Anordnung und die Lösung nimmt einen glasartigen Zustand ein (LIEBERMANN, 2003). Aufgrund des direkten Kontaktes der Zellen mit flüssigem Stickstoff besteht dabei die Gefahr der Kontamination durch Bakterienrückstände im Eis (TEDDER ET AL., 1995; FoUNTAIN ET AL., 1997; BIELANSKI ET AL., 2000). Als Vorteile gegenüber der konventionellen Einfriertechnik gelten verringerte Eiskristallbildung während des Vitrifizierens und während des Erwärmens vermindertes Volumen des Gefriergutes, höhere Kühlraten, geringerer Zeitaufwand, niedrige Kosten und eine einfachere Handhabung der Protokolle (LIEBERMANN, 2003). 
Anders als bei der Vitrifizierung von Oozyten und Embryonen kann bei der Vitrifizierung von Spermien möglicherweise auf ein Kryoprotektivum verzichtet werden. 1942 gelang es erstmals, Hühnersperma zu vitrifizieren (SHAFFNER, 1942). Weitere Erfolge bei der Vitrifikation von Säugetiersperma blieben in den nächsten Jahren jedoch zunächst aus und es konnte keine Alternative zur herkömmlichen Tiefgefrierung gefunden werden. Nachdem RALL UND FAHY (1985) über die erfolgreiche eiskristallfreie Vitrifikation von Mäuseembryonen berichteten, blieb die Vitrifikation von Spermien weiterhin lange aufgrund der Verwendung eines hohen Anteils von Kryoprotektiva und den damit einhergehenden osmotischen und zytotoxischen Effekten auf die Zellen erfolglos (GILMORE ET AL., 1997).

Erst 2004 wurden humane Spermien ohne Verwendung von Kryoprotektiva vitrifiziert und mit konventionell kryokonservierten Spermatozoen hinsichtlich ihrer Motilität und DNA-Integrität verglichen. Die Ergebnisse der Motilität waren vergleichbar gut (47\% zu 52\%). Auch hinsichtlich der DNA-Integrität wurden keine Unterschiede festgestellt (ISACHENKO ET AL., 2004A). Ein möglicher Grund für die erfolgreiche Vitrifikation von Spermien in Abwesenheit von Kryoprotektiva könnte sein, dass diese Zellen kleiner sind als Oozyten und Embryonen und dadurch die Wahrscheinlichkeit intrazellulärer Eisbildung des Wachstums von Eiskristallen während des Abkühlens sowie die Gefahr der Rekristallisation während des Erwärmens geringer ist. Zudem ist der Anteil osmotisch inaktiven Wassers, gebunden an makromolekulare Strukturen wie der DNA, der Histone und der Hyaluronidase bei Spermien generell höher, was die Viskosität und die Glasübergangstemperatur im Zytoplasma der Spermien erhöht (BEHRENDT, 2009).

Eine zentrale Rolle bei der Vitrifikation spielt die gleichmäßige und sehr schnelle Abkühlung der zu vitrifizierenden Probe. Durch deren Eintauchen in den flüssigen Stickstoff entsteht normalerweise ein Dampfmantel, durch den der Kälteübergang in die Probe begrenzt wird (REED ET AL., 2002). Um diesem Effekt entgegenzuwirken sind verschiedene Trägersysteme entwickelt worden. Neben Geräten, die durch Überdruck die Flüssigphase des Stickstoffs erhöhen (Supercooling), wird mit Systemen gearbeitet, die das Vitrifizieren kleiner Volumina $(0,5-1,0 \mu l)$ ermöglichen. Mit dem Cryoloop, einer kleinen Nylonschlinge mit einer Länge von $20 \mu \mathrm{m}$ und einem Durchmesser von 0,5-0,7 mm, ist es möglich, kleinste Volumina, z.B. Eizellen, zu konservieren (MUKAIDA ET AL., 2001; 
REED ET AL., 2002). Eine weiteres Trägersystem ist der Open Pulled Straw, eine dünne Plastikkapillare zum Einfrieren von Embryonen (ISACHENKO ET AL., 2000).

Während humane Spermien den Vitrifikationsprozess gut durchlaufen (ISACHENKO ET AL., 2004A; ISACHENKO ET AL., 2004B), ist die Vitrifikation von Nutztierspermien bis heute nicht mit der konventionellen Methode vergleichbar. Dies bestätigt eine Studie von BEHRENDT (2009), in der Hengstspermien vitrifiziert und mit der konventionellen Einfriermethode verglichen wurden. Dabei blieb der Anteil progressiv motiler Spermien mit 17,4\% aus dem Cryoloop unter dem Anteil progressiv motiler Spermien aus dem konventionellen Straw (20,6\%).

\subsubsection{Alternativen zur Tiefgefrierung von Bullensperma in Straws}

Nach der Entdeckung der kryoprotektiven Eigenschaften von Glyzerin (POLGE ET AL., 1949) und der Möglichkeit, Sperma durch Tiefgefrierung haltbar zu machen, wurde Sperma überwiegend in Glasampullen tiefgefroren (PICKETT UND BERNDTSON, 1974). Üblicherweise umfasste damals das Volumen einer Glasampulle 1,0 ml. Die Spermaqualität war nach PICKET UND BERNDTSON (1974) akzeptabel. Die Kosten und das Handling überstiegen jedoch die Effizienz dieses Vorgehens.

Eine Methode, Sperma in Pellets zu gefrieren, wurde von japanischen Wissenschaftlern entwickelt (NAGASE ET AL., 1964). Hierbei wurden kleine Löcher in einen Block aus Trockeneis gebohrt und mit Spermavolumina von 0,05-0,2 ml gefüllt. Nach zehn Minuten konnte das auf $-79^{\circ} \mathrm{C}$ heruntergekühlte Sperma in flüssigen Stickstoff überführt werden. Dieses System wurde aufgrund eines zu hohen Kontaminationsrisikos durch Bakterien sowie der Problematik der Kennzeichnung trotz vieler Vorteile von der Straw-Methode verdrängt (NAGASE ET AL., 1964; PICKETT UND BerndTson, 1974). Die Spermienkonzentration ist in Pellets ca. zehnmal höher als in einer Ampulle. Die Pellets werden sehr schnell in einem Auftauverdünner aufgetaut und versamt (PICKETT UND BERNDTSON, 1978). In einer Studie von ADLER ET AL. (1968) wurde die Kryokonservierung von Bullenspermien in Pellets mit der Tiefgefrierung in Straws verglichen. Es wurden 
1.872 Rinder mit Pellets und 1993 Rinder mit Straws besamt. Die Pellets erzielten eine NRR von 59\%, die Straws lagen mit $68,5 \%$ deutlich darüber.

Dänische Wissenschaftler entwickelten bereits 1940 die Idee, Sperma in Straws zu konfektionieren und tiefzugefrieren. Ihre ersten Versuche mit Soda-Straws ebneten die Grundlage für die Entwicklung des heutigen Straws (SØRENSEN, 1940). Französische Wissenschaftler revolutionierten die Technik und entwickelten den French-Straw, einen $113 \mathrm{~mm}$ langen Kunststoffhalm mit einem Durchmesser von 2 bis $4 \mathrm{~mm}$, der in flüssigem Stickstoff eingefroren wurde (JONDET, 1964). Gleichzeitig wurden Kunststoffstraws von Arbeitsgruppen in Kanada (MACPherson UND PenNeR, 1972), den USA (AlmQUist UND Wiggin, 1973) und in Deutschland (SIMMET, 1972) entwickelt. Wissenschaftler aus Frankreich und aus Kanada entwickelten dabei die noch heute gängige Verschlusstechnik mittels eines Polyvinylalkoholstopfens, der nach Kontakt mit der Spermasuspension polymerisiert (JONDET, 1964; MACPHERSON UND PENNER, 1972). Erste Versuche aus Kanada und den USA, in denen die Fruchtbarkeitsraten von Besamungsportionen aus Glasampullen und Straws verglichen wurden, lieferten unterschiedliche Ergebnisse. Es wurden $4,4 \%$ bis $5,8 \%$ geringere NRR nach Besamung mit den neu entwickelten Straws beobachtet (PICKetT Und Berndtson, 1974). PiCKetT und Berndtson (1974) vermuteten, dass Schwankungen in der NNR der ungeübten Handhabung der Kunststoffhalme zuzuschreiben waren.

Resümierend stellten PICKETT UND BERNDTSON (1974) fest, dass die Fruchtbarkeit der Spermien, die in Straws tiefgefroren wurden, mit der Qualität von Spermien kryokonserviert in Glasampullen oder Pellets vergleichbar war. In einer Studie von AAMDAL ET AL. (1969) wurden 725 Rinder mit Spermaportionen aus Glasampullen besamt. Sie erzielten eine NRR von $73,8 \%$. Weitere 880 Rinder, die mit dem Straw besamt wurden, erzielten eine NRR von $70,7 \%$. 1968-1969 wurden 176.293 Erstbesamungen bei Rindern in Norwegen mit dem Plastikstraws durchgeführt. Zum Vergleich dienten 161.151 Erstbesamungen mit Glasampullen. Die Straws erreichten eine NRR von 67,7\%, die Glasampullen erzielten eine NRR von 69,1\% (FILSETH, 1970). Ein gutes Fruchtbarkeitsergebnis mit Straws ist jedoch nur durch ein sorgsames Umgehen in Bezug auf 
Gefriergeschwindigkeit, Auftaugeschwindigkeit und mit einem erfahrenen und geschulten Techniker zu erreichen (PICKETT UND BERNDTSON, 1974).

Nach wie vor kann es zu bullenindividuellen Schwierigkeiten bezüglich der Motilität sowie geschädigter Akrosom- und Plasmamembranen der Spermien nach dem Auftauen kommen. Weltweit wird das Sperma am häufigsten in 0,25 ml Straws in flüssigem Stickstoff oder in programmierten Einfrierautomaten kryokonserviert (JOHNSON ET AL., 1995). Konservierung in einem 0,25 ml Straw führt bei einem optimal angepassten Kühlprotokoll mit anschließenden schnellen Auftauen im Wasserbad zu guten Spermaqualitätsparametern (SENGER ET AL., 1983). Im Gegensatz zum $0,25 \mathrm{ml}$ Straw hat der früher üblichere $0,5 \mathrm{ml}$ Straw ein größeres Oberflächen-Volumen-Verhältnis, das theoretisch das Risiko für Temperaturschwankungen beim Auftauen erhöht und somit zur Verschlechterung der Fruchtbarkeit führen kann. JOHNSON ET AL. (1995) untersuchten die Befruchtungsfähigkeit von $0,25 \mathrm{ml}$ und $0,5 \mathrm{ml}$ Straws anhand von Erstbesamungen bei 1360 Färsen. Sie konnten keinen signifikanten Unterschied $(p=0,05)$ im Befruchtungserfolg zwischen den Spermaportionierungen feststellen $(0,25 \mathrm{ml}=$ $63,6 \%$ zu $0,5 \mathrm{ml}=62,0 \%$ ).

Der Einsatz von Frischsamen ermöglicht eine Umgehung der Kryokonservierung und des Auftauens und ist somit für die Spermien weniger belastend, was eine höhere Ausverdünnung der Ejakulate erlaubt und daher für besonders stark nachgefragte Bullen gerne von den Besamungsstationen angeboten wird (ShANNON UND VishWANATH,1995; FOOTE UND KAPROTH, 1997). Aufgrund der begrenzten Haltbarkeit von Frischsamen wird kryokonserviertes Sperma der Flüssigkonservierung aber generell vorgezogen. Weltweit wurden ca. 95\% der 200 Mio. Besamungsportionen, die im Jahr 1995 produziert wurden, kryokonserviert. Die übrigen 5\% wurden als Flüssigsperma hauptsächlich in Neuseeland versamt (VISHWANATH UND SHANNON, 2000).

Der Einsatz geschlechtsspezifisch differenzierter Spermien gewinnt in der Rinderzucht an Bedeutung (RATH ET AL., 2009). Die Anzahl der Spermien ist bei der aufwendigen Herstellung bei geschlechtsdifferenziertem Sperma begrenzt. Daher wäre eine Versamung in Form von Frischsperma von Vorteil, wenn die logistischen Voraussetzungen gegeben sind (KLINC UND RATH, 2007). Die Ver- 
wendung von Frischsperma setzt besondere Anforderungen hinsichtlich Lagerung und Logistik voraus. Eine konstante Lagertemperatur zwischen $12^{\circ} \mathrm{C}$ und $15^{\circ} \mathrm{C}$ sollte dabei unbedingt eingehalten werden (KLINC, 2005). Für eine Frischspermaproduktion von geschlechtsdifferenziertem Spermien sprechen zudem die Schädigungen an den Membranen, die durch den Sortierprozess hervorgerufen werden und meist erst nach dem Einfrieren und Auftauen sichtbar werden (MOCE ET AL., 2006). Als Nachteil kann dabei jedoch der lange Produktionsprozess gegenüber konventionellem Frischsperma gesehen werden. Nach der Ejakulatgewinnung vergehen mehrere Stunden bis die sortierten Proben erstellt sind. KLINC UND RATH (2007) erzielten erstmals Besamungsergebnisse von 60\% mit sortiertem Frischsperma, das 72 Stunden gelagert wurde. Ergänzend fand BERGMANN (2010) heraus, dass die Lagerung von sortiertem Frischsperma drei Tage, d.h. 72 Stunden nicht überschreiten sollte, da die Qualitätsparameter in Bezug auf die Motilität mit 22,3\% deutlich von den Richtlinien nach RATH ET AL. (2009) abweichen, in denen ein Grenzwert von 30\% motiler Spermien nach sechsstündiger Inkubation gilt.

\subsection{Minimierung der Spermienzahl zur Nachkommenerzeugung}

Für den Routinebetrieb der Besamungsstationen wurden ausreichend erfolgreiche Einfrierprotokolle entwickelt, deren Spermienzahl und Volumen weitgehend standardisiert sind. Dabei gilt es, die Spermienzahl aus ökonomischen Gründen so weit zu reduzieren, dass möglichst viele Besamungsportionen aus einem Bullenejakulat gewonnen werden, ohne dass sich dies negativ auf die NRR auswirkt (DEN DAAS ET AL., 1998). In der heutigen Praxis verwendete konventionelle tiefgefrorene Besamungsportionen enthalten ca. $15-20 \times 10^{6}$ Spermien. Das Volumen beträgt zumeist 230 l (CRAMER ET AL., 2009).

Bislang wurden in der Milchrinderzucht Bullen anhand des Töchterleistungsvergleiches bewertet, was zur Folge hatte, dass die Zuchtwertschätzung erst nach fünf Jahren vorlag (REENTS UND REINHARDT, 2007). Durch die 2010 eingeführte genomische Zuchtwertschätzung werden die Bullen in den ersten Lebensmonaten geprüft und bereits ab einem Alter von 12 Monaten und somit mit dem Ein- 
tritt in die Geschlechtsreife zur Spermaproduktion von den Besamungsstationen genutzt. Nach WOLF ET AL. (1965) erreicht der Bulle die Geschlechtsreife im Durchschnitt nach 45 Wochen, sobald ein Ejakulat mit einer Spermienkonzentration von mindestens $50 \times 10^{6}$ Gesamtspermien pro Ejakulat und einer Vorwärtsbeweglichkeit von mindestens $10 \%$ im Ejakulat gewonnen wird. Zu bedenken ist dabei, dass Jungbullen mit einem Jahr lediglich ein durchschnittliches Ejakulatvolumen von 2 bis $4 \mathrm{ml}$ aufweisen und damit deutlich unter dem Volumen von Altbullen mit einem Alter von sieben Jahren liegen. Bullen $\mathrm{ab}$ einem Alter von fünf Jahren produzieren ein Volumen von 5-8 ml (LICHTNER, 2010). Entweder müssen daher mehr genomisch geprüfte Jungbullen zum Einsatz kommen oder die Besamungsportionen auf wesentlich geringere Spermienkonzentration reduziert werden. Ältere Untersuchungen von FOOTE UND KAPROTH (1997) zeigten, dass die Anzahl der tiefgefrorenen Bullenspermien pro Besamungsportion auf $10 \times 10^{6}$ Spermien reduziert werden kann ohne Einbußen in der Trächtigkeitsrate zu erhalten. In einem Besamungsversuch mit 31.399 Rindern kamen dabei verschiedene Spermakonzentrationen zum Einsatz $\left(10 \times 10^{6}, 13 \times 10^{6}, 16 \times 10^{6}\right.$ und $20 \times 10^{6}$ Spermien pro Besamungsportion). Die NRR zeigten keinen dosisabhängigen Effekt $(70 \%, 72 \%, 73 \%$ und $71,5 \%)$.

Viele Untersuchungen haben sich in den letzten Jahren mit dem Einfluss hoher Verdünnungen, insbesondere bei geschlechtsspezifisch differenziertem Sperma, auf den Besamungserfolg beschäftigt. SCHENK ET AL. (2009) untersuchten die Trächtigkeitsraten bei einer kleinen Gruppe $(n=57)$ laktierender Kühe, bei denen gesextes Sperma mit Konzentrationen von $2 \times 10^{6}$ und $10 \times 10^{6}$ pro Besamungsdosis zum Einsatz kam. Es wurden keine signifikanten Unterschiede im Besamungserfolg aufgezeigt (40,5\% vs. $43,9 \%)$, was von DEJARNETTE ET AL. (2008) bestätigt wurde. Letztere untersuchten den Besamungserfolg von drei Bullen, von denen geschlechtsspezifisch differenziertes Sperma unterschiedlicher Konzentrationen bei Färsen und Kühen zum Einsatz kam $\left(2,1 \times 10^{6}, 3,5 \times\right.$ $10^{6}$ und 5,0 $\times 10^{6}$ Spermien/Besamungsdosis). Dabei konnte bei zwei der drei Bullen ein dosisabhängiger Effekt festgestellt werden, da bei Erhöhung der Spermienkonzentration von 2,1 $\times 10^{6}$ auf 3,5 $\times 10^{6}$ Spermien pro Besamungsdosis ein um $5 \%$ bzw. um $10 \%$ besseres Trächtigkeitsergebnis erzielt werden 
konnte. Die Trächtigkeitsraten bei Kühen zeigten keinen dosisabhängigen Befruchtungs- oder Bulleneffekt (DEJARNETTE ET AL., 2008). In einem weiteren Versuch untersuchte DEJARNETTE ET AL. (2010) die Fruchtbarkeitsraten mit 2,1 x $10^{6}$ und 3,5 $\times 10^{6}$ geschlechtsspezifisch differenzierten Spermien pro Besamungsportion von sieben leistungsgeprüften Bullen. Bei sechs von sieben Bullen konnte kein dosisabhängiger Effekt auf die Trächtigkeitsrate festgestellt werden. Im Durchschnitt lagen die Trächtigkeitsraten in jenen Versuchen mit 2,1 $\times 10^{6}$ Spermien bei $43,9 \%$ und mit $3,5 \times 10^{6}$ Spermien bei $45,7 \%$. Weiterhin verglich die Arbeitsgruppe in einer neuen Studie den Befruchtungserfolg zweier Besamungsgruppen $\left(2,1 \times 10^{6}\right.$ und $10 \times 10^{6}$ Spermien/Besamungsportion) geschlechtsdifferenzierter Spermien mit zwei Gruppen konventionellen, nicht sortierten Spermas gleicher Dichte. Dabei erzielten Portionen mit $2 \times 10^{6}(\mathrm{n}=$ 2319) und $10 \times 10^{6}(n=2279)$ konventionellen Spermien mit $55 \%$ und $60 \%$ höhere Trächtigkeitsraten als Portionen mit $2 \times 10^{6}(\mathrm{n}=2282)$ und $10 \times 10^{6}(\mathrm{n}=$ 2292) gesexten Spermien, die lediglich Trächtigkeitsraten von $38 \%$ und $44 \%$ erreichten. Innerhalb der Gruppen waren die Besamungsportionen mit $10 \times 10^{6}$ Spermien den Portionen mit 2,1 × $10^{6}$ Spermien überlegen. Die Studie zeigte interessanterweise, dass die Auswirkungen des Sortierprozesses und nicht die Verdünnung den hauptsächlichen Effekt auf eine Reduzierung der Fruchtbarkeit hatten (DeJARNeTte ET AL., 2011). SeIDEL UND SCHENK (2008) zeigten in ihren Versuchen bei 719 Besamungen, dass der Einsatz von $1,5 \times 10^{6}$ und $6 \times 10^{6}$ Spermien pro Besamung zu vergleichbaren Trächtigkeitsraten führt. Eine weitere Reduzierung auf $1 \times 10^{6}$ Spermien führt hingegen zu einem verringerten Befruchtungserfolg. Die unterschiedlichen Versuchsergebnisse lassen vermuten, dass weitere, wahrscheinlich nicht erkennbare Effekte, das Befruchtungsergebnis deutlich beeinflussen, was u.a. auf epigenetische Effekte während der Embryonalentwicklung zurückzuführen sein könnte (BERRY ET AL., 2011).

\subsection{Intrauterine und intracornuale Besamung}

In den Anfängen der KB beim Rind wurde mit Hilfe eines Spekulums das Ejakulat in die Öffnung des kaudalen Gebärmutterhalses abgesetzt (BuscH, 2007). 1940 wurde die instrumentelle Samenübertragung revolutioniert. Mit der bis 
heute verwendete Methode der Samenübertragung wird unter rektaler Kontrolle der Besamungskatheter intrauterin eingeführt und das Ejakulat abgesetzt (SALISBURY UND VANDENMARK, 1951).

Mehrere Autoren widmeten sich der Fragestellung, ob mit der Deponierung des Inseminates näher am Ort der Befruchtung eine höhere Trächtigkeitsrate zu erzielen sei. Dabei zeigte sich zunächst, dass kein signifikanter Unterschied bei den NRR nach intrazervikaler, intrauteriner und intracornualer Besamung festgestellt werden konnte (SALISBURY UND VANDENMARK, 1951; KNIGHT ET AL., 1951). Die Arbeitsgruppe McKENNA ET AL. (1990) zeigte anhand von Feldstudien eine Trächtigkeitsrate von $70,8 \%$ bei Milchkühen $(n=2195)$, die intracornual besamt wurden, und eine vergleichbare Trächtigkeitsrate von 69,5\% bei Tieren ( $n=2428$ ), die intrauterin besamt wurden (McKENNA ET AL., 1990). Versuchsergebnisse, bei denen Spermiendosen von $2 \times 10^{6}$ Spermien im Uteruskörperalternativ in der Hornspitze oder aber in der Hornmitte platziert wurden, zeigten keine höheren Trächtigkeitsraten ( $41,8 \%$ vs. $49,1 \%$ vs. $39,3 \%$ ) (KURYKIN ET AL., 2007). Zudem war kein signifikanter dosisabhängiger Effekt ( $p>0,05)$ nach intracornualer Besamung von $2 \times 10^{6}$ Spermien und $40 \times 10^{6}$ Spermien auf die Trächtigkeitsraten (68\% vs. 56,9\%) von Milchkühen zu verzeichnen (KURYKIN ET AL., 2003; KURYKIN ET AL., 2007). Ähnliche Ergebnisse waren in zwei Feldversuchen an Kühen von der Arbeitsgruppe MOMONT ET AL. (1989) zu sehen, die den Einfluss der intracornualen Besamung auf die Fruchtbarkeit testeten. Dabei wurden die Kühe in zwei Gruppen eingeteilt und ipsi- sowie contralateral zum dominanten Follikel besamt. 59\% der Tiere, die ipsilateral besamt wurden, wurden tragend, $60 \%$ der Tiere, die contralateral besamt wurden. Daraus wurde geschlossen, dass die Platzierung des Spermas in nur ein Horn keine Beeinträchtigungen, aber auch keine Verbesserungen der Fruchtbarkeitsrate mit sich brachte (MOMONT ET AL., 1989). Gegensätzliche Ergebnisse beschrieb LOPEZGatIUS (1996), der 1.686 Kühe tief-intrauterin besamte. Bei 867 Tieren wurde der Samen ipsilateral zum dominanten Follikel im Uterushorn abgelegt, bei den übrigen 810 Tieren erfolgte eine contralaterale Besamung. Die Ergebnisse zeigten, dass die ipsilaterale Besamung zu deutlich höheren Trächtigkeitsergebnissen führte $(46,6 \%$ vs. $35,7 \%)$. Untersuchungen von WILLIAMS ET AL. (1988) zeigten eine Verbesserung der Fruchtbarkeit bei intracornualer Be- 
samung im Vergleich zur zervikalen Samenablage. Es wurden 2.127 Kühe der Rasse Holstein und Jersey intrauterin oder intracornual besamt. Die intrauterine Besamung erzielte eine Trächtigkeitsrate von 39,4\%, die intracornuale Samenablage der Spermien führte zu einer Trächtigkeitsrate von 49,3\% (WILLIAMS ET AL., 1988). Die Arbeitsgruppe SENGER ET AL. (1988) führte 4178 Besamungen bei Milchkühen mit erfahrenen Technikern durch. Dabei wurden $44,7 \%$ der Kühe tragend, wenn sie intrauterin besamt wurden und 64,4\% der Kühe wenn die Spermienablage intracornual erfolgte. SENGER ET AL. (1988) fanden heraus, dass bei korrekter Platzierung der Besamungspipette in eines der beiden Uterushörner fast 20\% höhere Trächtigkeitsraten zu erzielen sind ( $n=4178$ Kühe). Auch Lopez-Gatius UND CAMON-URgel (1988) zeigten bei 344 laktierenden Kühen eine 10\%ige Überlegenheit der unilateralen Besamung in die kraniale Hälfte des Gebärmutterhorns gegenüber der Insemination in den Uteruskörper.

Eine speziell entwickeltes Besamungsgerät zur tief-intrauterinen Besamung ist der "Ghent Katheter", der die Besamung nahe der uterotubalen Verbindung mittels einer flexiblen Besamungspipette, die sich der Gebärmutterkrümmung anpasst (VERBERCKMOES ET AL., 2004), ermöglicht. Ein Vergleich dieser Methode mit der Samenablage im Uteruskörper erbrachte aber keine signifikanten Unterschiede hinsichtlich der Trächtigkeitsraten. Auch eine Reduzierung der Samendosis von $10-15 \times 10^{6}$ auf 8,4 , oder $2 \times 10^{6}$ Spermien führte nicht zur Veränderung der Trächtigkeitsrate bei der Besamung in die Uterushornspitze gegenüber der konventionellen Besamung (VERBERCKMOES ET AL., 2005).

\subsection{Spermien- und Gametentransfer in den Eileiter}

Eine Funktion des Eileiters ist es, für den Transport der Gameten in die korrekte Richtung zu sorgen (ELLINGTON, 1991). Dieser erfolgt durch Kontraktion des Myometriums, der Schleimhautfalten, durch Flüssigkeitsströme, durch die Zilienaktivität und der Eigendynamik der Spermatozoen (YANIZ ET AL., 2000). Während die Transportbewegung für Spermien zunächst Richtung Eileiterampulle ausgerichtet ist, erfolgt nach der Befruchtung der Transport des frühen Embryos in die entgegengesetzte Richtung (YANIZ ET AL., 2000; BESENFELDER ET AL., 
2010). 1959 berichtete Björkman über die Veränderungen der Morphologie des Eileiterepithels im Zyklusverlauf. In der lutealen Phase ist das Epithel von Zellvorwölbungen geprägt, wobei das Epithel in der follikularen Phase glatt erscheint. Die Mikrovilli nehmen in der follikularen Phase eine lange und dünne Gestalt an. In der lutealen Phase erscheinen sie flacher und stumpfer und sind in ihrer Anzahl vermindert. Während das Epithel in der Lutealphase kompakt vorliegt, ist es in der follikularen Phase durch Flüssigkeitsansammlungen geweitet und ödematös (BJÖRKMAN, 1959). Für den Transport der Spermatozoen durch die Mukosafalten des Eileiters ist die hyperaktivierte Bewegung unabdingbar. Dabei spielt die Kombination aus Chemotaxis und Thermotaxis eine Rolle. Beim Kaninchen wurde eine Temperaturdifferenz von $2^{\circ} \mathrm{C}$ zwischen dem Isthmus und der Ampulle nachgewiesen. Es wird vermutet, dass die Spermien aus dem Reservoir auf die wärmere Ampulle zu schwimmen (HUNTER, 2010). Weiterhin können chemotaktische Signale der Eizelle auf die Motilität der Spermien wirken, was wiederum eng mit der Kapazitation verknüpft ist. Zu berücksichtigen ist, dass es sich um einen geregelten Spermientransport handelt, der sicherstellt, dass nur funktionsfähige Spermien die ovulierte Eizelle erreichen (TÖPFER-PETERSEN, 2007).

VAZQUEZ ET AL. (2008) führten die Besamung beim Schwein laparoskopisch in dem Eileiter durch und erzielten damit gute Trächtigkeitsraten mit einer Besamungsdosis von 0,3 × $10^{6}$ geschlechtsdifferenzierten Spermien. 1954 wurde erstmals die intraperitoneale Besamung beim Rind durchgeführt. SKJERVEN (1954) durchdrang dabei mit einer Kanüle das obere Scheidengewölbe und deponierte Samen auf das rektal herangeführte Ovar einer brünstigen Färse. Die Besamungsmethode führte $z u$ einer positiv verlaufenden Trächtigkeit (SKJERVEN, 1954). Eine neuere Studie zur intraperitonealen Besamung von Rindern, die zuvor konventionell mindestens sechsmal erfolglos inseminiert wurden, führte zu einer Trächtigkeitsrate von 14,6\%. Das ausgewählte Tiermaterial wies bei voriger rektaler Untersuchung keinerlei pathologische Befunde auf und zeigte normale Brunstzyklen (LOPEZ-GATIUS, 1995).

Der Eileiter des Rindes ist zur Übertragung von Gameten bzw. der Spülung früher Embryonalstadien bislang nur auf chirurgischem oder minimal-invasivem 
Weg zugänglich gewesen (BESENFELDER UND BREM, 1998). JILLELLA ET AL. (1977) übertrugen zwei in vitro erzeugte bovine Embryonen im 16- bis 32-Zellstadium chirurgisch mittels einer Kanüle, die über die Flanke des Empfängertieres in den Uterus eingeführt wurde. Daraus resultierte die Geburt eines Kalbes. SIRARD UND LAMBERT (1986) übertrugen 27 in vitro gereifte Embryonen im Zellstadium zwei bis acht chirurgisch in den Eileiter. Keines der 13 Empfängertiere wurde tragend. Nach einer vorherigen Reifung der befruchteten Eizellen im Eileiter der Maus und der darauffolgenden direkten Übertragung in den Uterus der Rinder wurden sechs von 14 Tieren tragend (SIRARD UND LAMBERT, 1986). FAYRER-HOSKEN ET AL. (1989) übertrugen bovine Embryonen mit Hilfe eines Bronchoskopes über die rechte paralumbale Fossa auf vier Empfängertiere, woraus eine Trächtigkeit resultierte.

BESENFELDER UND BREM (1998) entwickelten eine neue Methode der transvaginalen minimal invasiven endoskopischen Übertragung von Embryonen in den Eileiter beim Rind. Dabei wird das Endoskop mit Hilfe einer Metallhülse in die Vagina eingeführt. Unter rektaler Kontrolle wird das Ovar mit zwei Fingern fixiert und vor dem Endoskop positioniert. Mit einer Glaskapillare, die über den Arbeitskanal des Endoskops eingeführt und durch das obere Scheidendach gestochen wird, werden die Embryonen über das Infundibulum in die Ampulla des Eileiters übertragen. In einem ersten Versuch wurden 26 Embryonen auf 24 Empfängertiere übertragen, wovon neun Tiere tragend wurden (BESENFELDER UND BREM, 1998). WeTSCHER ET AL. (2005) machten sich diese Methode zu Nutze und verglichen die Entwicklung von in vivo und in vitro gereiften Eizellen und Blastozysten. Dabei übertrugen sie mit der von BESENFELDER UND BREM (1998) entwickelten Methode in vitro gereifte Eizellen und kapazitierte Spermien in den Eileiter. Es wurden 351 Embryonen von zuvor 514 übertragenen Eizellen zurückgespült.

GROSSFELD ET AL. (2011A) entwickelten eine nicht-chirurgische Methode der Übertragung von Spermien in den Eileiter, den sogenannten „Sperm-IntraFallopian-Transfer" $\left(\mathrm{SIFT}^{\circledR}\right)$. Mit einem speziell entwickelten Katheter werden dabei Spermien direkt in den Eileiter ipsilateral zum dominanten Follikel übertragen. Bei 24 zuvor synchronisierten Milchkühen wurden in einem ersten Ver- 
such $10^{5}$ in Andromed ${ }^{\mathrm{TM}}$ verdünnte und kryokonservierte Spermien in den Eileiter übertragen. An Tag 7 wurden bei sieben Kühen insgesamt vier Embryonen gespült. Die restlichen 17 Tiere wurden nach 28-30 Tagen einem Trächtigkeitsultraschall unterzogen. Sieben Tiere waren tragend $(41,2 \%)$.

In einem Feldversuch wurden auf 93 spontan ovulierende Milchkühe 0,85 $1,1 \times 10^{6}$ Spermien zweier leistungsgeprüfter Bullen in den Eileiter übertragen. Die Trächtigkeitsrate für den Bullen A lag in allen Gruppen bei $30 \%$, die für den Bullen B bei 15,2\%. In der Kontrollgruppe wurden 22,9\% der Tiere, die mit $15 x$ $10^{6}$ Spermien des Bullen A konventionell besamt wurden, tragend. Bulle B erzielte in der Kontrollgruppe eine Trächtigkeitsrate von 35,4\%. Die Ergebnisse zeigten einen bullenindividuellen Effekt durch die Verwendung gering dosierter Besamungsportionen (GROSSFELD ET AL., 2011B). 


\section{$3 \quad$ Material und Methoden}

Die neue in der Entwicklungsphase befindliche Übertragungsmethode für Spermien SIFT ${ }^{\circledR}$ ermöglicht es, Spermien nicht chirurgisch direkt in den Eileiter zu übertragen. Hierbei ist die Reduzierung des Volumens der Besamungsportion von $230 \mu \mathrm{l}$ auf 30-50 $\mu \mathrm{l}$ eine notwendige Voraussetzung, um das Spermien/Volumenmengenverhältnis der üblichen Dosierung beizubehalten. Vorstudien der Arbeitsgruppe zeigten, dass das maximale Volumen, welches bei einer Übertragung in den Eileiter verwendet werden kann, $50 \mu \mathrm{l}$ nicht überschreiten sollte (GROSSFELD ET AL., 2011B). Ziel der Arbeit war es daher, grundlegende Aspekte der Tiefgefrierung von Spermien in kleinen Volumina zu bearbeiten, um die Praxistauglichkeit von $\mathrm{SIFT}^{\circledR}$ zu überprüfen. Abbildung 1 gibt einen Überblick über den Ablauf dieser Arbeit.

Versuch 1: Im ersten Teil der Arbeit wurde einer neuer Straw zur Kryokonservierung minimal dosierter Spermaportionen konfektioniert (Nanostraw) und durch Screeningversuche ein angepasstes Kryokonservierungsprotokoll entwickelt.

Versuch 2: Der Hauptversuch diente der Überprüfung des ausgewählten Kryokonservierungsprotokolls und der Konfektionierung des Nanostraws aus Versuch 1. Dabei wurden die Spermien nach dem Auftauen unter Laborbedingungen auf ihre Lebensfähigkeit getestet.

Versuch 3: Da sich die Besamungsmethode $\mathrm{SIFT}^{\circledR}$ noch in einem Entwicklungsstadium befindet wurden bis jetzt nur Besamungen an Kühen mit konventionell kryokonserviertem Sperma durchgeführt (GROSSFELD ET AL., 2011B). Der erste Besamungsversuch diente der Weiterentwicklung von SIFT ${ }^{\circledR}$ durch den Einsatz von geschlechtsspezifisch differenziertem Frischsamen bei Färsen und Kühen.

Versuch 4: Um die aus Versuch 2 unter Laborbedingungen erhobenen Daten auf ihre Praxistauglichkeit hin zu überprüfen wurde ein zweiter Besamungsversuch mit den TG-Spermien aus dem Nanostraw durchgeführt. 


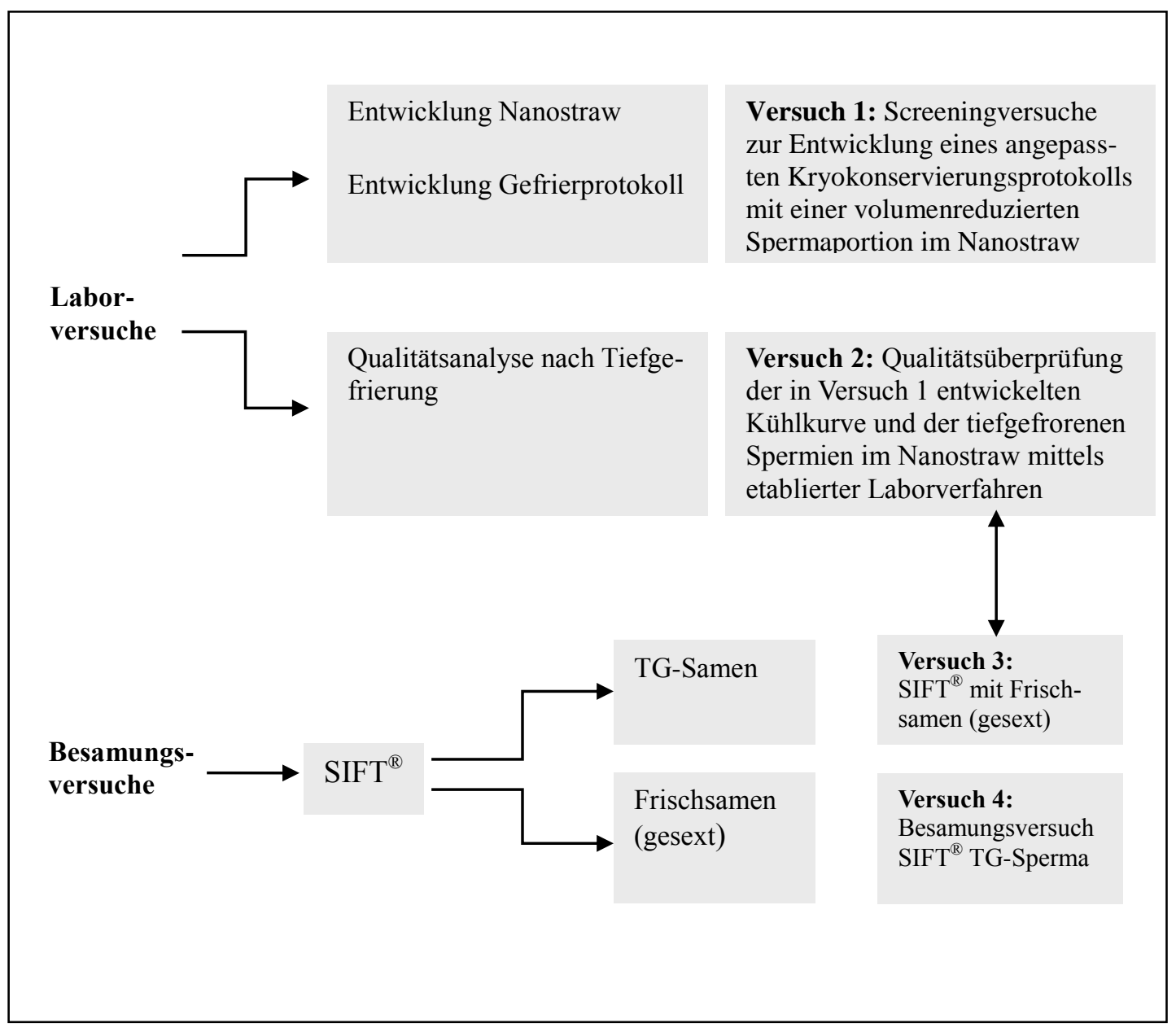

Abbildung 1: Übersicht über den Versuchsablauf.

\subsection{Wiederkehrende Arbeitsschritte}

\subsubsection{Samengewinnung}

Das Sperma wurde von fruchtbarkeitsgetesteten Besamungsbullen der Rasse Holstein Friesian durch erfahrene Techniker mittels künstlicher Vagina gewonnen. Die Bullen wurden zweimal wöchentlich abgesamt und die Ejakulate in das benachbarte Labor transportiert. Alle Bullen sind in der Besamungsstation der Masterrind, Verden, unter einheitlichen Bedingungen während des Versuchszeitraums, gehalten worden (Tabelle 5). 
Tabelle 5: Geburtsjahr, Gesamtzuchtwert (RZG), Relativzuchtwert Milch (RZM), Relativzuchtwert Exterieur (RZE), Relativzuchtwert Nutzungsdauer (RZN) und Relativzuchtwert Kalbeverlauf (KV) der in den Versuchen eingesetzten Bullen

\begin{tabular}{|c|c|c|c|c|c|c|c|c|c|c|}
\hline \multirow[b]{2}{*}{ Bulle } & \multirow[b]{2}{*}{ Geburtsjahr } & \multirow[b]{2}{*}{ RZG } & \multirow[b]{2}{*}{ RZM } & \multirow[b]{2}{*}{ RZE } & \multirow[b]{2}{*}{ RZN } & \multirow[b]{2}{*}{ KV } & \multicolumn{4}{|c|}{ Versuch } \\
\hline & & & & & & & 1 & 2 & 3 & 4 \\
\hline A & 2009 & 136 & 115 & 124 & 125 & 114 & & $x$ & & $x$ \\
\hline B & 2005 & 119 & 110 & 111 & 110 & 113 & & $x$ & & $x$ \\
\hline C & 2008 & 143 & 133 & 123 & 123 & 109 & $x$ & & $x$ & \\
\hline D & 2004 & 112 & 113 & 113 & 106 & 114 & $x$ & & $x$ & \\
\hline
\end{tabular}

\subsubsection{Eingangsuntersuchung}

Unmittelbar nach der Samengewinnung wurde die Dichte der Ejakulate mittels Coulter Counter ${ }^{\circledR}$ (Beckmann Coulter, Krefeld, Deutschland) bestimmt. Zudem wurde direkt nach der Gewinnung eine Beurteilung der Motilität und der Massenbewegung im Phasenkontrastmikroskop bei 200-facher Vergrößerung durchgeführt. Ejakulate mit einer Anfangsmotilität von $\leq 70 \%$ wurden von weiteren Untersuchungen ausgeschlossen.

Aus einem Anteil des nativen Ejakulats wurde ein Aliquot von $1 \mathrm{ml}$ durch die Verdünnung mit Sexcess ${ }^{\circledR}$-Sample (s. Kapitel 9.2) auf eine Konzentration von $100 \times 10^{6}$ Spermien/ml für den Sortierprozess im Flowzytometer für den Versuch 3 eingestellt.

Ein weiterer Anteil des Ejakulates wurde mit dem Tiefgefrierverdünner Sexcess ${ }^{\circledR}$ I, dem ersten nicht glyzerinhaltigen Teil des zweiphasigen Tiefgefrierverdünners Sexcess ${ }^{\circledR}$ (Masterrind $\mathrm{GmbH}$, Verden, Deutschland), auf $50 \times 10^{6}$ Spermien/ml in einem $10 \mathrm{ml}$ Röhrchen verdünnt (Versuche 1, 2 und 4).

Nach Eintreffen des verdünnten Ejakulates in Mariensee wurden mit Hilfe des computerassistierten Spermaanalysegerätes (CASA; Hamilton Thorne Biosciences, Version 12 IVOS, Hamilton Thorne Biosciences, Berverly, USA) die in Kapitel 2.2.1 beschriebenen Motilitätsparameter bestimmt. Anschließend erfolgte eine flowzytometrische Untersuchung der Spermienmembranen mit 
einem FACS-Gerät $\left(\right.$ FACScan ${ }^{\odot}$, Becton Dickinson Bioscience, Heidelberg, Deutschland). Bei der flowzytometrischen Untersuchung wurde eine SYBR14/Propidiumjodid (PI)-Färbung für die in eidotterhaltigem Medium verdünnten Spermien angewendet (s. Kapitel 2.2.3). Zudem wurde der prozentuale Anteil morphologisch intakter Spermien mit einem Phasenkontrastmikroskop bei 1000-facher Vergrößerung unter Öl ermittelt. Es wurden jeweils 200 Zellen gezählt. Die Proben wurden hierzu in Hancock-Lösung fixiert und ausgezählt (s. Kapitel 2.2.2).

\subsubsection{Thermoresistenztest}

Um die Überlebensfähigkeit der Spermien unter Temperaturbedingungen, die denen des weiblichen Genitaltraktes beim Rind ähnlich sind, festzustellen, und um Rückschlüsse auf die Qualität des Ejakulates zu ziehen, wurde in dem Versuch 2 ein Thermoresistenztest über sechs Stunden bei $37^{\circ} \mathrm{C}$ durchgeführt (MÜLLER, 2000).

Für die Versuche 1 und 2 wurden etwa 10 tiefgefrorene Portionen aus den Nanostraws (s. Kapitel 3.1.8) für 60 Sekunden bei Raumtemperatur aufgetaut und in einem vorgewärmten $1,5 \mathrm{ml}$ Eppendorfgefäß gepoolt, um Variationen innerhalb verschiedener Pailletten eines Ejakulates auszugleichen. Der Kontrollstraw (160 - $250 \mu \mathrm{l}$ ) wurde 20 Sekunden in einem Wasserbad bei $37^{\circ} \mathrm{C}$ aufgetaut und in ein vorgewärmtes $1,5 \mathrm{ml}$ Eppendorfgefäß gefüllt. Um eine gleichmäßige Temperaturanpassung zu gewährleisten, wurden die Proben zunächst 10 Minuten bei $37^{\circ} \mathrm{C}$ auf dem Wärmeblock gelagert. Nach dieser Anpassungsphase erfolgte die erste Bestimmung der spermatologischen Eigenschaften. Die verbliebenen Proben wurden bei $37^{\circ} \mathrm{C}$ weiter inkubiert und die Qualitätsparameter Motilität, Morphologie und Membranintegrität, wie in den folgenden Kapiteln beschrieben, nach drei- und sechsstündiger Lagerung erneut gemessen. 


\subsubsection{Motilitätsanalyse}

Die Motilitätsanalyse wurde mit einem IVOS-Spermaanalyse-System (Hamilton Thorne Biosciences, Beverly, Ma, USA) durchgeführt. Die gewählten Parametereinstellungen befinden sich im Anhang unter Kapitel 9.3. Messungen von in eidotterhaltigem Medium verdünnten Spermienproben wurden anhand einer Fluoreszenzmessung mit dem CASA-System nach Anregung mit einer Halogen-Lichtquelle durchgeführt. Für die Messung des Anteils motiler Spermien wurden diese mit Hoechst $33342(3 \mu \mathrm{l} / \mathrm{ml})$ angefärbt. Der Farbstoff bindet an die DNA und die Spermienköpfe können somit durch die Fluoreszenzmessung von den Eidotterpartikeln differenziert werden. Zur zuverlässigen Beurteilung der Motilitätsparameter wurden auf 10 Feldern insgesamt 400-800 Zellen pro Messung ausgewertet. Hierzu wurden jeweils $10 \mu \mathrm{l}$ der zu untersuchenden Proben in eine Makler-Kammer (SEFI Medical Instruments, Haifa, Israel) gegeben und jeweils 60 Bilder von 10 Feldern analysiert. Die Temperatur des Probentisches wurde auf $37^{\circ} \mathrm{C}$ eingestellt.

\subsubsection{Morphologische Untersuchung}

Für die morphologische Untersuchung wurden $10 \mu \mathrm{l}$ Sperma mit 10 ml Hancock Medium (s. Kapitel 9.2) fixiert und unter einem Phasenkontrastmikroskop (Olympus BX 60, Hamburg, Deutschland) bei 1.000-facher Vergrößerung mit Ölimmersion analysiert. Für Auswertung wurden jeweils 200 Spermien ausgezählt. Für die primären, sekundären und tertiären Veränderungen wurde jeweils zwischen folgenden Abweichungen unterschieden:

Wurden bei einem Spermium mehrere morphologische Veränderungen festgestellt, erfolgte die Einteilung hierarchisch nach primärer, sekundärer oder tertiärer Genese.

In der weiteren Darstellung wurden die morphologisch intakten Spermien in zwei Klassen eingeteilt. Die erste Klasse beinhaltet die Spermien mit morphologisch intaktem Akrosom. Diese schließt alle Zellen ein, bei denen die Kopfkappen, unabhängig von der morphologischen Beschaffenheit der übrigen Zelle, 
sich nicht im Zustand „abgelöst", „in Ablösung“, „geschwollen“ oder "deformiert" befanden. Die zweite Klasse steht für alle morphologisch unveränderten Spermien und beschreibt sämtliche Zellen, bei denen keinerlei Abweichungen der Spermienmorphologie ermittelt wurden (s. Kapitel 2.2.2).

\subsubsection{Durchflusszytometrische Untersuchungen}

Sämtliche durchflusszytometrischen Untersuchungen wurden mit einem FACScan ${ }^{\odot}$ Durchflusszytometer (Becton Dickinson Bioscience, Heidelberg, Deutschland) durchgeführt. Der luftgekühlte Argon-Laser arbeitet mit einer Wellenlänge von $488 \mathrm{~nm}$ und einer Leistung von $15 \mathrm{~mW}$. Bei jeder Messung werden 10.000 Zellen ausgezählt. Zur Messung der Emission wurden ein Filter FL1 (530/30 nm) des FACScan ${ }^{\odot}$ für die Grünfluoreszenz, ein Filter FL-2 (585/42 $\mathrm{nm}$ ) für die Orangefluoreszenz und ein Filter FL-3 (650LP nm) für die Rotfluoreszenz eingesetzt. Jede Messung wurde zudem wiederholt. Die für die Datenerfassung eingestellten Geräteparameter sind im Anhang unter Kapitel 9.4 aufgeführt.

Die Auswertung der erfassten Daten erfolgte mit der Software FCS Express, Version 3.0 (DeNovo Software, Thornhill, Ontario, Kanada).

\section{Sybr14/PI-Färbung}

Im Thermoresistenztest wurde für die durchflusszytometrische Analyse der Membranintegrität das aus zwei Komponenten bestehende LIVE/DEAD ${ }^{\circledR}$ Sperm Viability Kit (L-7011, Invitrogen, Karlsruhe, Deutschland) verwendet. Komponente $A$ ist der Farbstoff SYBR ${ }^{\circledR} 14$, Komponente B besteht aus dem Farbstoff Propidiumjodid (PI).

Die Probenanalyse erfolgte in Anlehnung an das Protokoll von GARNER ET AL. (1994). Hierzu wurden die Proben aus Spermiensuspension und TRIS-Sample mit einem Gesamtvolumen von $500 \mu \mathrm{l}$ sowie einer Spermienkonzentration von 
$1 \times 10^{6}$ Spermien $/ \mathrm{ml}$ erstellt. Zu den Proben wurden jeweils $3 \mu \mathrm{l}$ einer verdünnten SYBR ${ }^{\circledR} 14$ Stammlösung ( $1 \mathrm{mM}$ in DMSO) gegeben und 10 Minuten bei

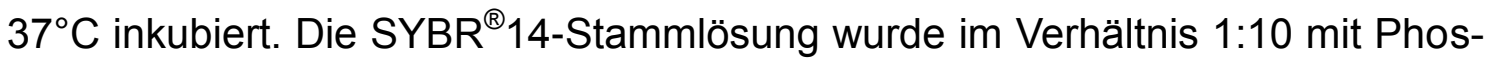
phat gepufferten Salzen (PBS) verdünnt. Anschließend wurden $3 \mu \mathrm{II}$ hinzugegeben und die Lösung 10 Minuten bei Raumtemperatur dunkel gelagert. Danach erfolgte die Messung im Durchflusszytometer (GARNER ET AL. 1994).

SYBR ${ }^{\circledR} 14$ ist ein membrangängiger Fluoreszenzfarbstoff im grünen Wellenbereich, der die DNA der Spermien, unabhängig vom funktionellen Zustand der Membran, anfärbt. Der rotfluoreszierende Farbstoff Propidiumjodid hingegen penetriert lediglich Spermien mit geschädigter Plasmamembran. Er bindet an die DNA und überlagert dabei den FarbstoffSYBR ${ }^{\circledR} 14$. Spermien mit einer intakten Plasmamembran sind grünfluoreszierend (SYBR ${ }^{\circledR} 14$ - positiv), jene mit einer geschädigten Membran sind PI-positiv und emittieren Licht im roten Wellenbereich. Membrandefekte Spermien, bei denen die PI-Färbung den Farbstoff SYBR ${ }^{\circledR} 14$ nicht vollständig überlagert, emittieren sowohl Licht im grünen als auch im roten Bereich. Sie werden zu den Spermien mit geschädigter Plasmamembran gezählt (GARNER ET AL. 1994).

Für die flowzytometrische Analyse wurden nicht fluoreszierende Partikel, wie z.B. die aus dem Verdünner stammenden Eidotterpartikel, aus der Berechnung ausgeschlossen.

\subsubsection{Sperm Intra Fallopian Transfer $\left(\mathrm{SIFT}^{\circledR}\right)$}

Bei der endoskopischen Besamung SIFT ${ }^{\circledR}$ wurde ein Videoendoskop (EG-1840) der Firma Pentax (Hamburg) verwendet. Das flexible Endoskop mit abwinkelbarer Spitze war mit zwei Lichtkanälen, einer Kamera und einem Arbeitskanal ausgestattet. Die visuelle Übertragung erfolgte über einen Monitor. Per Knopfdruck konnten über den Arbeitskanal Luft insuffliert und die Optik gespült werden. 
Die Übertragung der Besamungsportion erfolgte endoskopisch an der fixierten Kuh. Zunächst wurde mittels rektaler Ultraschalluntersuchung (Easy-scan, BCF Technology) der dominante Follikel bestimmt. Unter rektaler Kontrolle wurde dann von einer Person ein Führungsrohr aus Edelstahl für das Endoskop in die Zervix eingeführt. Das Führungsrohr wurde neu entwickelt und an den Durchmesser des Endoskops angepasst. Letzteres wurde anschließend von einer zweiten Person in die Gebärmutter eingeführt. Über einen Videochip am vorderen Ende des Endoskops ließ sich die Position im Uterus am Monitor darstellen. Über Sichtkontrolle wurde das Endoskop ipsilateral zum dominanten Follikel bis zur uterotubalen Verbindung vorgeschoben. Durch den Arbeitskanal des Endoskops wurde daraufhin ein in der Arbeitsgruppe entwickelter Kunststoffschlauch aus Polytetrafluoroethylen (PTFE) inklusive eines Innenkatheters, die so genannte SIFT ${ }^{\circledR}$-Sonde (s. Abbildung 2) mit einem Durchmesser von 0,4 mm eingeführt.

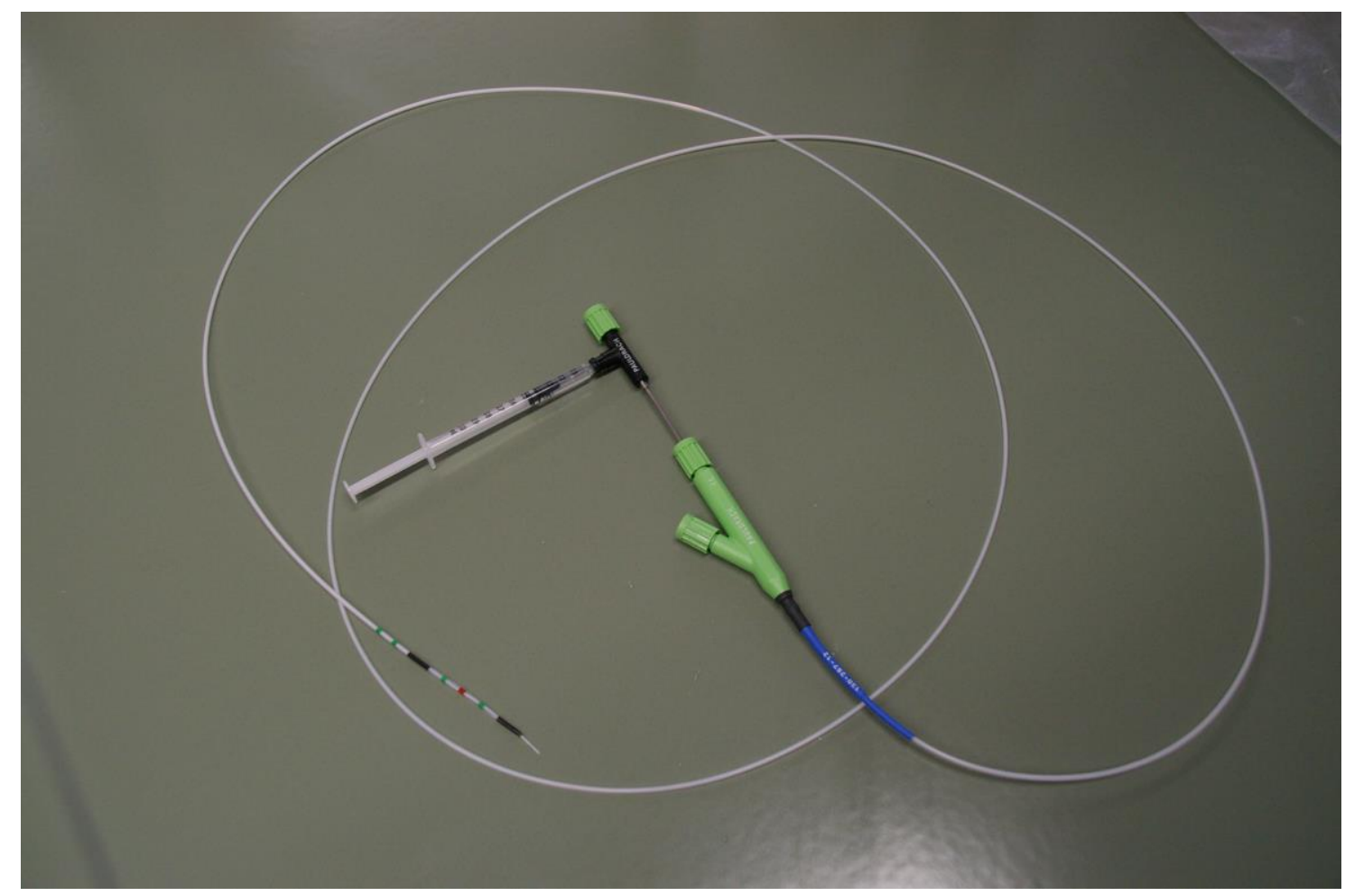

Abbildung 2: Besamungskatheter (SIFT ${ }^{\circledR}$ - Sonde). 
Das Inseminatvolumen von $20-40 \mu \mathrm{l}\left(0,5\right.$ bis $1 \times 10^{6}$ Samenzellen/Straw) wurde zuvor in die Schlauchspitze des Innenkatheters aufgesogen (Abbildung 3). Durch die Sichtkontrolle wurde der Eingang des Eileiters fokussiert und der Katheter bzw. dessen Innenkatheter in den vorderen Teil des Eileiters vorgeschoben. Mittels luftgefüllter Spritze erfolgte die Entleerung der Spermasuspension in den Eileiter.

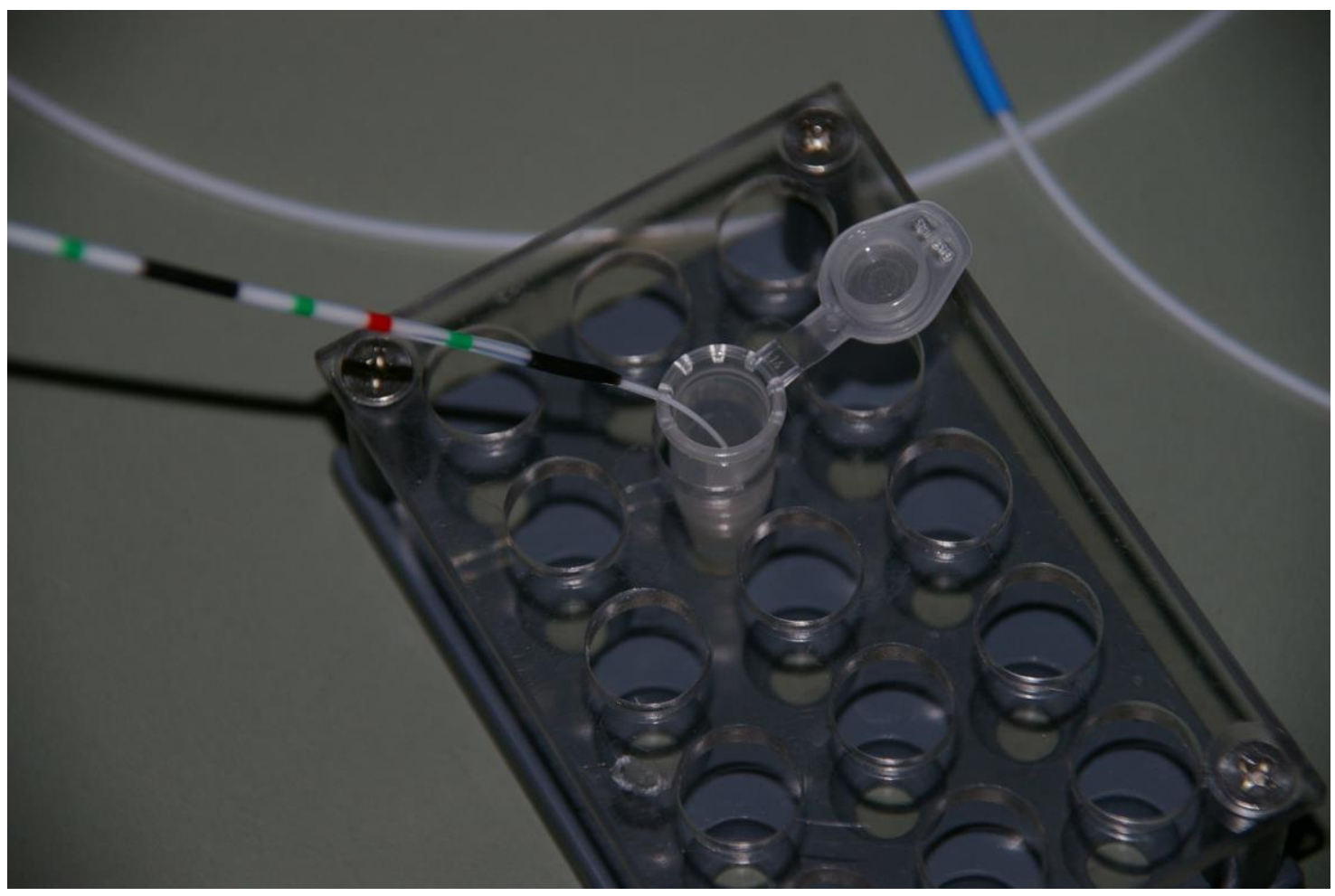

Abbildung 3: Aufsaugen des Inseminatvolumens in den Innenkatheter.

Die Abbildung 4 beschreibt den Weg des Endoskops und zeigt die Bilder der Öffnung der Zervix, der Bifurkation und des Eileitereingangs. 


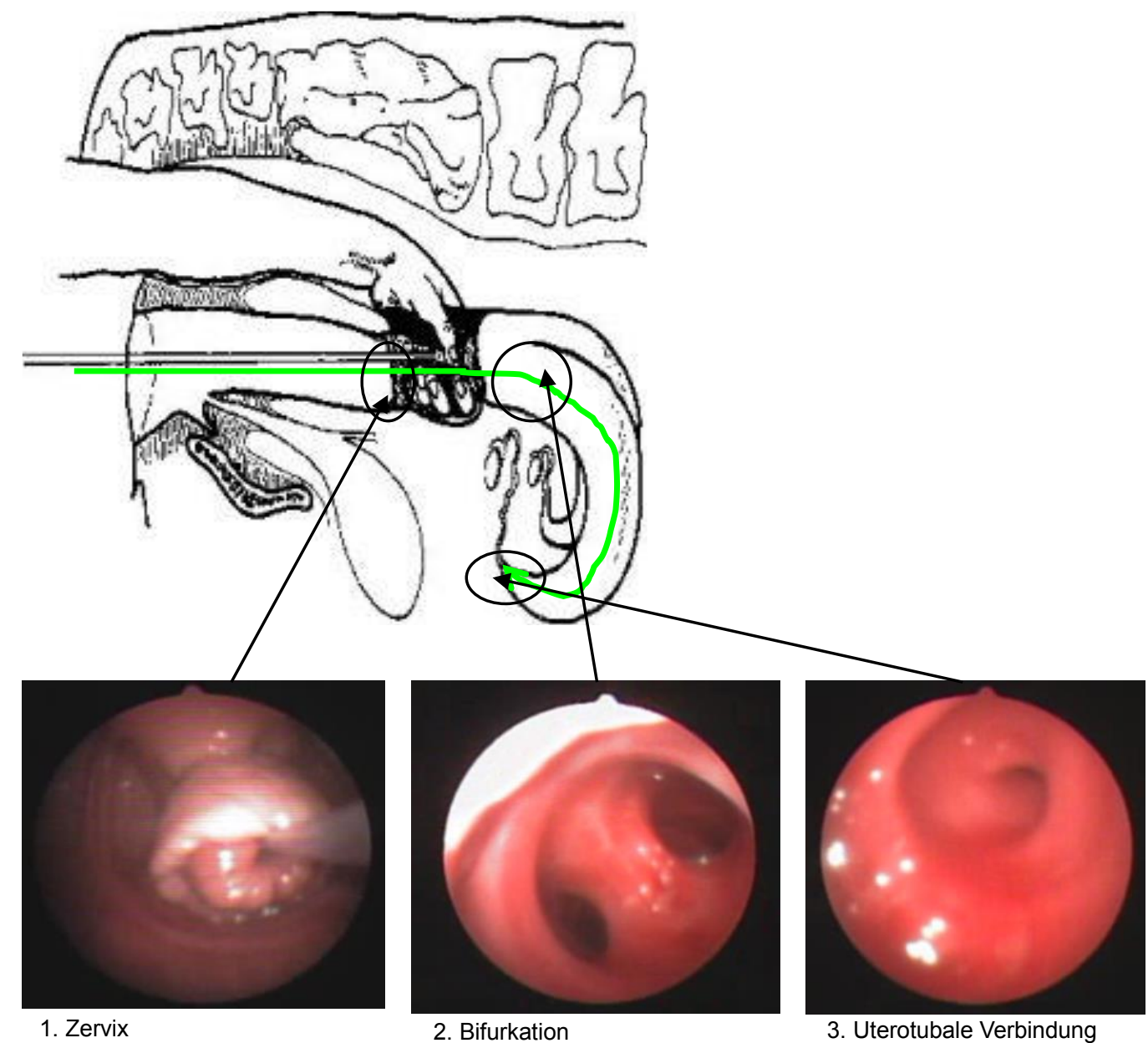

Abbildung 4: Graphische Darstellung der einzelnen Schritte des Besamungsvorgangs SIFT ${ }^{\circledR}$ anhand von endoskopischen Aufnahmen der Zervix, Bifurkation und der uterotubalen Verbindung im Uterus (THOMSON, 2011).

\subsubsection{Entwicklung eines Nanostraws und dessen Handhabung}

Im Nanostraw wurden ca. $20 \mu \mathrm{l}$ einer Spermasuspension mit einer Dichte von 500.000 Samenzellen kryokonserviert. Dies entsprach einer Dichte von ca. $50 \times 10^{6} \mathrm{Spermien} / \mathrm{ml}$. Die Befüllung des Nanostraws erfolgte über den Sog einer Spritze mit Kanüle. Jeder Nanostraw wurde zusätzlich mit einer 0,5 ml Paillette (Minitüb, Tiefenbach, Deutschland; IMV, L`Aigle, Frankreich) überzogen, um durch seine volumenabhängigen Puffereigenschaften eine stabile Einfrierkurve zu gewährleisten (Abbildung 5). Der sich in der Paillette befindliche Nanostraw wurde mit einem Ultraseal 21TM (Minitüb, Tiefenbach, Deutschland) verschlossen. Dabei wurde der Nanostraw mit der handelsüblichen Paillette verschweißt. Zur Kontrolle erfolgte die zusätzliche Abfüllung des endverdünnten Spermas in einer 0,25 ml-Paillette (Minitüb, Tiefenbach, Deutschland; IMV, 
L`Aigle, Frankreich). Die Proben wurden mittels der Einfriermaschine „Ice Cube 14 S“ (Minitüb, Tiefenbach, Deutschland) eingefroren und zur Lagerung in flüssigen Stickstoff $\left(\mathrm{LN}_{2}\right)$ überführt.

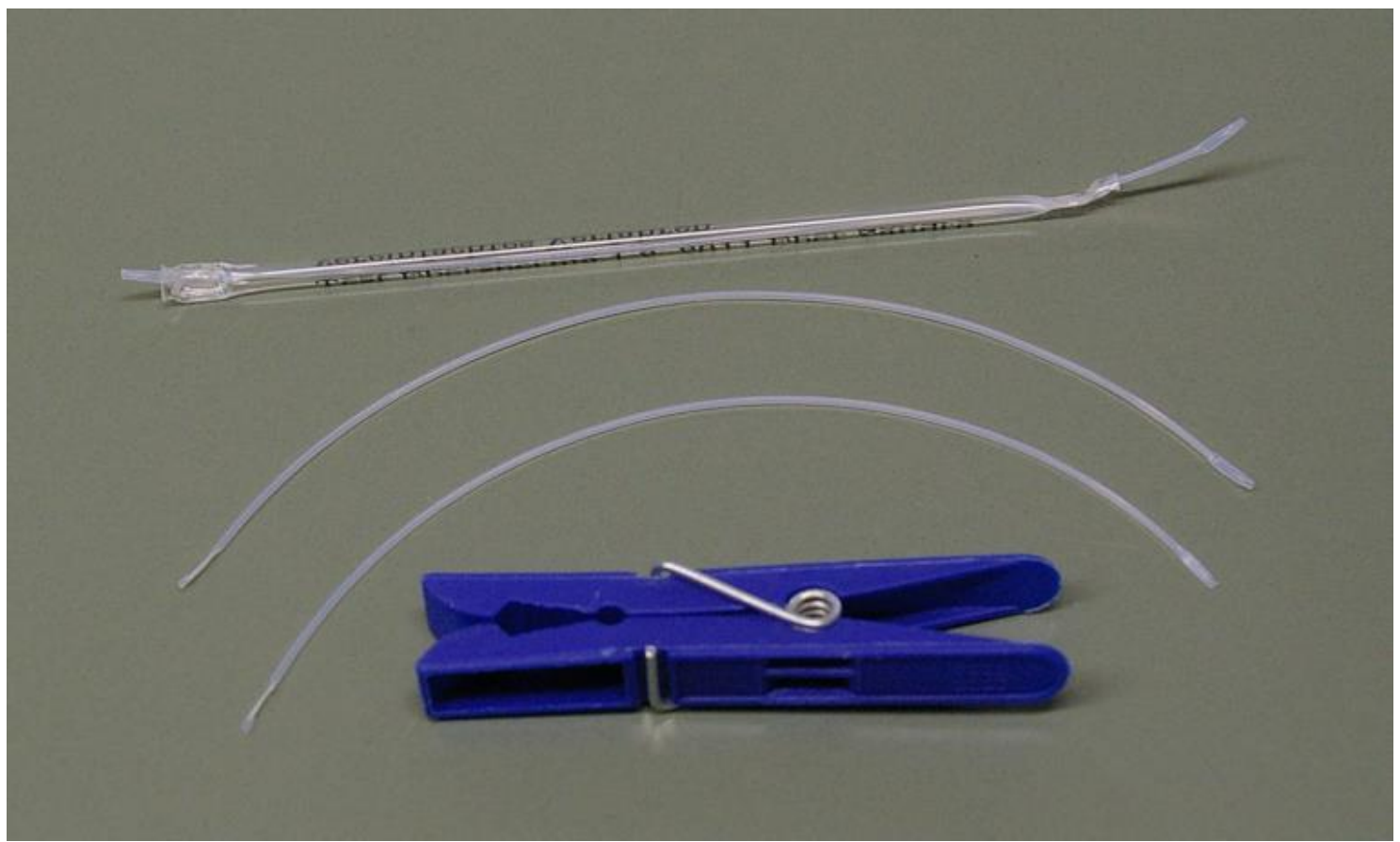

Abbildung 5: Darstellung des Nanostraws in seinen Einzelbestandteilen, dem Innenkatheter sowie der Endversion in der ein handelsüblicher Straw zum Schutz vor Temperaturschwankungen und zur besseren Kennzeichnung über den Innenkatheter gezogen wird (siehe oben im Bild). Zum Größenvergleich ist eine handelsübliche Wäscheklammer dargestellt.

\subsubsection{Sperma-Sexing}

Die geschlechtsspezifische Differenzierung der Spermien erfolgte in Anlehnung an die von KLINC UND RATH (2007) beschriebene Sortiermethode. Da das Sperm-Sexing in der Arbeit von MÖNCH-TEGEDER (2011) bereits ausführlich beschrieben wurde, wird hier lediglich eine grobe Zusammenfassung des Ablaufs dargestellt.

Nach dem Sortierprotokoll Sexcess ${ }^{\circledast}(\mathrm{Sx})$ wurden Teile des nativen Ejakulats mit einem „TRIS-Verdünner“ auf eine Konzentration von $100 \times 10^{6}$ Spermien $/ \mathrm{ml}$ eingestellt. Danach wurde eine Hälfte der Proben mit $20 \mu \mathrm{l}$, und die andere Hälfte mit $25 \mu$ leiner 8,9 mM Hoechst 33342-Lösung (BisBenzimide H33342, Tri-hydrochloride, Sigma-Aldrich Chemie, Taufkirchen, Deutschland) versetzt 
(MöNCH-TEGEDER, 2011). Die, wie unter Kapitel 3.1.2. untersuchten, gefärbten und hochverdünnten Samenproben wurden unmittelbar vor dem Sortieren durch ein $51 \mu \mathrm{m}$ Zellenmikrosieb (Falcon Becton Dickinson und Company, Franklin Lakes, USA) gegeben und in ein Flow-Röhrchen überführt, um zu verhindern, dass größere Partikel der Samenprobe die Strömungsverhältnisse im Flowzytometer behindern. Anschließend wurde $1 \mu$ l Lebensmittelfarbstoff FD\&C\#40 (Warner Jenkinson Company Inc., St. Louis, MO, USA) zu den Spermien pipettiert, um die membrangeschädigten Spermien vor dem Sortiervorgang zu differenzieren. Der Sortierprozess erfolgte mit einem modifizierten High-Speed-Flowzytometer MoFlo (Beckmann-Coulter, USA). Dieses arbeitet bei einer Wellenlänge von $351 \mathrm{~nm}$ und einer Leistung von $180 \mathrm{~mW}$ (MöNCHTEGEDER, 2011). Als Medium für den Hüllstrom wurde eine TRIS-basierte Salzlösung verwendet. Pro Sortiervorgang wurden 7,0 × 10 $0^{6}$ Spermien jeden Geschlechts in konischen $10 \mathrm{ml}$ Kunststoffröhrchen mit einem Durchmesser von 8 $\mathrm{mm}$ aufgefangen, die zuvor mit $500 \mu \mathrm{l}$ TEST-TRIS-Eigelb Puffer befüllt wurden (JOHNSON ET AL., 1999).

Das sortierte Sperma wurde direkt nach dem Sortierprozess zentrifugiert, auf $12^{\circ} \mathrm{C}$ abgekühlt und für die in Kapitel 3.4 beschriebenen Versuche bereitgestellt. 


\subsection{Versuch 1: Screeningversuche zur Entwicklung eines angepassten Kryokonservierungsprotokolls mit einer volumen-reduzierten Spermaportion im Nanostraw}

Zielsetzung der Untersuchung war die Entwicklung eines Tiefgefrierverfahrens für gering dosierte Verpackungssysteme mit einem Volumen bis $50 \mu \mathrm{l}$. Dabei sollten vergleichbare Auftauqualitäten üblicher Besamungsportionen erreicht werden.

Die Probengewinnung erfolgte wie unter 3.1.1 beschrieben. Das Ejakulat wurde einer Eingangsuntersuchung unterzogen, die in Kapitel 3.1.2 beschrieben wird.

\subsubsection{Samenaufbereitung}

Die Ejakulate der Bullen C und D wurden wie in Kapitel 3.1.2 beschrieben jeweils mit dem ersten Teil des nicht glyzerinhaltigen Verdünners Sexcess ${ }^{\circledR}$ | (Masterrind $\mathrm{GmbH}$, Verden, Deutschland) auf $50 \times 10^{6}$ Samenzellen $/ \mathrm{ml}$ auf $4 \mathrm{ml}$ Gesamtvolumen verdünnt. Die Proben wurden im Wassermantel innerhalb von 3 Stunden auf $5^{\circ} \mathrm{C}$ heruntergekühlt. Kurz vor dem Einfrieren wurden die Proben mit dem glyzerinhaltigen Verdünner Sexcess ${ }^{\circledR}$ II (Masterrind $\mathrm{GmbH}$, Verden, Deutschland) auf eine Endkonzentration von $25 \times 10^{6}$ Spermien $/ \mathrm{ml}$ verdünnt. Die Spermaportion im Nanostraw sowie in der handelsüblichen Paillette wurde mit einem Ultraseal 21TM (Minitüb, Tiefenbach, Deutschland) verschlossen. Jeder Nanostraw enthielt 500.000 Samenzellen/20 $\mu$ l. Die Spermienkonzentration betrug $25 \times 10^{6} \mathrm{Spermien} / \mathrm{ml}$. Die Daten aus dem Versuch 1 wurden bullenindividuell (Bulle $C$ und $D$ ) erhoben, zur besseren statistischen Absicherung aber für die Auswertung zusammengefasst. Somit ergaben sich zwölf Wiederholungen pro Kühlkurve. 


\subsubsection{Kryokonservierung der Spermien}

Die Proben wurden mit der Einfriermaschine „Ice Cube 14S“ (Minitüb, Tiefenbach, Deutschland) eingefroren und zur Lagerung in flüssigen Stickstoff (LN2) überführt.

Zur Entwicklung des optimalen Nanostraw-Kryokonservierungsprotokolls wurde zunächst mit dem Gefrierprogramm A gestartet (s. Tabelle 6).

Tabelle 6: Detaillierte Darstellung in ${ }^{\circ} \mathrm{C}$ pro Minute der Gefrierkurve A

\begin{tabular}{|cccc|}
\hline Segment & Endtemperatur $\left(\right.$ in $\left.{ }^{\circ} \mathbf{C}\right)$ & Rel. Zeit (in $\mathbf{m i n})$. & Rampe (in $\left.{ }^{\circ} \mathbf{C} / \mathbf{m i n}\right)$ \\
\hline 0 & 5 & 0 & 0 \\
\hline 1 & -8 & 4,33 & -3 \\
\hline 2 & -8 & 1 & 0 \\
\hline 3 & -120 & 5,6 & -20 \\
\hline 4 & -140 & 2 & -10 \\
\hline
\end{tabular}

Als kryoprotektiver Schutz wurde dem Verdünnermedium 6,4\% Glycerin hinzugegeben. Im Verlauf der Untersuchungen wurde die Kühlkurve A weiter modifiziert, und es entwickelten sich die Gefrierprogramme B, C, D und D+. Die Gefrierprogramme wurden in einzelne Segmente unterteilt, die den Temperaturabfall in ${ }^{\circ} \mathrm{C}$ pro Minute definierten. Alle Programme starteten bei $5^{\circ} \mathrm{C}$. Das Gefrierprogramm der Kurve A kühlte dann in $3^{\circ} \mathrm{C}$-Schritten pro Mi-nute auf $-8^{\circ} \mathrm{C}$ herunter. Daraufhin folgte ein einminütiger Haltepunkt bei $-8^{\circ} \mathrm{C}$. Im nächsten Segment erfolgte eine Abkühlung auf $-120^{\circ} \mathrm{C}$ in $20^{\circ} \mathrm{C}$-Schritten pro Minute. Das letzte Segment kühlte in $10^{\circ} \mathrm{C}$ Schritten pro Minute auf $-140^{\circ} \mathrm{C}$ herunter. Die Straws wurden nach Erreichen der Endtemperatur von $-140^{\circ} \mathrm{C}$ in flüssigen Stickstoff überführt. Um den kryoprotektiven Schutz des Glycerins zu testen wurden zudem vier unterschiedliche Glyzerinkonzentrationen $(5 \%, 6,4 \%$, $7 \%$ und $7,5 \%$ ) ausgetestet. Die folgende Tabelle 7 gibt einen Überblick über die verwendeten Gefrierprogramme und zeigt die getesteten Glycerinkonzentrationen je Kurve mit einem $x$ auf. 
Tabelle 7: Darstellung der angewandten Kühlkurven unter Verwendung unterschiedlicher Glyzerinkonzentrationen

\begin{tabular}{|c|cccccc|}
\hline $\begin{array}{c}\text { Glycerin } \\
(\%)\end{array}$ & Kurve A & Kurve B & Kurve C & Kurve D & $\begin{array}{c}\text { Kurve } \\
\text { D+ }\end{array}$ & Kurve E \\
\hline $5 \%$ & & & & & $x$ & \\
\hline $6,4 \%$ & $\mathrm{x}$ & $\mathrm{x}$ & $\mathrm{x}$ & $\mathrm{x}$ & $\mathrm{x}$ & $\mathrm{x}$ \\
\hline $7 \%$ & & & & & $\mathrm{x}$ & \\
\hline $7,5 \%$ & & & & & & $\mathrm{x}$ \\
\hline
\end{tabular}

In der Kurve D + kam eine Modifizierung des Einfrierautomaten zum Einsatz. Dabei wurde ein zusätzliches Metallgitter eingebaut, um die Nanostraws vor dem direkten Stickstoffeinstrom zu schützen (Abbildung 6).

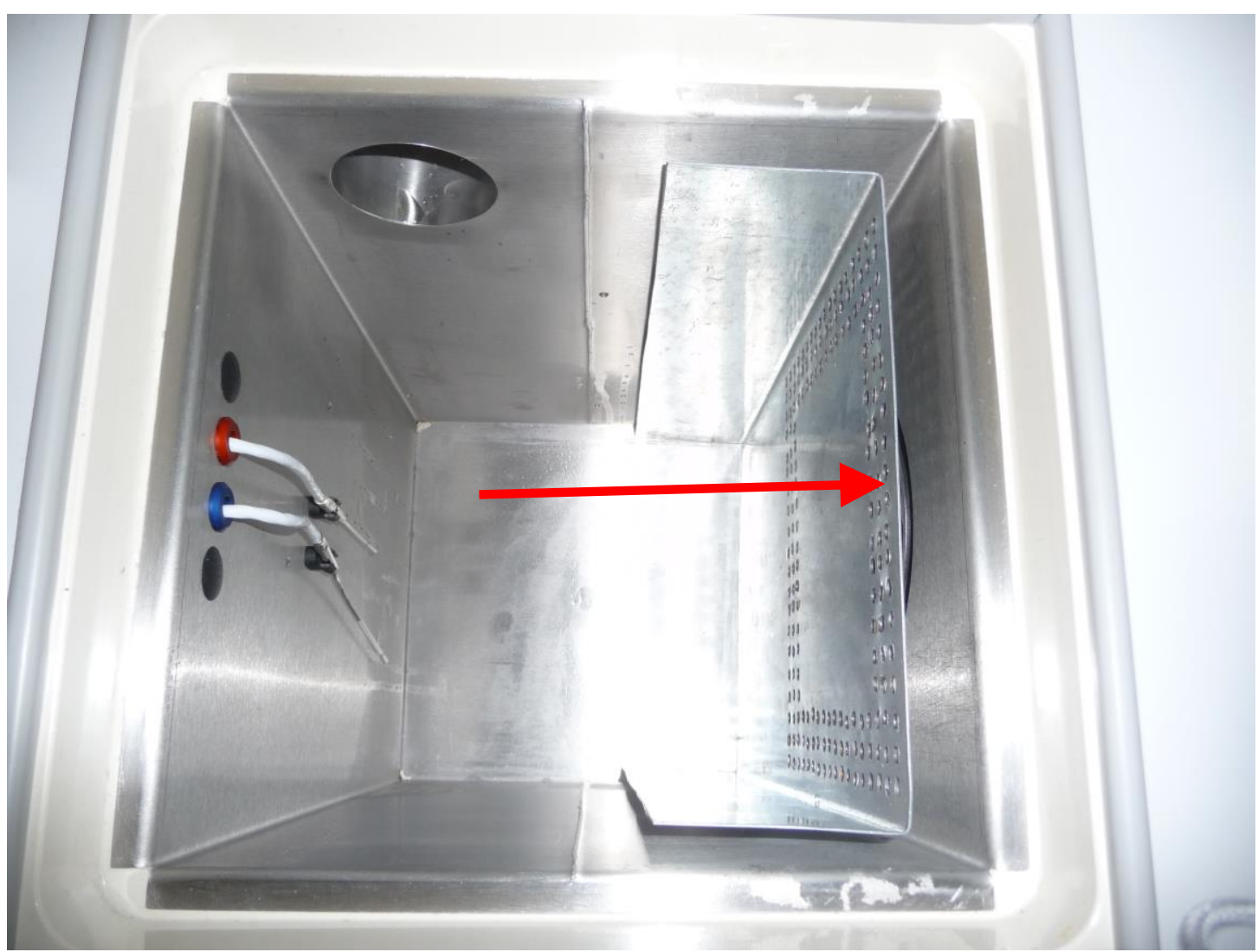

Abbildung 6: Modifizierung des Ice Cube 14S mittels eines Schutzgitters (roter Pfeil) aus Metall. 


\subsubsection{Auftauen der Spermien}

Das Auftauen der Nanostraws erfolgte bei Raumtemperatur. Der Kontrollstraw wurde bei $37^{\circ} \mathrm{C}$ im Wasserbad aufgetaut.

Direkt nach dem Auftauen wurden $230 \mu$ des Kontrollstraws und ca. $200 \mu$ aus 10 gepoolten Nanostraws in 1,5 ml Eppendorfgefäße gegeben und anhand der in den Kapiteln 3.1.4, 3.1.5 und 3.1.6 aufgeführten Parameter bezüglich ihrer Spermaqualität untersucht. 


\subsection{Versuch 2: Qualitätsüberprüfung der in Versuch 1 entwickelten Kühlkurve und der tiefgefrorenen Spermien im Nanostraw mittels etablierter Laborverfahren}

Die Probengewinnung erfolgte aus Ejakulaten wie in Kapitel 3.1.1 beschrieben. Ein Teil der Nanostraws verblieb für den in Kapitel 3.5 beschriebenen Besamungsversuch zur Lagerung in flüssigem Stickstoff.

\subsubsection{Spermatologische Qualitätsanalyse}

Das Sperma wurde direkt nach dem Auftauen einem Thermoresistenztest unterzogen. Die Vorgehensweise und der Ablauf des Thermoresistenztests sind in Kapitel 3.1.3 erläutert.

\subsubsection{Kryokonservierung der Spermien}

Die Tiefgefrierung der Spermien erfolgte anhand des in Versuch 1 entwickelten Kryokonservierungsprotokolls (s. Kapitel 3.2).

\subsubsection{Auftauen der Spermien}

Das Auftauen der Nanostraws erfolgte in Luft 60 Sekunden bei Raumtemperatur. Anschließend wurden die Straws in einem 1,5 ml Eppendorfgefäß gepoolt und auf einen $37^{\circ} \mathrm{C}$ Wärmeblock gelagert. Der Kontrollstraw wurde in einem $37^{\circ} \mathrm{C}$ warmen Wasserbad aufgetaut, ebenfalls in ein Eppendorfgefäß abgefüllt und auf dem Wärmeblock gelagert. 


\subsection{Versuch 3: $\mathrm{SIFT}^{\circledR}$ mit Frischsamen (gesext)}

Für einen ersten Besamungsversuch wurden Kühe aus erster und zweiter Laktation und Färsen aus dem Tierbestand des Instituts für Nutztiergenetik in Mariensee verwendet. Das Sperma wurde von zwei leistungsgeprüften Bullen der Rasse Deutsch Holstein (Bulle $C$ und D) verwendet und wie in 3.1.1 beschrieben geschlechtsspezifisch differenziert.

Die Besamung erfolgte wie in Kapitel 3.1.7 beschrieben. Es wurden 16 Färsen und 10 Kühe aus dem Bestand des Instituts für Nutztiergenetik in Mariensee mit gesextem Frischsamen nach der Methode SIFT ${ }^{\circledR}$ besamt.

Färsen

Insgesamt wurden 20 Färsen mittels einer Progesteron-Spirale (Prida ${ }^{\circledR} 1,55 \mathrm{~g}$, CEVA, Düsseldorf, Deutschland) synchronisiert. Nachdem mittels Ovum Pick Up (OPU) die vorhandenen Follikel punktiert worden waren, wurde den Tieren nochmals einer Progesteron Spirale in die Scheide eingesetzt. Am Tag 6 wurden den Tieren 2,5 ml Estrumate ${ }^{\circledR}$ i.m. (Intervet $\mathrm{GmbH}$, Unterschleißheim, Deutschland) gespritzt und am Tag 8 die Spirale entfernt. Die Übertragung der Spermien erfolgte am elften Tag. Es wurden $0,5 \times 10^{6}$ geschlechtsspezifisch differenzierte Spermien je Tier übertragen. Tabelle 8 gibt einen Überblick über die Anzahl der besamten Tiere je Bulle sowie der Aufteilung der X- und Ychromosomal sortierten Spermaportionen.

Tabelle 8: Anzahl besamter Färsen je Bulle sowie die Aufteilung der nach X- und Ychromosomal verwendeten Spermaportionen

\begin{tabular}{|l|c|c|c|}
\hline & $\begin{array}{c}\text { Anzahl Tiere } \\
(\mathbf{n})\end{array}$ & $\begin{array}{c}\mathbf{0 , 5} \times \mathbf{1 0 ^ { 6 }} \text { Spermien } \\
\text { X-chromosomal sortiert }\end{array}$ & $\begin{array}{c}\mathbf{0 , 5} \times \mathbf{1 0 ^ { 6 }} \text { Spermien } \\
\text { Y-chromosomal sortiert }\end{array}$ \\
\hline Bulle C & 7 & 6 & 1 \\
Bulle D & 9 & 6 & 3 \\
\hline
\end{tabular}


Kühe

Insgesamt wurden 12 Kühe mit einem Ovsynch-Programm synchronisiert. An Tag 1 wurde den Tieren $3 \mathrm{ml}$ Receptal ${ }^{\circledR}$ (Intervet $\mathrm{GmbH}$, Unterschleißheim, Deutschland) i.v. in die Schwanzvene verabreicht. Am achten Tag erhielten sie 2,5 ml Estrumate ${ }^{\circledR}$ i.m. (Intervet GmbH, Unterschleißheim, Deutschland). An Tag 10 erfolgte eine weitere $3 \mathrm{ml}$ i.v. Injektion Receptal ${ }^{\circledR}$ in die Schwanzvene. Die SIFT ${ }^{\circledR}$-Besamung erfolgte am elften Tag. Hierzu wurde zehn Tieren mittels $\mathrm{SIFT}^{\circledR}$-Spermien unterschiedlicher Dosis in den Eileiter übertragen.

Die Tiere wurden mit dem Bullen D besamt. Bei sechs Kühen wurden 250.000 geschlechtsspezifisch differenzierte Samenzellen mittels SIFT $^{\circledR}$ in den Eileiter übertragen. Die restlichen vier erhielten 500.000 geschlechtsspezifisch differenzierte Samenzellen (s. Tabelle 9).

Tabelle 9: Anzahl besamter Kühe des Bullen D, aufgeteilt nach unterschiedlichen Besamungsdosen

\begin{tabular}{|c|c|c|c|}
\hline & $\begin{array}{c}\text { Anzahl Tiere } \\
\text { (n) }\end{array}$ & $\begin{array}{c}0,5 \times 10^{6} \text { Spermien } \\
\mathrm{X} \text { - chromosomal sortiert }\end{array}$ & $\begin{array}{l}0,25 \times 10^{6} \text { Spermien } \\
\text { X-chromosomal sortiert }\end{array}$ \\
\hline Bulle D & 10 & 4 & 6 \\
\hline
\end{tabular}

Die Trächtigkeitsprüfung (TU) erfolgte 28-40 Tage nach der Besamung mittels Ultraschalluntersuchung. Aufgrund der späten Durchführung des Besamungsversuches im Zeitraum der Fertigstellung der Arbeit liegen keine Abkalbedaten vor. 


\subsection{Versuch 4: Besamungsversuch SIFT $^{\circledR}$-Tiefgefriersperma}

Die Besamungsmethode SIFT ${ }^{\circledR}$ erfolgte wie in Kapitel 3.1.7 beschrieben. Es wurden ausschließlich Färsen und Kühe in erster bzw. zweiter Laktation aus dem Bestand des Instituts für Nutztiergenetik in Mariensee verwendet. Alle Tiere standen zur Erstbesamung an. Das Sperma stammte von zwei leistungsgeprüften Bullen der Rasse Deutsch Holstein (Bullen A und B) und wurde wie in Kapitel 3.3 beschrieben kryokonserviert. Die weiblichen Tiere wurden nicht synchronisiert.

Sie wurden mindestens 24 Stunden nach Brunstbeginn mittels SIFT® in den Eileiter besamt. Die Brunstbeobachtung erfolgte durch erfahrene Techniker des Instituts für Nutztiergenetik in Mariensee. Vor SIFT ${ }^{\circledR}$ fand eine Follikelkontrolle mittels Ultraschalls statt. Die Besamung der Tiere erfolgte wie in Kapitel 3.1.7 beschrieben. Die TU wurde 28-40 Tage nach dem Besamungsdatum mittels Ultraschalls durchgeführt. Aufgrund der späten Durchführung des Besamungsversuches im Zeitraum der Fertigstellung der Arbeit liegen keine Abkalbedaten vor.

\subsection{Statistische Auswertung}

Für die statistische Auswertung wurden die Programme „SigmaStat 2.0 for Windows $^{\circledR \text { (w }}$ (Jandel Scientific Cooperation, San Rafael, CA, USA) und SAS 9.1 (SAS Institute) genutzt. Die Ergebnisse aus dem Versuch 1 wurden auf Normalverteilung geprüft und mittels One-way ANOVA oder One-way ANOVA on Ranks ausgewertet. Kamen bei nicht normalverteilten Daten eine One-Way Anova on Ranks oder eine Two-Way ANOVA on Ranks zum Einsatz, wurden multiple Mittelwertsvergleiche mit dem Dunn`s Test durchgeführt. Unterschiede zwischen den Versuchsgruppen wurden bei einer Überschreitungswahrscheinlichkeit von $p \leq 0,05$ als signifikant angesehen. Die Daten aus dem Versuch 1 (Kapitel 3.2) wurden bullenindividuell (Bulle $C$ und $D$ ) erhoben, zur besseren statistischen Absicherung aber für die Auswertung zusammengefasst. Als fixer Effekt wurde sich auf den Strawtyp (Nanostraw vs. Kontrolle) beschränkt. 
$Y_{i j k}=\mu+$ Strawtyp $_{j}+e_{i j k}$

wobei

$\mathrm{Y}_{\mathrm{ijke}} \quad=$ Beobachtungswert

$\mu \quad=$ Populationsmittel

Strawtyp $_{\mathrm{j}}=$ fixer Effekt des Strawtyps $(\mathrm{j}=1-2)$

Die Daten aus dem Versuch 2 (Kapitel 3.3) wurden mit Hilfe eines gemischten linearen Modells (SAS Prozedur "mixed“) ausgewertet, um die wiederholten Messungen pro Ejakulat im Thermoresistenztest (Zeit und Straw) zu berücksichtigen. Bulle, Strawtyp und Zeit sowie deren Interaktionen wurden als fixe Effekte in das Modell aufgenommen. Die Residuen waren normalverteilt (Shapiro-Wilk Test). Der Einfluss eines Effektes wurde bei einer Überschreitungswahrscheinlichkeit von $p \leq 0,05$ als signifikant angesehen (SAS 9.2 Help and Documentation, SAS Institute Inc., Cary, NC, 2008).

$Y_{i j k l}=\mu+$ Bulle $_{i}+$ Strawtyp $_{j}+$ Zeit $_{k}+e_{i j k l}$

wobei

$\mathrm{Y}_{\mathrm{ijkl}} \quad=$ Beobachtungswert

$\mu \quad=$ Populationsmittel

Bulle $_{\mathrm{i}} \quad=$ fixer Effekt des Bullen ( $\left.i=1-2\right)$

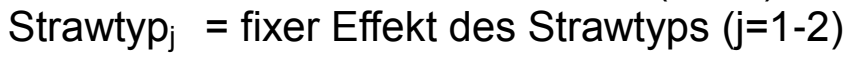

Zeit $t_{k} \quad=$ fixer Effekt der Zeit $(\mathrm{k}=1-3)$

$\mathrm{e}_{\mathrm{ijkl}} \quad=$ zufälliger Restfehler

Bei allen Tabellen wurde der korrigierte Mittelwert (Least Square Mean) \pm dem Standardfehler (SEM, $\bar{x}$ ) angegeben. 


\section{$4 \quad$ Ergebnisse}

\subsection{Versuch 1: Screeningversuche zur Entwicklung eines angepassten Kryokonservierungsprotokolls mit volumen-reduzierten Sperma- portionen im Nanostraw}

Aus der Kühlkurve A wurden 4 verschiedene Kühlkurven (B-D+) entwickelt (s. Abbildung 7). In dem Gefrierprogramm B erfolgte zunächst eine Absenkung der Kühlgeschwindigkeit von $-20^{\circ} \mathrm{C}$ pro Minute auf $-10^{\circ} \mathrm{C}$ pro Minute in dem Segment 3. In Kurve $\mathrm{C}$ wurden die Temperaturschritte nach Erreichen von $-8^{\circ} \mathrm{C}$ nochmals stark auf $-5^{\circ} \mathrm{C}$-Schritte pro Minute bis zum Erreichen der Zieltemperatur von $-140^{\circ} \mathrm{C}$ verlangsamt. In Kurve $D$ wurde ein zusätzliches Segment eingeführt. Es erfolgte eine Abkühlung nach dem Segment 2 in $-5^{\circ} \mathrm{C}$-Schritten pro Minute auf $-35^{\circ} \mathrm{C}$. Die weitere Abkühlung wurde in $-10^{\circ} \mathrm{C}$-Schritten weitergeführt. Um die Nanostraws vor dem direkten starken Stickstoffeinstrom zu schützen wurde der Einfrierautomat, wie in Kapitel 3.2.2 beschrieben, für die Kurve D+ modifiziert. Es zeigte sich, dass aufgrund der Stickstoff-Volumeneinströme ein Haltepunkt bei $-8^{\circ} \mathrm{C}$ für kleine Volumina bei Verwendung des Stickstoffschutzgitters nicht zu etablieren war. Dies ist u.a. auf die bauartbedingten Vorgaben des verwendeten Einfrierautomaten zurückzuführen. Aufgrund der Modifizierung konnte der Haltepunkt bei $-8^{\circ} \mathrm{C}$ nicht konstant gehalten werden, und es kam zu starken Temperaturschwankungen. Der Haltepunkt bei $-8^{\circ} \mathrm{C}$ wurde entfernt, und es entstand Kurve D+. Eine genaue tabellarische Darstellung aller Gefrierprogramme ist im Anhang unter Kapitel 9.5 (Tabellen 39-42) zu finden. 


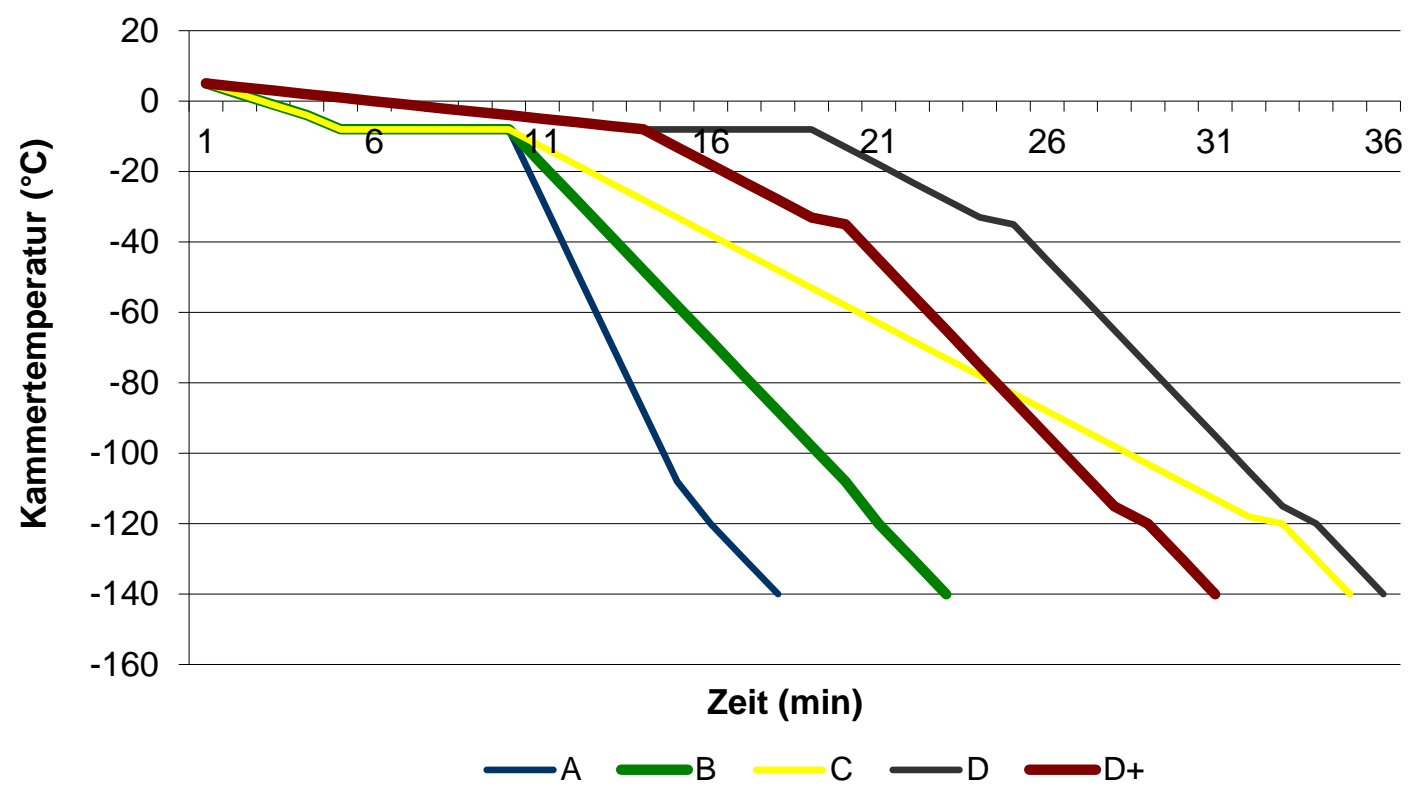

Abbildung 7: Darstellung der fünf entwickelten Kühlkurven in ${ }^{\circ} \mathrm{C}$ pro Minute.

\subsubsection{Motilität}

Anteil motiler Spermien nach dem Auftauen in Abhängigkeit von den Gefrierkurven

Tabelle 10 zeigt den prozentualen Anteil motiler Spermien unmittelbar nach dem Auftauen unter Verwendung der Kühlkurven A, B, C, D und D+. Innerhalb jeder untersuchten Kühlkurve war der Anteil motiler Spermien aus den Kontrollstraws signifikant höher $(p \leq 0,05)$ als der Anteil motiler Spermien aus den Nanostraws. Der Prozentsatz motiler Spermien aus dem Kontrollstraw lag zwischen 27,8 \% (Kurve A) und 9,7 \% (Kurve D+) höher als der Anteil motiler Spermien aus den Nanostraws. Der höchste Anteil motiler Spermien aus dem Nanostraw war in Kühlkurve D+ zu verzeichnen. Der höchste Anteil motiler Spermien aus dem Kontrollstraw war in Kurve D zu sehen. 
Tabelle 10: Anteil motiler Spermien (in \%) aus den Gefrierkurven A, B, C, D und D+ unmittelbar nach dem Auftauen

\begin{tabular}{lccccc}
\hline & Kurve A & Kurve B & Kurve C & Kurve D & Kurve D+ \\
Gruppe & $\bar{x} \pm$ SEM & $\bar{x} \pm$ SEM & $\bar{x} \pm$ SEM & $\bar{x} \pm$ SEM & $\bar{x} \pm$ SEM \\
\hline $\begin{array}{l}\text { Nanostraw } \\
(\mathbf{n}=12)\end{array}$ & $22,1 \pm 3,0^{\mathrm{a}}$ & $45,4 \pm 2,1^{\mathrm{a}}$ & $48,4 \pm 2,7^{\mathrm{a}}$ & $50,4 \pm 2,5^{\mathrm{a}}$ & $52,9 \pm 1,6^{\mathrm{a}}$ \\
$\begin{array}{l}\text { Kontrollstraw } \\
(\mathbf{n}=12)\end{array}$ & $49,9 \pm 4,1^{\mathrm{b}}$ & $62,4 \pm 1,8^{\mathrm{b}}$ & $64,1 \pm 3,2^{\mathrm{b}}$ & $71,9 \pm 1,8^{\mathrm{b}}$ & $62,6 \pm 2,2^{\mathrm{b}}$ \\
\hline
\end{tabular}

a, b: Werte mit unterschiedlichen Indizes unterscheiden sich innerhalb einer Kühlkurve signifikant $(p \leq 0,05)$.

Tabelle 11 zeigt die Auswirkungen der Veränderung der Glyzerinkonzentration auf den Anteil motiler Spermien nach dem Auftauen. Die Verwendung von 7\% Glycerin im Verdünner führte zu einem höheren Prozentsatz motiler Spermien aus dem Nanostraw sowie aus dem Kontrollstraw. Der Anteil motiler Spermien war unter Verwendung beider Glycerinkonzentrationen signifikant $(p \leq 0,05)$ höher in der Kontrollstrawgruppe im Vergleich zu der Nanostrawgruppe.

Tabelle 11: Anteil motiler Spermien (in \%) der Gefrierkurve D+ mit einem Anteil von 5\% und $7 \%$ Glyzerin unmittelbar nach dem Auftauen

\begin{tabular}{lcc}
\hline Kruppe & $\begin{array}{c}\text { Kurve D+5\% GLY } \\
\bar{x} \pm \text { SEM }\end{array}$ & $\begin{array}{c}\text { Kurve D+7\% GLY } \\
\text { Nanostraw }(\mathbf{n = 1 2})\end{array}$ \\
Kontrollstraw $(\mathbf{n = 1 2})$ & $51,5 \pm 0,6^{\mathrm{a}}$ & $43,2 \pm 4,1^{\mathrm{a}}$ \\
\hline
\end{tabular}

a, b: Werte mit unterschiedlichen Indizes unterscheiden sich innerhalb einer Kühlkurve signifikant $(p \leq 0,05)$.

Anteil vorwärtsbeweglicher Spermien nach dem Auftauen in Abhängigkeit von den Gefrierkurven

Tabelle 12 zeigt den Anteil vorwärtsbeweglicher Spermien der Kühlkurven A-D und D+ aus dem Nanostraw und dem Kontrollstraw unmittelbar nach dem Auftauen. Für jede Kühlkurve lag ein signifikant höherer Anteil $(p \leq 0,05)$ vorwärts- 
beweglicher Spermien nach Gefrierung im Kontrollstraw im Vergleich zum Nanostraw vor. Der Prozentsatz vorwärtsbeweglicher Spermien aus der Kontrollgruppe lag in Kurve A mit 24,7\% und in Kurve D+ mit 5,7\% signifikant $(p \leq 0,05)$ höher als in der Nanostrawgruppe.

Tabelle 12: Anteil vorwärtsbeweglicher Spermien (in \%) der Gefrierkurven A, B, C, D und D+ unmittelbar nach dem Auftauen

\begin{tabular}{lccccc}
\hline Kruppe & $\begin{array}{c}\text { Kurve A } \\
\bar{x} \pm \text { SEM }\end{array}$ & $\begin{array}{c}\text { Kurve B } \\
\bar{x} \pm \text { SEM }\end{array}$ & $\begin{array}{c}\text { Kurve C } \\
\bar{x} \pm \text { SEM }\end{array}$ & $\begin{array}{c}\text { Kurve D } \\
\bar{x} \pm \text { SEM }\end{array}$ & $\begin{array}{c}\text { Kurve D+ } \\
\bar{x} \text { SEM }\end{array}$ \\
\hline $\begin{array}{l}\text { Nanostraw } \\
(\mathbf{n = 1 2 )}\end{array}$ & $16,1 \pm 2,2^{\mathrm{a}}$ & $37,3 \pm 1,8^{\mathrm{a}}$ & $32,3 \pm 3,7^{\mathrm{a}}$ & $34,9 \pm 2,8^{\mathrm{a}}$ & $36,4 \pm 1,9^{\mathrm{a}}$ \\
$\begin{array}{l}\text { Kontroll- } \\
\text { straw } \\
(\mathbf{n}=\mathbf{1 2})\end{array}$ & $40,8 \pm 3,4^{\mathrm{b}}$ & $50,2 \pm 1,6^{\mathrm{b}}$ & $48,3 \pm 2,3^{\mathrm{b}}$ & $54,6 \pm 1,7^{\mathrm{b}}$ & $42,1 \pm 2,2^{\mathrm{b}}$ \\
$\begin{array}{l}\mathbf{a}, \mathbf{b}: \text { Werte } \\
(\mathrm{p} \leq 0,05) .\end{array}$ & & & & & \\
\hline
\end{tabular}

Nachfolgend werden die zusätzlich im CASA gemessenen Qualitätsparameter VSL, VCL, VAP, ALH, BCF, STR und LIN dargestellt (Tabellen 13-19).

Velocity straight line (VSL) in Abhängigkeit von den Gefrierkurven

Bei dem in Tabelle 13 dargestellten Wert VSL ist lediglich in Kurve A ein signifikanter Unterschied $(p \leq 0,05)$ zwischen den Ergebnissen aus dem Nanostraw zu dem Kontrollstraw zu erkennen. Der höchste Wert bei den Spermien aus dem Nanostraw ist in Kurve B, bei den Kontrollstrawspermien in Kurve A zu finden. 
Tabelle 13: VSL der Spermien (in \%) der Gefrierkurven A, B, C, D und D+ unmittelbar nach dem Auftauen

\begin{tabular}{lccccc}
\hline Kurve A & Kurve B & Kurve C & Kurve D & Kurve D+ \\
Gruppe & $\bar{x} \pm$ SEM & $\bar{x} \pm$ SEM & $\bar{x} \pm$ SEM & $\bar{x} \pm$ SEM & $\bar{x} \pm$ SEM \\
\hline $\begin{array}{l}\text { Nanostraw } \\
(\mathbf{n = 1 2})\end{array}$ & $48,2 \pm 1,5^{\mathrm{a}}$ & $50,3 \pm 0,9$ & $47,2 \pm 1,6$ & $44,9 \pm 1,4$ & $40,5 \pm 0,6$ \\
$\begin{array}{l}\text { Kontrollstraw } \\
\text { (n=12) }\end{array}$ & $59,4 \pm 3,4^{\mathrm{b}}$ & $50,3 \pm 1,1$ & $49,3 \pm 1,0$ & $46,5 \pm 1,0$ & $40,8 \pm 0,9$ \\
\hline
\end{tabular}

a, b: Werte mit unterschiedlichen Indizes unterscheiden sich innerhalb einer Kühlkurve signifikant $(p \leq 0,05)$.

Die volle zurückgelegte Distanz (VCL) und die geglättete zurückgelegte Distanz (VAP) der Spermien in Abhängigkeit von den Gefrierkurven

Die Werte VCL (Tabelle 14) und VAP (Tabelle 15) zeigten keine einheitlichen Ergebnisse, die einen Effekt der verwendeten Gefrierprotokolle aufzeigen ließen. In Kurve A lag der Prozentsatz der Spermien aus dem Kontrollstraw im Wert VCL signifikant $(p \leq 0,05)$ unter den Spermien aus dem Nanostraw. Gleiches wurde in Kurve $C$ und $D$ beobachtet.

Tabelle 14: VCL der Spermien (in \%) der Gefrierkurven A, B, C, D und D+ unmittelbar nach dem Auftauen

\begin{tabular}{lccccc}
\hline & Kurve A & Kurve B & Kurve C & Kurve D & Kurve D+ \\
Gruppe & $\bar{x} \pm$ SEM & $\bar{x} \pm$ SEM & $\bar{x} \pm$ SEM & $\bar{x} \pm$ SEM & $\bar{x} \pm$ SEM \\
\hline $\begin{array}{l}\text { Nanostraw } \\
(\mathbf{n}=12)\end{array}$ & $100,1 \pm 3,5^{\mathrm{a}}$ & $115,7 \pm 2,0$ & $122,6 \pm 1,9^{\mathrm{a}}$ & $111,9 \pm 3,9^{\mathrm{a}}$ & $105,2 \pm 0,9$ \\
$\begin{array}{l}\text { Kontrollstraw } \\
(\mathbf{n}=\mathbf{1 2})\end{array}$ & $128,7 \pm 6,2^{\mathrm{b}}$ & $120,9 \pm 2,4$ & $128,4 \pm 0,9^{\mathrm{b}}$ & $120,5 \pm 3,0^{\mathrm{b}}$ & $105,9 \pm 3,4$ \\
\hline
\end{tabular}

$\mathbf{a}, \mathbf{b}$ : Werte mit unterschiedlichen Indizes unterscheiden sich innerhalb einer Kühlkurve signifikant $(p \leq 0,05)$.

Der Prozentsatz VAP der Spermien aus dem Kontrollstraw lag in den Kurven A und $C$ signifikant $(p \leq 0,05)$ über dem Anteil aus den Nanostraws. 
Tabelle 15: VAP der Spermien (in \%) der Gefrierkurven A, B, C, D und D+ unmittelbar nach dem Auftauen

\begin{tabular}{lccccc}
\hline & Kurve A & Kurve B & Kurve C & Kurve D & Kurve D+ \\
Gruppe & $\bar{x} \pm$ SEM & $\bar{x} \pm$ SEM & $\bar{x} \pm$ SEM & $\bar{x} \pm$ SEM & $\bar{x} \pm$ SEM \\
\hline $\begin{array}{l}\text { Nanostraw } \\
(\mathbf{n = 1 2})\end{array}$ & $57,6 \pm 1,9^{\mathrm{a}}$ & $64,8 \pm 1,2$ & $67,4 \pm 1,4^{\mathrm{a}}$ & $62,8 \pm 2,3$ & $58,2 \pm 0,8$ \\
$\begin{array}{l}\text { Kontrollstraw } \\
\text { (n=12) }\end{array}$ & $74,8 \pm 4,7^{\mathrm{b}}$ & $68,3 \pm 1,6$ & $72,6 \pm 0,5^{\mathrm{b}}$ & $67,1 \pm 1,5$ & $60,1 \pm 1,8$ \\
\hline
\end{tabular}

a, b: Werte mit unterschiedlichen Indizes unterscheiden sich innerhalb einer Kühlkurve signifikant $(p \leq 0,05)$.

Seitliche Auslenkung der Spermienköpfe (ALH) in Abhängigkeit von den Gefrierkurven

Die Ergebnisse der Werte für die ALH aus der Tabelle 16 zeigten keinen signifikanten Unterschied in den Kurven B, C, D und D+ zwischen den Spermien aus dem Nanostraw und der Kontrolle. Lediglich in Kurve A war ein signifikanter Unterschied $(p \leq 0,05)$ zwischen den Ergebnissen aus dem Kontrollstraw im Vergleich zu den Ergebnissen aus dem Nanostraw zu beobachten.

Tabelle 16: ALH der Spermien (in \%) der Gefrierkurven A, B, C, D und D+ unmittelbar nach dem Auftauen

\begin{tabular}{|c|c|c|c|c|c|}
\hline Gruppe & $\begin{array}{l}\text { Kurve A } \\
\bar{x} \pm \text { SEM }\end{array}$ & $\begin{array}{l}\text { Kurve B } \\
\bar{x} \pm \text { SEM }\end{array}$ & $\begin{array}{l}\text { Kurve C } \\
\bar{x} \pm \text { SEM }\end{array}$ & $\begin{array}{l}\text { Kurve D } \\
\bar{x} \pm \text { SEM }\end{array}$ & $\begin{array}{l}\text { Kurve D+ } \\
\bar{x} \pm \text { SEM }\end{array}$ \\
\hline Nanostraw $(n=12)$ & $5,0 \pm 0,2^{\mathrm{a}}$ & $6,1 \pm 0,1$ & $6,3 \pm 0,1$ & $6,2 \pm 0,1$ & $6,2 \pm 0,1$ \\
\hline Kontrollstraw $(n=12)$ & $6,0 \pm 0,2^{b}$ & $6,3 \pm 0,1$ & $6,2 \pm 0,1$ & $6,3 \pm 0,1$ & $6,0 \pm 0,1$ \\
\hline
\end{tabular}


Frequenz der Pendelbewegung (BCF) der Spermien in Abhängigkeit von den Gefrierkurven

Die Frequenz der Pendelbewegung der Spermien aus dem Nanostraw verschlechterte sich bei Verwendung der Kühlkurven A bis D+ signifikant. Die Werte zwischen dem Nanostraw und der Kontrolle unterscheiden sich in keiner Kühlkurve signifikant voneinander (Tabelle 17).

Tabelle 17: BCF der Spermien (in \%) der Gefrierkurven A, B, C, D und D+ unmittelbar nach dem Auftauen

\begin{tabular}{lccccc}
\hline & Kurve A & Kurve B & Kurve C & Kurve D & Kurve D+ \\
Gruppe & $\bar{x} \pm$ SEM & $\bar{x} \pm$ SEM & $\bar{x} \pm$ SEM & $\bar{x} \pm$ SEM & $\bar{x} \pm$ SEM \\
\hline $\begin{array}{l}\text { Nanostraw } \\
(\mathbf{n}=\mathbf{1 2})\end{array}$ & $29,2 \pm 1,2$ & $24,1 \pm 0,5$ & $21,7 \pm 0,1$ & $21,3 \pm 0,6$ & $20,9 \pm 0,4$ \\
$\begin{array}{l}\text { Kontrollstraw } \\
(\mathbf{n}=\mathbf{1 2})\end{array}$ & $30,5 \pm 0,1$ & $24,7 \pm 0,5$ & $22,8 \pm 0,9$ & $21,7 \pm 0,6$ & $21,1 \pm 0,3$ \\
\hline
\end{tabular}

Die Straightness (STR) der Spermien in Abhängigkeit von den Gefrierkurven

Die Werte STR zeigten eine Verschlechterung der Spermien aus dem Nanostraw und dem Kontrollstraw bei Verwendung der Kurven A bis D+. Dabei lag der Wert der Spermien aus dem Nanostraw bei Betrachtung der Gefrierkurven $A, B, C$ und $D+$ signifikant $(p \leq 0,05)$ höher als bei den Spermien aus dem Kontrollstraw (Tabelle 18). 
Tabelle 18: STR der Spermien (in \%) der Gefrierkurven A, B, C, D und D+ unmittelbar nach dem Auftauen

\begin{tabular}{lccccc}
\hline & Kurve A & Kurve B & Kurve C & Kurve D & Kurve D+ \\
Gruppe & $\bar{x} \pm$ SEM & $\bar{x} \pm$ SEM & $\bar{x} \pm$ SEM & $\bar{x} \pm$ SEM & $\bar{x} \pm$ SEM \\
\hline $\begin{array}{l}\text { Nanostraw } \\
(\mathbf{n}=\mathbf{1 2})\end{array}$ & $83,7 \pm 1,0^{\mathrm{a}}$ & $77,9 \pm 0,9^{\mathrm{a}}$ & $72,2 \pm 1,5^{\mathrm{a}}$ & $72,8 \pm 1,2$ & $70,9 \pm 0,4^{\mathrm{a}}$ \\
$\begin{array}{l}\text { Kontrollstraw } \\
(\mathbf{n}=\mathbf{1 2})\end{array}$ & $79,7 \pm 0,7^{\mathrm{b}}$ & $74,2 \pm 0,9^{\mathrm{b}}$ & $69,3 \pm 1,0^{\mathrm{b}}$ & $70,4 \pm 0,9$ & $69,5 \pm 1,2^{\mathrm{b}}$ \\
\hline
\end{tabular}

a, b: Werte mit unterschiedlichen Indizes unterscheiden sich innerhalb einer Kühlkurve signifikant $(p \leq 0,05)$.

Die Linearität (LIN) der Spermien in Abhängigkeit von den Gefrierkurven

Der Wert LIN aus dem Nanostraw hatte sich in Kühlkurve D+ gegenüber der Kurve A verringert (Tabelle 19). Die Linearität unterschied sich in keiner der Kühlkurven signifikant zwischen dem Nanostraw und dem Kontrollstraw.

Tabelle 19: LIN der Spermien (in \%) der Gefrierkurven A, B, C, D und D+ unmittelbar nach dem Auftauen

\begin{tabular}{lccccc}
\hline & Kurve A & Kurve B & Kurve C & Kurve D & Kurve D+ \\
Gruppe & $\bar{x} \pm$ SEM & $\bar{x} \pm$ SEM & $\bar{x} \pm$ SEM & $\bar{x} \pm$ SEM & $\bar{x} \pm$ SEM \\
\hline $\begin{array}{l}\text { Nanostraw } \\
(\mathbf{n}=\mathbf{1 2})\end{array}$ & $50,6 \pm 1,6$ & $45,1 \pm 0,7$ & $40,9 \pm 1,1$ & $42,3 \pm 1,0$ & $40,5 \pm 0,4$ \\
$\begin{array}{l}\text { Kontrollstraw } \\
(\mathbf{n}=\mathbf{1 2})\end{array}$ & $48,1 \pm 1,2$ & $43,4 \pm 0,8$ & $41,1 \pm 0,9$ & $40,3 \pm 0,6$ & $41,4 \pm 1,3$ \\
\hline
\end{tabular}

a, b: Werte mit unterschiedlichen Indizes unterscheiden sich innerhalb einer Kühlkurve signifikant $(p \leq 0,05)$. 


\subsubsection{Membranintegrität}

Tabelle 20 zeigt den Anteil membranintakter Spermien nach dem Auftauen. Der Anteil membranintakter Spermien aus den Kontrollstraws war in allen verwendeten Kühlkurven signifikant $(p \leq 0,05)$ höher als der Anteil membranintakter Spermien aus den Nanostraws. Eine Zunahme des Anteils intakter Spermien von Kurve $A$ zu $B$ und von $D$ zu D+ war bei den Versuchsanstellungen mit den Nanostraws zu beobachten. Bei den Kontrollstraws war lediglich eine Zunahme von Kurve $A$ bis $D$ zu sehen. In Kurve D+ nahm der Anteil membranintakter Spermien wieder $a b$.

Tabelle 20: Anteil membranintakter Spermien (PI-negativ; in \%) der Kurven A, B, C, D und D+ unmittelbar nach dem Auftauen

\begin{tabular}{lccccc}
\hline Kruppe & Kurve A & Kurve B & Kurve C & Kurve D & Kurve D+ \\
& $\bar{x} \pm$ SEM & $\bar{x} \pm$ SEM & $\bar{x} \pm$ SEM & $\bar{x} \pm$ SEM & $\bar{x} \pm$ SEM \\
\hline $\begin{array}{l}\text { Nanostraw } \\
(\mathbf{n = 1 2})\end{array}$ & $41,5 \pm 1,2^{\mathrm{a}}$ & $45,7 \pm 0,9^{\mathrm{a}}$ & $37,9 \pm 3,7^{\mathrm{a}}$ & $46,2 \pm 1,1^{\mathrm{a}}$ & $50,0 \pm 0,7^{\mathrm{a}}$ \\
$\begin{array}{l}\text { Kontrollstraw } \\
(\mathbf{n}=\mathbf{1 2})\end{array}$ & $57,5 \pm 1,7^{\mathrm{b}}$ & $59,3 \pm 1,1^{\mathrm{b}}$ & $60,1 \pm 1,6^{\mathrm{b}}$ & $60,8 \pm 0,3^{\mathrm{b}}$ & $56,9 \pm 1,5^{\mathrm{b}}$ \\
\end{tabular}

a, b: Werte mit unterschiedlichen Indizes unterscheiden sich innerhalb einer Kühlkurve signifikant $(p \leq 0,05)$.

Die Zugabe von $5 \%$ bzw. $7 \%$ Glyzerin im Gefrierprotokoll D+ führte zu einer Verbesserung des Anteils membranintakter Spermien nach dem Auftauen (Tabelle 21). Dabei war mit einem Prozentsatz von 13\% eine deutliche Verbesserung bei den Nanostraws zu beobachten. Im Vergleich dazu wurde bei den Kontrollstrawspermien lediglich eine Verbesserung von 2,6\% ermittelt. Unter Verwendung der geänderten Glyzerinkonzentrationen waren signifikant bessere Werte $(p \leq 0,05)$ bei den Spermien aus dem Kontrollstraw im Vergleich zu den Spermien aus dem Nanostraw zu beobachten. 
Tabelle 21: Anteil membranintakter Spermien (PI-negativ; in \%) der Kurve D+ mit einem Anteil von $5 \%$ und $7 \%$ Glyzerin (GLY) unmittelbar nach dem Auftauen

\begin{tabular}{lcc}
\hline Kurve $\mathbf{D}+\mathbf{5} \%$ GLY & Kurve D+7\% GLY \\
$\bar{x} \pm$ SEM & $\bar{x} \pm$ SEM \\
\hline Nanostraw ( $\mathbf{n = 1 2 )}$ & $28,0 \pm 1,5^{\mathrm{a}}$ & $41,0 \pm 2,9^{\mathrm{b}}$ \\
Kontrollstraw ( $\mathbf{n}=\mathbf{1 2})$ & $55,5 \pm 0,8^{\mathrm{b}}$ & $58,1 \pm 1,5^{\mathrm{b}}$ \\
\hline $\begin{array}{l}\text { a, b: Werte mit unterschiedlichen } \\
(\mathrm{p} \leq 0,05) .\end{array}$ & Indizes unterscheiden sich innerhalb einer Kühlkurve signifikant
\end{tabular}

\subsubsection{Morphologie}

Der Anteil morphologisch intakter Spermien aus dem Nanostraw nimmt mit einer Verringerung der Einfriergeschwindigkeit zu. Tabelle 22 zeigt eine Verbesserung morphologisch intakter Spermien aus dem Nanostraw von Kurve A bis D+. In Kurve D+ wiesen 66,6\% der Spermien aus dem Nanostraw keine morphologischen Veränderungen auf. In allen verwendeten Gefrierkurven sind signifikant höhere Anteile $(p \leq 0,05)$ morphologisch intakter Spermien aus dem Kontrollstraw im Vergleich zum Anteil Spermien aus dem Nanostraw zu beobachten.

Tabelle 22: Anteil morphologisch intakter Spermien (in \%) der Kurven A, B, C, D und D+ unmittelbar nach dem Auftauen

\begin{tabular}{lccccc}
\hline Kurve A & Kurve B & Kurve C & Kurve D & Kurve D+ \\
& $\bar{x} \pm$ SEM & $\bar{x} \pm$ SEM & $\bar{x} \pm$ SEM & $\bar{x} \pm$ SEM & $\bar{x} \pm$ SEM \\
\hline $\begin{array}{l}\text { Nanostraw } \\
(\mathbf{n = 1 2})\end{array}$ & $38,4 \pm 1,3^{\mathrm{a}}$ & $48,3 \pm 0,6^{\mathrm{a}}$ & $54,6 \pm 1,1^{\mathrm{a}}$ & $60,3 \pm 1,0^{\mathrm{a}}$ & $66,6 \pm 0,6^{\mathrm{a}}$ \\
$\begin{array}{l}\text { Kontrollstraw } \\
(\mathbf{n = 1 2})\end{array}$ & $53,5 \pm 1,3^{\mathrm{b}}$ & $64,5 \pm 1,6^{\mathrm{b}}$ & $58,9 \pm 1,0^{\mathrm{b}}$ & $64,5 \pm 1,6^{\mathrm{b}}$ & $75,4 \pm 0,6^{\mathrm{b}}$ \\
$\begin{array}{l}\mathbf{a}, \mathbf{b}: \text { Werte mit } \\
(\mathbf{p} \leq 0,05) .\end{array}$
\end{tabular}

Eine Veränderung der Glyzerinkonzentration im Gefrierprotokoll D+ von 5\% auf $7 \%$ führte sowohl bei den Nanostraws als auch bei den Kontrollstraws zu keiner 
Verbesserung des Anteils morphologisch intakter Spermien nach dem Auftauen (Tabelle 23). Der Prozentsatz morphologisch intakter Spermien war jedoch bei der Verwendung der Kontrollstraws höher und unterschied sich signifikant $(p \leq 0,05)$ von dem der Nanostraws.

Tabelle 23: Anteil morphologisch intakter Spermien (in \%) der Kurve D+ mit einem Anteil von $5 \%$ bzw. 7\% Glyzerin (GLY) unmittelbar nach dem Auftauen

\begin{tabular}{|c|c|c|}
\hline & Kurve D+5\% GLY & Kurve D+7\% GLY \\
\hline Gruppe & $\bar{x} \pm$ SEM & $\bar{x} \pm$ SEM \\
\hline Nanostraw $(n=12)$ & $58,5 \pm 1,3^{\mathrm{a}}$ & $60,3 \pm 2,9^{a}$ \\
\hline Kontrollstraw $(n=12)$ & $71,0 \pm 1,3^{b}$ & $73,8 \pm 1,5^{b}$ \\
\hline
\end{tabular}

Der Anteil der Spermien mit intaktem Akrosom nach dem Auftauen ist in Tabelle 24 dargestellt. Die Verringerung der Gefriergeschwindigkeit hatte einen positiven Einfluss auf die Verbesserung des Anteils akrosomintakter Spermien. Im Gegensatz zu Spermien, die mit dem Protokoll D+ behandelt wurden, wiesen solche nach Protokoll $A$ einen signifikant niedrigen Anteil intakter Akrosomen auf. In den Kühlkurven A, B und D+ unterschied sich der Anteil Spermien mit intaktem Akrosom aus dem Kontrollstraw signifikant $(p \leq 0,05)$ von dem Anteil intakter Spermien aus dem Nanostraw.

Tabelle 24: Anteil Spermien (in \%) mit einem intakten Akrosom der Kurven A, B, C, D und D+ unmittelbar nach dem Auftauen

\begin{tabular}{lccccc}
\hline Kruppe & Kurve A & Kurve B & Kurve C & Kurve D & Kurve D+ \\
\hline $\begin{array}{l}\bar{x} \pm \text { SEM } \\
(\mathbf{n = 1 2})\end{array}$ & $\bar{x} \pm$ SEM & $\bar{x} \pm$ SEM & $\bar{x} \pm$ SEM & $\bar{x} \pm$ SEM \\
\hline $\begin{array}{l}\text { Kontrollstraw } \\
(\mathbf{n}=\mathbf{1 2})\end{array}$ & $55,7 \pm 1,6^{\mathrm{b}}$ & $65,8 \pm 0,7^{\mathrm{b}}$ & $60,3 \pm 1,7$ & $66,7 \pm 1,8$ & $76,7 \pm 0,9^{\mathrm{b}}$ \\
$\begin{array}{l}\mathbf{a}, \mathbf{b}: \text { Werte mit } \\
(\mathbf{p} \leq 0,05) .\end{array}$ & $54,0 \pm 1,0^{\mathrm{a}}$ & $57,0 \pm 1,1$ & $63,8 \pm 1,5$ & $67,7 \pm 0,5^{\mathrm{a}}$ \\
& & & & & \\
\hline
\end{tabular}


Eine Veränderung der Glyzerinkonzentration des Gefrierprotokolls D+ führte sowohl in der Nanostrawgruppe als auch in der Kontrollgruppe zu einer Verschlechterung des Anteils Spermien mit intaktem Akrosom nach dem Auftauen (Tabelle 25). Der Prozentsatz akrosomintakter Spermien pro Behandlungsgruppe ist signifikant unterschiedlich. Spermien aus den Kontrollstraws weisen höhere Anteile auf. Während bei den Nanostraws der Anteil akrosomintakter Spermien mit höheren Glyceringehalten sank, stieg dieser bei den Spermien in den Kontrollstraws an.

Tabelle 25: Anteil Spermien ( $\bar{x} \pm$ SEM \%) mit einem intakten Akrosom der Kurve D+ mit einem Anteil von 5\% und 7\% Glyzerin (GLY) unmittelbar nach dem Auftauen

Kurve D+5\% GLY Kurve D+7\% GLY

\begin{tabular}{lcc} 
Gruppe & $\bar{x} \pm$ SEM & $\bar{x} \pm$ SEM \\
\hline Nanostraw (n=12) & $59,7 \pm 2,0^{\mathrm{a}}$ & $57,7 \pm 4,9^{\mathrm{a}}$
\end{tabular}

Kontrollstraw ( $\mathbf{n = 1 2}) \quad 72,2 \pm 1,6^{\mathrm{b}} \quad 73,0 \pm 0,8^{\mathrm{b}}$

a, b: Werte mit unterschiedlichen Indizes unterscheiden sich innerhalb einer Kühlkurve signifikant $(p \leq 0,05)$.

Zusammenfassend lässt sich feststellen, dass die Parameter für die Spermaqualität unter Verwendung der Kühlkurve D+ besser waren als bei den anderen Versuchsansätzen. Daher wurde diese Kühlkurve für die weiteren Versuche genutzt. In Versuch 2 erfolgte deren qualitative Überprüfung. 


\subsection{Versuch 2: Qualitätsüberprüfung der in Versuch 1 entwickelten Kühlkurve und der tiefgefrorenen Spermien im Nanostraw mittels etablierter Laborverfahren}

\subsubsection{Auswertung der spermatologischen Qualitätsparameter}

Zwischen den Versuchsgruppen ergaben sich signifikante Unterschiede hinsichtlich der Motilität, der Membranintegrität sowie der Morphologie der Spermien. Diese sind im Folgenden aufgeführt. Dazu sind der korrigierte Mittelwert (Least Square Means, LSM) und der Standardfehler (SEM) angegeben. Die Unterschiede zwischen den zwei Bullen waren stets signifikant $(p \leq 0,05)$.

Tabelle 26 gibt einen Überblick über den Einfluss der fixen Effekte Bulle, Strawtyp und Zeit sowie deren Interaktionen. Kein Einfluss bestand vom Bullen auf die Parameter ALH, BCF, VAP, VCL, VSL, LIN, STR, auf den Anteil morphologisch-intakter Spermien und auf den Anteil akrosomintakter Spermien. Der Anteil PI-negativer Spermien und der Anteil motiler Spermien wurden signifikant $(p \leq 0,01)$ ebenso wie der Anteil progressiver Spermien $(p \leq 0,05)$ vom Bullen beeinflusst. Der Strawtyp erwies sich als signifikant in Bezug auf die aufgeführten Merkmale mit Ausnahme des BCF-, des VAP- und des VSL-Wertes. Während für $A L H, V C L$ und STR signifikante Beziehungen $(p \leq 0,05)$ bestanden, lagen für alle anderen Merkmale höchst signifikante Effekte vor $(p \leq 0,001)$. Die Zeit (Thermoresistenztest) hatte auf alle gemessenen Spermaqualitätsparameter mit Ausnahme des BCF $(p \leq 0,01)$ einen höchst signifikanten $(p \leq 0,001)$ Einfluss. Ein Effekt der Interaktion zwischen Bulle und Strawtyp bestand lediglich bei dem im CASA gemessenen Parameter BCF $(p \leq 0,05)$. Eine Interaktion zwischen Bulle und Zeit bestand nicht. Die Interaktion zwischen Straw und Zeit wirkte sich signifikant auf den Anteil motiler und progressiver Spermien ( $p \leq 0,001)$, den BCF $(p \leq 0,01)$ sowie auf den ALH, den Anteil morphologischintakter und akrosomintakter Spermien im Thermoresistenztest aus $(p \leq 0,05)$. Die Dreifachinteraktion zwischen Bulle, Straw und Zeit wirkte sich lediglich signifikant auf den Anteil motiler Spermien aus $(p \leq 0,01)$. 
Tabelle 26: Einfluss der fixen Effekte Bulle, Strawtyp und Zeit (Thermoresistenztest) sowie deren Interaktionen auf die Merkmale der Spermaqualität

\begin{tabular}{|c|c|c|c|c|c|c|c|}
\hline \multirow[b]{2}{*}{ Merkmal } & \multicolumn{7}{|c|}{ Faktor } \\
\hline & Bulle & Strawtyp & Zeit & $\begin{array}{c}\text { Bulle x } \\
\text { Straw }\end{array}$ & $\begin{array}{c}\text { Bulle } \\
\text { X } \\
\text { Zeit }\end{array}$ & $\begin{array}{c}\text { Straw } \\
\text { X } \\
\text { Zeit }\end{array}$ & $\begin{array}{c}\text { Bulle } \\
\mathbf{x} \\
\text { Straw } \\
\mathbf{x} \\
\text { Zeit }\end{array}$ \\
\hline $\begin{array}{l}\text { Anteil motiler } \\
\text { Spermien }\end{array}$ & ** & $* * *$ & $* \star *$ & n.s. & n.s. & $* * *$ & ** \\
\hline $\begin{array}{l}\text { Anteil progressiver } \\
\text { Spermien }\end{array}$ & * & $* * *$ & $\star * *$ & n.s. & n.s. & $\star \star \star *$ & n.s. \\
\hline ALH & n.s & * & $* \star *$ & n.s. & n.s. & * & n.s. \\
\hline BCF & n.s & n.s. & $\star *$ & * & n.s. & ** & n.s. \\
\hline VAP & n.s & n.s. & 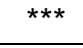 & n.s. & n.s. & n.s. & n.s. \\
\hline VCL & n.s & * & $* * *$ & n.s. & n.s. & n.s. & n.s. \\
\hline VSL & n.s & n.s. & $* \star *$ & n.s. & n.s. & n.s. & n.s. \\
\hline LIN & n.s & $\star \star \star *$ & $* * *$ & n.s. & n.s. & n.s. & n.s. \\
\hline STR & n.s & * & $\star * *$ & n.s. & n.s. & n.s. & n.s. \\
\hline $\begin{array}{l}\text { Morphologisch } \\
\text { intakt }\end{array}$ & n.s. & $* \star \star$ & $\star \star \star *$ & n.s. & n.s. & * & n.s. \\
\hline Intaktes Akrosom & n.s. & $* * *$ & $* * *$ & n.s. & n.s. & ${ }^{*}$ & n.s. \\
\hline $\begin{array}{l}\text { Anteil PI-negativer } \\
\text { Spermien }\end{array}$ & $* *$ & $* * *$ & $* * *$ & n.s. & n.s. & n.s. & n.s. \\
\hline
\end{tabular}

${ }^{*} p \leq 0,05,{ }^{* *} p \leq 0,01,{ }^{* * *} p \leq 0,001$, n.s. $=$ nicht signifikant

\subsubsection{Motilität}

Aus der Vielzahl der Qualitätsparameter die im CASA erhoben werden, wird im Ergebnisteil dieses Kapitels nur der Anteil motiler Spermien in \% sowie der Anteil STR und LIN aufgrund der Aussagekraft der Ergebnisse angegeben. Die Auswertungen der im CASA-System generierten Daten (Progressive, ALH, BCF, VAP, VCL, VSL) sind im Anhang unter Kapitel 9.5 (Tabellen 43-58) zu finden.

Anteil motiler Spermien bei den Bullen A und B

Der Anteil motiler Spermien lag beim nativen Ejakulat des Bullen $\mathbf{A}$ bei $88,1 \pm 0,9 \%$. Wie aus Tabelle 27 hervorgeht, wurde in der Kontrollgruppe zu allen Untersuchungszeitpunkten ein höherer Wert für den Anteil motiler Spermien aus 
den Kontrollstraws als bei den Spermien aus dem Nanostraw gemessen $(p \leq 0,05)$. Der Anteil motiler Spermien nahm jedoch in beiden Gruppen nach dem Auftauen $(0 \mathrm{~h})$ im Laufe der Inkubation über $3 \mathrm{~h}$ zu $6 \mathrm{~h}$ bei $37^{\circ} \mathrm{C}$ signifikant ab.

Tabelle 27: Anteil motiler Spermien (in \%) des Bullen A unmittelbar nach dem Auftauen sowie nach drei- und sechsstündiger Inkubation bei $37^{\circ} \mathrm{C}$

\begin{tabular}{|c|c|c|c|}
\hline Gruppe & $\begin{array}{c}0 \text { Std. } \\
\bar{x} \pm \text { SEM }\end{array}$ & $\begin{array}{c}3 \text { Std. } \\
\bar{x} \pm \text { SEM }\end{array}$ & $\begin{array}{c}6 \text { Std. } \\
\bar{x} \pm \text { SEM }\end{array}$ \\
\hline Nanostraw $\quad(n=24)$ & $51,1 \pm 2,8^{a, A}$ & $41,6 \pm 2,8^{\mathrm{a}, \mathrm{B}}$ & $26,7 \pm 2,8^{\mathrm{a}, \mathrm{C}}$ \\
\hline Kontrollstraw $(n=24)$ & $64,9 \pm 2,8^{\mathrm{b}, \mathrm{A}}$ & $52,1 \pm 2,8^{\mathrm{b}, \mathrm{B}}$ & $32,6 \pm 2,8^{b, C}$ \\
\hline
\end{tabular}

Der Anteil motiler Spermien des Bullen B vor der Kryokonservierung mit 83,3 \pm $0,7 \%$ war signifikant $(p \leq 0,05)$ niedriger als der des Bullen $A$. Wie aus Tabelle 28 hervorgeht, wurden bei dem Thermoresistenztest zu den Zeitpunkten null und drei Stunden signifikant höhere Motilitätswerte $(p \leq 0,05)$ in der Kontrollgruppe als in der Nanostrawgruppe gemessen, während die Unterschiede nach sechsstündiger Inkubation nicht statistisch signifikant unterschiedlich waren. Wie bereits die Ergebnisse des Bullen A gezeigt haben, ist eine signifikante Abnahme des Anteils motiler Spermien des Bullen B bei den betrachteten Gruppen im Laufe der Inkubation bei $37^{\circ} \mathrm{C}$ zu beobachten. 
Tabelle 28: Anteil motiler Spermien (in \%) des Bullen B unmittelbar nach dem Auftauen sowie nach drei- und sechsstündiger Inkubation bei $37^{\circ} \mathrm{C}$

\begin{tabular}{|c|c|c|c|}
\hline Gruppe & $\begin{array}{c}0 \text { Std. } \\
\bar{x} \pm \text { SEM }\end{array}$ & $\begin{array}{c}3 \text { Std. } \\
\bar{x} \pm \text { SEM }\end{array}$ & $\begin{array}{c}6 \text { Std. } \\
\bar{x} \pm \text { SEM }\end{array}$ \\
\hline Nanostraw $\quad(n=24)$ & $48,5 \pm 2,8^{\mathrm{a}, \mathrm{A}}$ & $30,5 \pm 2,8^{a, B}$ & $16,6 \pm 2,8^{\mathrm{a}, \mathrm{C}}$ \\
\hline Kontrollstraw $(n=24)$ & $60,4 \pm 2,8^{\mathrm{b}, \mathrm{A}}$ & $48,9 \pm 2,8^{b, B}$ & $25,3 \pm 2,8^{\mathrm{a}, \mathrm{C}}$ \\
\hline
\end{tabular}

\section{Anteil linearer Spermien bei den Bullen A und B}

Abbildung 8 zeigt die Linearität (\%) der Spermien der Bullen A und B über den gesamten Versuchsablauf. Die Spermien aus dem Kontrollstraw der betrachteten Bullen zeigten zu allen Untersuchungszeitpunkten eine höhere Linearität als die Nanostrawspermien. Ein signifikanter Einfluss des Merkmals Zeit $(p \leq 0,05)$ war erkennbar, wobei die Linearität der Spermien beider Untersuchungsgruppen nach einer Inkubationszeit von drei Stunden niedriger war als zum Zeitpunkt null und nach sechs Stunden. Im Gegensatz zu den anderen Versuchsanstellungen, die nach sechs Stunden Inkubation ähnliche Linearitäten wie unmittelbar nach dem Auftauen erreichten, erreichten Spermien des Bullen A aus dem Nanostraw lediglich Werte, die leicht höher waren $(34,4 \%)$ als die nach drei Stunden $(33,8 \%)$ gemessenen (Tabellen 47 und 55, die zusätzlich die Signifikanzanalyse aufzeigen). 


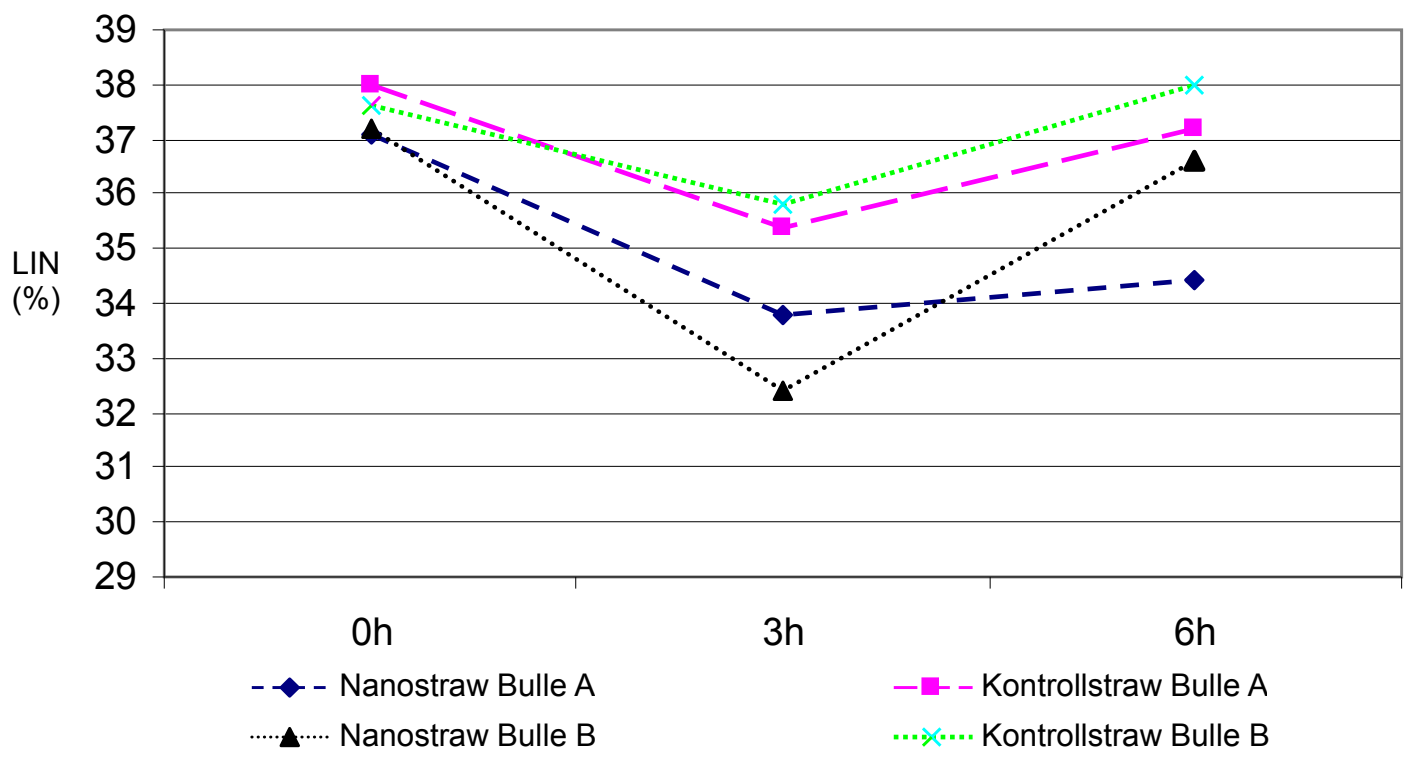

Abbildung 8: Linearität (in \%) der Spermien der Bullen A und B im Thermoresistenztest.

In der Abbildung 9 ist der prozentuale Anteil sich geradlinig bewegender Spermien aus dem Nanostraw und der Kontrolle beider Bullen dargestellt. Im Merkmal Straightness war derselbe Trend wie bei der Linearität zu beobachten. Im Thermoresistenztest lag der Wert der Straightness der Spermien beider Bullen zum Zeitpunkt drei Stunden unter dem Wert, der zu den Zeitpunkten null und sechs Stunden gemessen wurde. Zusätzlich fällt auf, dass die Straightness der Spermien im Kontrollstraw des Bullen B zum Auftauen am niedrigsten war und nach drei Stunden Inkubation höher war als die der Spermien bei den Nanostraws. Fast identische Werte mit den Spermien aus dem Kontrollstraw des Bullen A lagen erst nach sechs Stunden Inkubation vor (Tabellen 46 und 54, die zusätzlich die Signifikanzanalyse aufzeigen). 


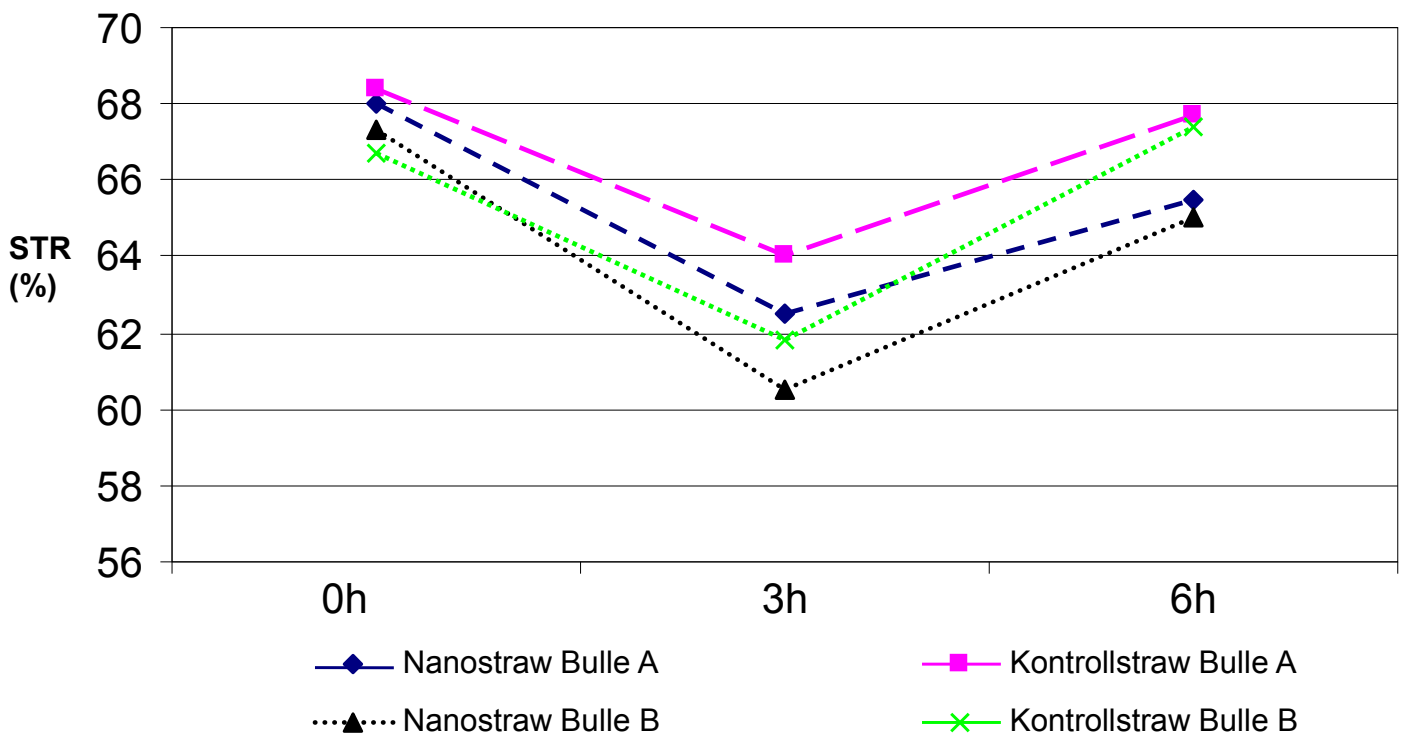

Abbildung 9: Straightness (in \%) der Spermien der Bullen A und B im Thermoresistenztest.

\subsubsection{Membranintegrität}

Der Anteil PI-negativer Spermien betrug bei der Messung des Ejakulats vor dem Einfrieren beim Bullen A 83,4 $\pm 0,76 \%$.

In Tabelle 29 sind die Ergebnisse des Thermoresistenztests durch die flowzytometrische Messung mit den Farbstoffen SYBR14/PI des Bullen A dargestellt. In allen Untersuchungszeitpunkten hatte die Kontrollgruppe einen signifikant höheren Anteil $(p \leq 0,05)$ membranintakter Spermien als die Nanostrawgruppe. Sowohl die Nanostraw- als auch die Kontrollstrawgruppe zeigten keine signifikanten Abnahmen im Anteil membranintakter Spermien nach drei Stunden Inkubation bei $37^{\circ} \mathrm{C}$. Nach sechs Stunden Inkubation war ein signifikant höherer Anteil membranintakter Spermien aus dem Kontrollstraw im Vergleich zu den Spermien aus dem Nanostraw zu sehen. 
Tabelle 29: Anteil membranintakter Spermien (PI-negativ; in \%) des Bullen A unmittelbar nach dem Auftauen sowie nach drei- und sechsstündiger Inkubation bei $37^{\circ} \mathrm{C}$

\begin{tabular}{|c|c|c|c|}
\hline Gruppe & $\begin{array}{c}0 \text { Std. } \\
\bar{x} \pm \text { SEM }\end{array}$ & $\begin{array}{c}3 \text { Std. } \\
\bar{x} \pm \text { SEM }\end{array}$ & $\begin{array}{c}6 \text { Std. } \\
\bar{x} \pm \mathrm{SEM}\end{array}$ \\
\hline Nanostraw $\quad(n=24)$ & $61,0 \pm 2,4^{\mathrm{a}, \mathrm{A}}$ & $56,4 \pm 2,4^{\mathrm{a}, \mathrm{A}}$ & $53,2 \pm 2,4^{a, B}$ \\
\hline Kontrollstraw $(n=24)$ & $69,2 \pm 2,4^{\mathrm{b}, \mathrm{A}}$ & $67,2 \pm 2,4^{\mathrm{b}, \mathrm{A}}$ & $64,9 \pm 2,4^{\mathrm{b}, \mathrm{A}}$ \\
\hline
\end{tabular}

Die Tabelle 30 zeigt den Anteil membranintakter Spermien nach dem Auftauen des Bullen B im Thermoresistenztest. Der Anteil membranintakter Spermien des Bullen $B$ vor dem Einfrieren war mit $85,2 \pm 1,0 \%$ signifikant besser als der Anteil $(p \leq 0,05)$ des Bullen $A$.

Beide Behandlungsgruppen unterschieden sich bereits nach null Stunden Anpassung an $37^{\circ} \mathrm{C}$ signifikant $(p \leq 0,05)$ voneinander, ebenso nach drei und sechs Stunden Inkubation. In der Nanostrawgruppe verringerte sich der Anteil membranintakter Spermien nach drei Stunden Inkubation um 9\%. Im weiteren Verlauf war keine signifikante Veränderung mehr zu beobachten. Die Kontrollstrawgruppe zeigte über den Zeitraum von sechs Stunden Inkubation eine signifikante $(p \leq 0,05)$ Verschlechterung im Anteil membranintakter Spermien von $66,1 \%$ auf $55,4 \%$.

Tabelle 30: Anteil membranintakter Spermien (PI-negativ; in \%) des Bullen B unmittelbar nach dem Auftauen sowie nach drei- und sechsstündiger Inkubation bei $37^{\circ} \mathrm{C}$

\begin{tabular}{|c|c|c|c|}
\hline Gruppe & $\begin{array}{c}0 \text { Std. } \\
\bar{x} \pm \text { SEM }\end{array}$ & $\begin{array}{c}3 \text { Std. } \\
\bar{x} \pm \mathrm{SEM}\end{array}$ & $\begin{array}{c}6 \text { Std. } \\
\bar{x} \pm \text { SEM }\end{array}$ \\
\hline Nanostraw $\quad(n=24)$ & $56,0 \pm 2,4^{\mathrm{a}, \mathrm{A}}$ & $47,0 \pm 2,4^{a, B}$ & $44,5 \pm 2,4^{\mathrm{a}, \mathrm{B}}$ \\
\hline Kontrollstraw $(n=24)$ & $66,1 \pm 2,4^{\mathrm{b}, \mathrm{A}}$ & $61,0 \pm 2,4^{\mathrm{b}, \mathrm{B}}$ & $55,4 \pm 2,4^{\mathrm{b}, \mathrm{c}}$ \\
\hline
\end{tabular}




\subsubsection{Morphologie}

\section{Anteil morphologisch intakter Spermien der Bullen A und B}

Die Eingangsuntersuchung unter dem Phasenkontrastmikroskop vor dem Einfrieren ergab für den Bullen A einen Anteil von 90,0 $\mathbf{A}, 5 \%$ morphologischintakter Spermien.

Tabelle 31 zeigt den Anteil morphologisch-intakter Spermien aus der Nanostraw- und Kontrollstrawgruppe im Thermoresistenztest. Erst nach sechs Stunden war ein signifikant höherer Anteil morphologisch-intakter Spermien $(p \leq 0,05)$ aus dem Kontrollstraw zu beobachten.

Betrachtet man jedoch den Inkubationszeitraum von sechs Stunden, war in beiden Behandlungsgruppen ein signifikanter Abfall $(p \leq 0,05)$ des Anteils morphologisch-intakter Spermien zu beobachten.

Tabelle 31: Anteil morphologisch intakter Spermien (in \%) des Bullen A unmittelbar nach dem Auftauen sowie nach drei- und sechsstündiger Inkubation bei $37^{\circ} \mathrm{C}$

\begin{tabular}{lccc}
\hline & 0 Std. & 3 Std. & 6 Std. \\
Gruppe & $\bar{x} \pm$ SEM & $\bar{x} \pm$ SEM & $\bar{x} \pm$ SEM \\
\hline Nanostraw $\quad(\mathbf{n = 2 4 )}$ & $82,0 \pm 1,3^{\mathrm{a}, \mathrm{A}}$ & $73,3 \pm 1,3^{\mathrm{a}, \mathrm{B}}$ & $69,2 \pm 1,3^{\mathrm{a}, \mathrm{C}}$ \\
Kontrollstraw (n=24) & $83,0 \pm 1,3^{\mathrm{a}, \mathrm{A}}$ & $76,7 \pm 1,3^{\mathrm{a}, \mathrm{B}}$ & $73,7 \pm 1,3^{\mathrm{b}, \mathrm{C}}$ \\
\hline
\end{tabular}

a, b: Werte mit unterschiedlichen Indizes unterscheiden sich innerhalb eines Untersuchungszeitpunktes signifikant $(p \leq 0,05)$.

A, B, C: Werte mit unterschiedlichen Indizes unterscheiden sich innerhalb einer Gruppe bei Betrachtung aller Untersuchungszeitpunkte signifikant $(p \leq 0,05)$.

In der Eingangsuntersuchung wurde beim Bullen B im Phasenkontrastmikroskop ein Anteil von 88,3 \pm 0,5\% morphologisch intakter Spermien dokumentiert. Der Anteil der Spermien mit intaktem Akrosom lag bei 89,7 $\pm 0,5 \%$.

Tabelle 32 zeigt den Anteil morphologisch intakter Spermien im Thermoresistenztest beider Untersuchungsgruppen. Die Gruppe Kontrollstraw wies zu allen Untersuchungszeitpunkten einen signifikant höheren Anteil morphologisch- 
intakter Spermien als die Nanostrawgruppe auf $(p \leq 0,05)$. Innerhalb der Gruppen nahm der Anteil moprhologischintakter Spermien über den Untersuchungszeitraum von sechs Stunden ab.

Tabelle 32: Anteil morphologisch intakter Spermien (in \%) des Bullen B unmittelbar nach dem Auftauen sowie nach drei- und sechsstündiger Inkubation bei $37^{\circ} \mathrm{C}$

\begin{tabular}{|c|c|c|c|}
\hline Gruppe & $\begin{array}{c}0 \text { Std. } \\
\bar{x} \pm \text { SEM }\end{array}$ & $\begin{array}{c}3 \text { Std. } \\
\bar{x} \pm \text { SEM }\end{array}$ & $\begin{array}{c}6 \text { Std. } \\
\bar{x} \pm \text { SEM }\end{array}$ \\
\hline Nanostraw $\quad(n=24)$ & $77,4 \pm 1,3^{\mathrm{a}, \mathrm{A}}$ & $71,3 \pm 1,3^{a, B}$ & $65,8 \pm 1,3^{\mathrm{a}, \mathrm{C}}$ \\
\hline Kontrollstraw $(n=24)$ & $81,2 \pm 1,3^{\mathrm{b}, \mathrm{A}}$ & $76,6 \pm 1,3^{\mathrm{b}, \mathrm{B}}$ & $72,0 \pm 1,3^{b, c}$ \\
\hline
\end{tabular}

\section{Anteil Spermien mit intaktem Akrosom der Bullen A und B}

Vor dem Einfrieren hatten 89,8 \pm 1,4 \% der Spermien des Bullen A ein intaktes Akrosom. Nach drei Stunden Inkubationszeit der Proben auf dem Wärmeblock war der Anteil akrosomintakter Spermien aus dem Kontrollstraw signifikant $(p \leq 0,05)$ höher als der Anteil aus dem Nanostraw (Tabelle 33). Wie in Tabelle 33 zu beobachten ist, fiel der Anteil akrosomintakter Spermien mit der Inkubationszeit bei $37^{\circ} \mathrm{C}$ in beiden Behandlungsgruppen signifikant ab. 
Tabelle 33: Anteil Spermien mit intaktem Akrosom (in \%) des Bullen A unmittelbar nach dem Auftauen sowie nach drei- und sechsstündiger Inkubation bei $37^{\circ} \mathrm{C}$

\begin{tabular}{|c|c|c|c|}
\hline Gruppe & $\begin{array}{c}\text { O Std. } \\
\bar{x} \pm \text { SEM }\end{array}$ & $\begin{array}{c}3 \text { Std. } \\
\bar{x} \pm \text { SEM }\end{array}$ & $\begin{array}{c}6 \text { Std. } \\
\bar{x} \pm \text { SEM }\end{array}$ \\
\hline Nanostraw $\quad(n=24)$ & $83,1 \pm 1,2^{\mathrm{a}, \mathrm{A}}$ & $74,7 \pm 1,2^{\mathrm{a}, \mathrm{B}}$ & $71,0 \pm 1,2^{\mathrm{a}, \mathrm{C}}$ \\
\hline Kontrollstraw $(n=24)$ & $84,0 \pm 1,2^{\mathrm{a}, \mathrm{A}}$ & $78,5 \pm 1,2^{b, B}$ & $75,1 \pm 1,2^{b, C}$ \\
\hline
\end{tabular}

Tabelle 34 zeigt den Anteil der Spermien mit intaktem Akrosom unter dem Phasenkontrastmikroskop des Bullen B. Die Spermien der Kontrollgruppe hatten einen signifikant höheren Anteil akrosomintakter Spermien als die Spermien aus dem Nanostraw $(p \leq 0,05)$. Auch in Bezug auf dieses Merkmal nahm der Anteil intakter Spermien im Laufe der Inkubation in beiden Gruppen signifikant ab.

Tabelle 34: Anteil Spermien mit intaktem Akrosom (in \%) des Bullen B unmittelbar nach dem Auftauen sowie nach drei- und sechsstündiger Inkubation bei $37^{\circ} \mathrm{C}$

\begin{tabular}{|c|c|c|c|}
\hline Gruppe & $\begin{array}{c}0 \text { Std. } \\
\bar{x} \pm \text { SEM }\end{array}$ & $\begin{array}{c}3 \text { Std. } \\
\bar{x} \pm \text { SEM }\end{array}$ & $\begin{array}{c}6 \text { Std. } \\
\bar{x} \pm \text { SEM }\end{array}$ \\
\hline Nanostraw $\quad(n=24)$ & $79,5 \pm 1,2^{\mathrm{a}, \mathrm{A}}$ & $72,5 \pm 1,2^{\mathrm{a}, \mathrm{B}}$ & $67,8 \pm 1,2^{\mathrm{a}, \mathrm{C}}$ \\
\hline Kontrollstraw $(n=24)$ & $83,0 \pm 1,2^{\mathrm{b}, \mathrm{A}}$ & $78,0 \pm 1,2^{\mathrm{b}, \mathrm{B}}$ & $74,2 \pm 1,2^{\mathrm{b}, \mathrm{C}}$ \\
\hline
\end{tabular}




\subsection{Versuch 3: SIFT mit Frischsamen (gesext)}

\subsubsection{Trächtigkeitsergebnisse der Färsen}

Es wurden insgesamt 16 Färsen mit geschlechtsdifferenziertem Frischsperma der Bullen A und B besamt.

Die Trächtigkeitsuntersuchungen wurden am 30. Tag nach der Besamung mittels Ultraschall durchgeführt. Von den sechs tragenden Tieren wurden fünf in einem vorherigen Versuch zur Follikelpunktion benutzt. Tabelle 35 gibt einen Überblick über die Größe der Follikel unmittelbar vor der Übertragung des Spermas sowie 24 Stunden danach sowie Ergebnisse der Trächtigkeitsuntersuchungen nach Übertragung der X- und Y-chromosomal sortierten Spermien durch SIFT ${ }^{\circledR}$ der Bullen C und D. 
Tabelle 35: Überblick über die vorherige Behandlung der Färsen sowie deren Follikelgrößen unmittelbar vor und $24 \mathrm{~h}$ nach der Samenübertragung sowie die Trächtigkeitsergebnisse nach der Übertragung von X- und Y-chromosomal sortierten Spermien der Bullen C und D durch SIFT ${ }^{\circledR}$

\begin{tabular}{|c|c|c|c|c|c|c|c|c|c|c|c|}
\hline \multirow{3}{*}{$\begin{array}{l}\text { Tier } \\
\text { Nr. }\end{array}$} & \multirow{3}{*}{$\begin{array}{c}\text { Anzahl KB } \\
\text { vor } \\
\text { SIFT }^{\circledR}\end{array}$} & \multicolumn{4}{|c|}{$\begin{array}{c}\text { Follikelgröße } \\
\text { zum Zeitpunkt SIFT }\end{array}$} & \multicolumn{3}{|c|}{$\begin{array}{c}\text { Follikelgröße } \\
24 \text { h nach SIFT }\end{array}$} & \multirow{3}{*}{$\begin{array}{l}\text { Bulle } \\
\text { C }\end{array}$} & \multirow{3}{*}{$\begin{array}{c}\text { Bulle } \\
\text { D }\end{array}$} & \multirow[b]{3}{*}{ TU } \\
\hline & & \multicolumn{2}{|c|}{$1,5-2,0 \mathrm{~cm}$} & \multicolumn{2}{|c|}{$2,0-2,5 \mathrm{~cm}$} & \multicolumn{2}{|c|}{$2,0-2,5 \mathrm{~cm}$} & \multirow[t]{2}{*}{ ovuliert } & & & \\
\hline & & $\mathbf{L}$ & $\mathbf{R}$ & $\mathbf{L}$ & $\mathbf{R}$ & $\mathbf{L}$ & $\mathbf{R}$ & & & & \\
\hline 9566 & 1 & $x$ & & & & & & $x$ & & $x$ & - \\
\hline 9567 & & & $x$ & & & & & $x$ & Y & & + \\
\hline 9588 & & $x$ & & & & & & $x$ & & Y & - \\
\hline 8582 & & & $x$ & & & & $x$ & & $X$ & & - \\
\hline 8584 & & $x$ & $x$ & & & & & $x$ & & $x$ & - \\
\hline 9600 & & & & & $x$ & & & $x$ & & $X$ & + \\
\hline 1053 & & & $x$ & & & & $x$ & & & Y & - \\
\hline 1063 & & $x$ & & & & & & $x$ & $X$ & & + \\
\hline 1075 & & & $x$ & & & & & $x$ & & $X$ & - \\
\hline 9593 & 1 & & & $x$ & $x$ & & & $x$ & $x$ & & - \\
\hline 9772 & & & & & $x$ & & & $x$ & $x$ & & + \\
\hline 9774 & & $x$ & & & & $x$ & & & & Y & - \\
\hline 9776 & & & $x$ & & & & & $x$ & $x$ & & + \\
\hline 9777 & & & $x$ & & & & & $x$ & & $x$ & + \\
\hline 9782 & & & $x$ & & & & $x$ & & & $X$ & - \\
\hline 9788 & & & $x$ & & & & & $x$ & $X$ & & - \\
\hline
\end{tabular}

Es zeigt sich, dass alle Tiere, die nach 30 Tagen positiv auf eine Trächtigkeit geschallt wurden, 24 Stunden nach SIFT ${ }^{\circledR}$ ovuliert hatten. Insgesamt hatten lediglich drei Tiere nach 24 Stunden nicht ovuliert. Zwei Färsen waren vor Beginn des Versuchs bereits künstlich besamt worden, wurden jedoch nicht tragend. Vier Tiere fielen aus, da sie zum Zeitpunkt der Besamung bereits ovuliert hatten. 
Sieben Färsen wurden mit 500.000 Spermien pro Portion des Bullen C in den Eileiter besamt. Vier Tiere waren tragend. Bei neun Färsen wurde Sperma des Bullen D in den Eileiter übertragen. Zwei Tiere wurden tragend. Zusammengefasst wurden 16 Tiere mittels $\mathrm{SIFT}^{\circledR}$ in den Eileiter besamt. Es wurde eine Trächtigkeitsrate von $37,5 \%$ erreicht.

Es wurden $41,7 \%$ der Tiere, die mit X-chromosomal sortiertem Sperma mittels SIFT besamt wurden, tragend. Von den mit Y-chromosomal sortiertem Sperma besamten Tieren wurde ein Viertel positiv auf eine Trächtigkeit geschallt.

\subsubsection{Trächtigkeitsergebnisse der Kühe}

Von den 12 synchronisierten Tieren wurden zehn Tiere mittels SIFT ${ }^{\circledR}$ in den Eileiter besamt. Zwei Tiere wurden nicht besamt, da sie keine Reaktion auf das Synchronisationsprogramm zeigten.

Tabelle 36 vermittelt einen Überblick über die vorherige Behandlung der Kühe sowie deren Follikelgrößen unmittelbar vor und 24 h nach der Samenübertragung. Bei insgesamt $40 \%$ der Tiere wurden in einem zuvor durchgeführten Versuch durch OPU Eizellen entnommen. Eine induzierte Superovulation mit anschließender Besamung und Spülung der Embryonen wurde bei 50\% der Tiere durchgeführt. $33 \%$ der Kühe wurden in dem aufgezeigten Versuch mittels SIFT ${ }^{\circledR}$ tragend. Jedes dieser tragenden Tiere wurde in einem der zuvor aufgezählten Versuche verwendet. Alle Kühe, die positiv auf eine Trächtigkeit geschallt wurden, ovulierten mindestens $24 \mathrm{~h}$ nach $\mathrm{SIFT}^{\circledR}$. 
Tabelle 36: Überblick über die vorherige Behandlung der Kühe sowie deren Follikelgrößen unmittelbar vor und $24 \mathrm{~h}$ nach der Samenübertragung

\begin{tabular}{|c|c|c|c|c|c|c|c|c|c|c|}
\hline \multirow{3}{*}{$\begin{array}{l}\text { Tier } \\
\text { Nr. }\end{array}$} & \multirow[b]{3}{*}{ Laktation } & \multirow{3}{*}{$\begin{array}{c}\text { Anzahl KB } \\
\text { vor } \\
\text { SIFT }^{\circledR} \\
\end{array}$} & \multicolumn{4}{|c|}{$\begin{array}{c}\text { Follikelgröße } \\
\text { Zum Zeitpunkt SIFT }\end{array}$} & \multicolumn{3}{|c|}{$\begin{array}{c}\text { Follikelgröße } \\
\text { 24h nach SIFT }{ }^{\circledR}\end{array}$} & \multirow[b]{3}{*}{ TU } \\
\hline & & & \multicolumn{2}{|c|}{$1,5-2,0 \mathrm{~cm}$} & \multicolumn{2}{|c|}{$2,0-2,5 \mathrm{~cm}$} & \multicolumn{2}{|c|}{$2,0-2,5 \mathrm{~cm}$} & \multirow[t]{2}{*}{ ovuliert } & \\
\hline & & & $\mathbf{L}$ & $\mathbf{R}$ & $\mathbf{L}$ & $\mathbf{R}$ & $\mathbf{L}$ & $\mathbf{R}$ & & \\
\hline 1791 & 3 & & & $x$ & & & & & $x$ & - \\
\hline 1734 & 3 & & & $x$ & & & & & $x$ & - \\
\hline 9208 & 2 & & & $x$ & & & & & $x$ & + \\
\hline 9171 & 2 & & & $x$ & & & & & $x$ & + \\
\hline 1677 & 1 & & & $x$ & & & & & $x$ & - \\
\hline 9419 & 1 & & $x$ & & & & & & $x$ & + \\
\hline 9358 & 1 & & & $x$ & & & $x$ & & $x$ & - \\
\hline 9220 & 2 & 2 & $x$ & & & & $x$ & & & - \\
\hline 1704 & 3 & & & & $x$ & & & & $x$ & - \\
\hline 9304 & 2 & 3 & & $x$ & & & & $x$ & & - \\
\hline
\end{tabular}

Vier Kühe wurden mit 500.000 und sechs Kühe mit 250.000 geschlechtsdifferenzierten Spermien des Bullen D in den Eileiter besamt. Insgesamt wurden $33,3 \%$ der Kühe tragend. Im Einzelnen wurden von den Kühen, die mit 250.000 Samenzellen (SZ) besamt wurden, 16\% der Tiere tragend. Hingegen wurden $50 \%$ der Tiere, denen $500.000 \mathrm{SZ}$ direkt in den Eileiter übertragen worden waren, tragend. 


\subsection{Versuch 4: Besamungsversuch $\mathrm{SIFT}^{\circledR}$-TG Sperma}

Für den Besamungsversuch wurde Sperma aus den Nanostraws verwendet, das wie in Kapitel 3.2 beschrieben, kryokonserviert wurde. Dabei wurden für jede Übertragung der Spermien zwei Nanostraws eines Bullen gepoolt. Somit wurden $1 \times 10^{6}$ Spermien pro Besamung übertragen. Die Tiere kamen spontan in Brunst und wurden 24 Stunden nach Brunstbeginn bzw. nach Beobachtung von „stehender Brunst“ besamt.

\subsubsection{Trächtigkeitsergebnisse der Färsen}

Tabelle 37 gibt einen Überblick über die Follikelgrößen vor und $24 \mathrm{~h}$ nach der Samenübertragung. Bei sechs spontan brünstigen Rindern wurden mittels $\mathrm{SIFT}^{\circledR}$ Spermien in den Eileiter übertragen. Alle Tiere wurden als Jungtiere für die Follikelpunktion in einem anderen Versuch verwendet. Fünf Tiere wurden mit dem Bullen A besamt. 40\% aller Tiere wurden tragend. Lediglich ein Tier wurde mit dem Bullen B besamt. Das Trächtigkeitsergebnis war negativ. Alle tragenden Tiere hatten 24 Stunden nach SIFT ${ }^{\circledR}$ ovuliert. Ihr Follikel hatte zum Zeitpunkt der Besamung einen Durchmesser von mindestens $2 \mathrm{~cm}$. 
Tabelle 37: Überblick über die vorherige Behandlung der Rinder sowie deren Follikelgrößen unmittelbar vor und $24 \mathrm{~h}$ nach der Samenübertragung mit dem Sperma aus dem Nanostraw

\begin{tabular}{|c|c|c|c|c|c|c|c|c|c|}
\hline \multirow[b]{3}{*}{ Tier Nr. } & \multicolumn{4}{|c|}{$\begin{array}{c}\text { Follikelgröße } \\
\text { zum Zeitpunkt SIFT }{ }^{\circledR}\end{array}$} & \multicolumn{3}{|c|}{$\begin{array}{c}\text { Follikelgröße } \\
24 \text { h nach SIFT }\end{array}$} & \multirow{3}{*}{ Bulle } & \multirow{3}{*}{ TU } \\
\hline & \multicolumn{2}{|c|}{$1,5-1,9 \mathrm{~cm}$} & \multicolumn{2}{|c|}{$2,0-2,5 \mathrm{~cm}$} & \multicolumn{2}{|c|}{$2,0-2,5 \mathrm{~cm}$} & \multirow[t]{2}{*}{ ovuliert } & & \\
\hline & $\mathbf{L}$ & $\mathbf{R}$ & $\mathbf{L}$ & $\mathbf{R}$ & $\mathbf{L}$ & $\mathbf{R}$ & & & \\
\hline 8951 & $x$ & $x$ & & & & & $x$ & A & - \\
\hline 9786 & & & $\mathrm{x}$ & $x$ & & & $x$ & A & + \\
\hline 9866 & & & & $x$ & & & $x$ & A & + \\
\hline 9869 & & & & $x$ & & & $x$ & A & - \\
\hline 9789 & & & $\mathrm{X}$ & & $x$ & & & A & - \\
\hline 9856 & & $x$ & & & & & $\mathrm{x}$ & B & - \\
\hline
\end{tabular}

Das Sperma aus dem Nanostraw des Bullen A erzielte eine Trächtigkeitsrate von $40 \%$. Lediglich eine Färse wurde mit dem Sperma des Bullen B besamt und nicht tragend.

\subsubsection{Trächtigkeitsergebnisse der Kühe}

Tabelle 38 zeigt die Follikelgrößen der Tiere vor und nach der Übertragung der Spermien aus dem Nanostraw mit SIFT ${ }^{\circledR}$. 33\% der Tiere, die mit dem Bullen A besamt wurden, wurden tragend. Ihre Follikelgröße betrug zum Zeitpunkt der Samenübertragung mindestens $2 \mathrm{~cm}$. Spätestens $24 \mathrm{~h}$ nach $\mathrm{SIFT}^{\circledR}$ hatte die Ovulation stattgefunden. Tiere, die nach $24 \mathrm{~h}$ nicht ovuliert hatten, wurden auch nicht tragend. Das betraf zwei Tiere. Ihre Follikelgröße zum Zeitpunkt der Besamung betrug weniger als $2 \mathrm{~cm}$ im Durchmesser.

Bei drei Tieren wurde TG-Sperma des Bullen B in den Eileiter übertragen. Ein Tier wurde tragend. Das tragende Tier hatte zum zweiten Mal gekalbt. Der dominante Follikel befand sich auf dem rechten Ovar und hatte einen Durchmesser von mindestens $2 \mathrm{~cm}$. Bei den anderen zwei Tieren hatte der dominante 
Follikel ebenfalls einen Durchmesser von mindestens $2 \mathrm{~cm}$. Die Tiere ovulierten $24 \mathrm{~h}$ nach Besamung.

Tabelle 38: Überblick über die vorherige Behandlung der Kühe sowie deren Follikelgrößen unmittelbar vor und $24 \mathrm{~h}$ nach der Samenübertragung mit dem Sperma aus dem Nanostraw

\begin{tabular}{|c|c|c|c|c|c|c|c|c|c|c|}
\hline \multirow{3}{*}{$\begin{array}{l}\text { Tier } \\
\text { Nr. }\end{array}$} & \multirow{3}{*}{ Laktation } & \multicolumn{4}{|c|}{$\begin{array}{c}\text { Follikelgröße } \\
\text { zum Zeitpunkt SIFT }\end{array}$} & \multicolumn{3}{|c|}{$\begin{array}{c}\text { Follikelgröße } \\
24 \text { h nach SIFT }\end{array}$} & \multirow{3}{*}{ Bulle } & \multirow{3}{*}{ TU } \\
\hline & & \multicolumn{2}{|c|}{$1,5-1,9 \mathrm{~cm}$} & \multicolumn{2}{|c|}{$2,0-2,5 \mathrm{~cm}$} & & & ovuliert & & \\
\hline & & L & $\mathbf{R}$ & $\mathbf{L}$ & $\mathbf{R}$ & $\mathbf{L}$ & $\mathbf{R}$ & & & \\
\hline 9581 & 1 & & & & $x$ & & & $x$ & A & + \\
\hline 9574 & 1 & & & & $\mathrm{x}$ & & & $x$ & A & - \\
\hline 9596 & 1 & & & $x$ & & & & $x$ & A & + \\
\hline 9560 & 1 & $x$ & & & $\mathrm{x}$ & $\mathrm{x}$ & & & A & - \\
\hline 1054 & 1 & & & & $x$ & & & $x$ & A & - \\
\hline 1046 & 1 & & $x$ & & & & $x$ & & A & - \\
\hline 9461 & 1 & & & $\mathrm{x}$ & & & & $\mathrm{x}$ & B & - \\
\hline 1051 & 1 & & & & $x$ & & & $x$ & B & - \\
\hline 9459 & 2 & & & & $x$ & & & $x$ & B & + \\
\hline
\end{tabular}

Sechs Tiere wurden mit dem TG-Sperma aus dem Nanostraw des Bullen A besamt. Es wurde eine Trächtigkeitsrate von $33 \%$ erzielt. Drei Tiere wurden mit dem TG-Sperma des Bullen B besamt. Es wurde eine Trächtigkeitsrate von $33 \%$ erzielt.

30 Tage nach der Samenübertragung in den Eileiter wurde eine Ultraschalluntersuchung durchgeführt. Abbildung 10 zeigt exemplarisch das Ultraschallbild der Trächtigkeit des Rindes mit der Nummer 9786. 


\section{Ergebnisse}

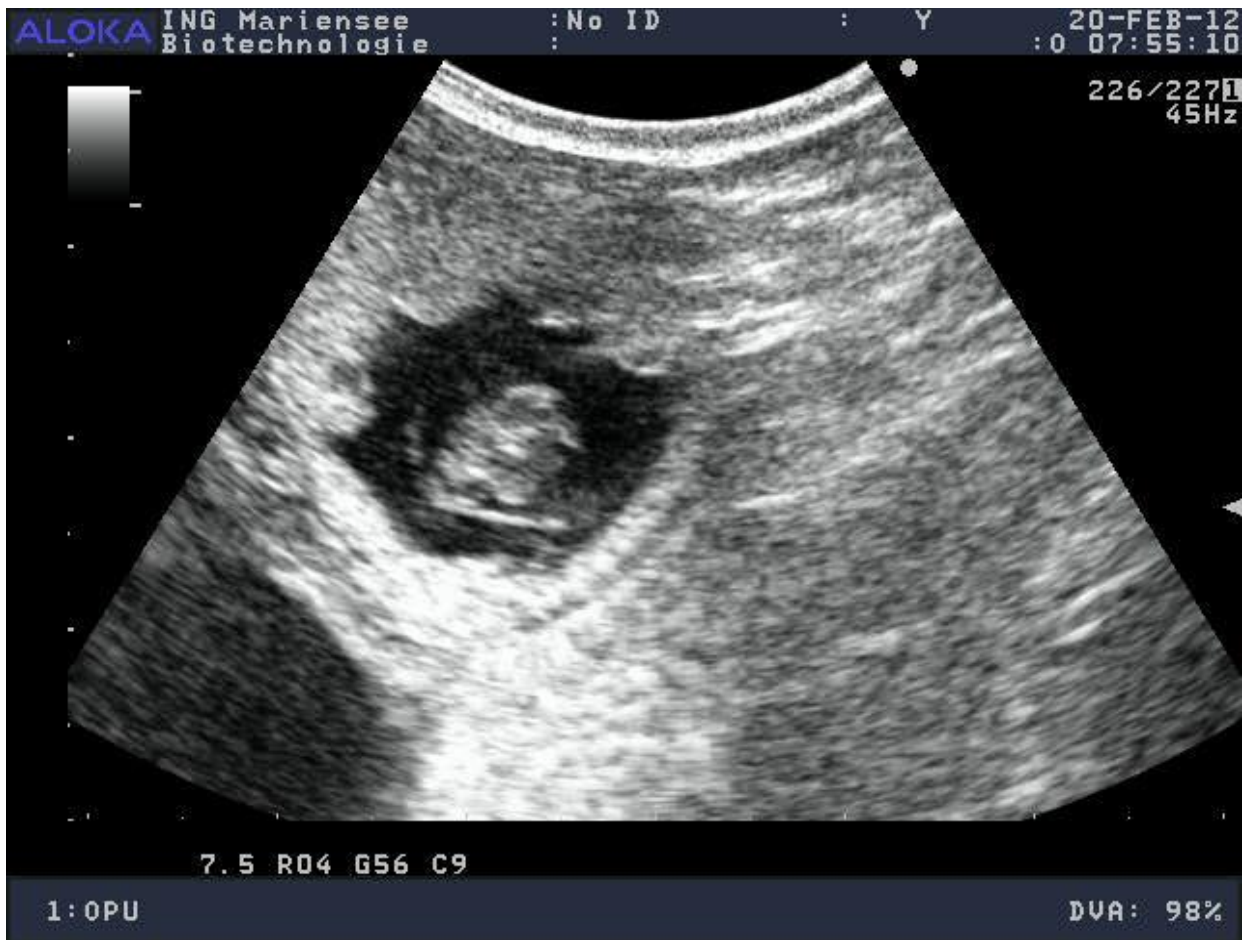

Abbildung 10: Darstellung eines Fetus ca. 30 Tage nach SIFT ${ }^{\circledR}$ von Tier 9786. 


\section{$5 \quad$ Diskussion}

Die am Institut für Nutztiergenetik entwickelte Methode $\mathrm{SIFT}^{\circledR}$ ermöglicht es, unter Beibehaltung des Spermien/Volumenmengenverhältnisses minimal dosierte Spermaportionen in den Eileiter zu übertragen (GROSSFELD ET AL., 2011B).

Die Zielstellung der vorliegenden Arbeit bestand darin, solch reduzierte Spermaportionen neu zu konfektionieren und ein angepasstes Kühl- und Gefrierprotokoll zu entwickeln. Der erste Teil der Arbeit wurde dabei im Labor durchgeführt und diente der Entwicklung eines Nanostraws mit einem Volumenfassungsvermögen von $20 \mu \mathrm{l}$. Gleichzeitig wurde ein neues Kryokonservierungsprotokoll für den Nanostraw entwickelt. Ziel war dabei, nach dem Auftauen Spermaqualitätsparameter zu erreichen, die mit jenen einer konventionellen TGBesamungsportion vergleichbar waren. Als Bewertungsgrundlage dienten die für Bullensperma festgelegten Mindestanforderungen (RATH ET AL., 2009). Im zweiten Versuchsabschnitt des Laborteils wurde ein Thermoresistenztest über sechs Stunden durchgeführt, um die Qualität der Spermien aus der in Versuch 1 entwickelten Kühlkurve zu testen. Zusätzlich wurde die Qualität des Spermas auch in Testbesamungen an Kühen und Färsen evaluiert. In einem ersten Versuchsabschnitt wurden geschlechtsdifferenzierte Spermien zweier Bullen in den Eileiter von 16 Färsen übertragen. Die Tiere waren synchronisiert. Zusätzlich wurden 10 synchronisierte Milchkühe mit gesextem Sperma mittels SIFT $®$ besamt. Um die Befruchtungsfähigkeit der Spermien aus dem Nanostraw zu überprüfen wurden, in einem zweiten Versuchsabschnitt, sechs spontan brünstige Färsen und neun Milchkühe mit kryokonserviertem Sperma aus dem Nanostraw in den Eileiter besamt.

Alle ausgewählten Bullen waren nachkommengeprüft, daher konnte davon ausgegangen werden, dass ausschließlich fruchtbare Bullen in dem Versuch getestet wurden (siehe Kapitel 3.1.1). 


\subsection{Laboruntersuchungen}

\subsubsection{Versuch 1: Screeningversuche zur Entwicklung eines angepassten Kryokonservierungsprotokolls mit einer volumenreduzierten Spermaportion im Nanostraw}

In diesem Versuch wurden die optimale Einfriergeschwindigkeit sowie der eigentliche Nanostraw entwickelt und konfiguriert.

Der Nanostraw besteht aus einem PTFE-Schlauch. Zum Schutz vor Temperaturschwankungen während des Einfriervorgangs durch unregelmäßige Stickstoffvolumeneinströme, wurde der Straw mit einem handelsüblichen $0,5 \mathrm{ml}$ Straw verpackt und verschweißt. Die Befüllung des Nanostraws erfolgte über Druck durch eine Spritze mit Kanüle, um eine gleichmäßige Aufnahme der Spermasuspension in den Straw zu gewährleisten. Innerhalb des Versuches wurde zudem jeder Straw nach Anpassung an $5^{\circ} \mathrm{C}$ über 2 Stunden von Hand in einem $5^{\circ} \mathrm{C}$ Kühlraum befüllt. Aufgrund der minimalen Größe des Nanostraws konnten Berührungen und somit Temperaturschwankungen innerhalb des Straws jedoch nicht ausgeschlossen werden.

Für eine Etablierung des Nanostraws in kommerziellen Besamungsstationen, sollten dessen Befüllung und Verschweißen automatisiert werden. Dabei könnte der handelsüblich käufliche $25 \mathrm{~m}$ lange PTFE-Schlauch mittels Sog in einem Arbeitsschritt mit der Spermasuspension befüllt werden und daraufhin in $11 \mathrm{~cm}$ Intervalle mit Hilfe eines Messers abgetrennt werden. Dabei sollte der Nanostraw wiederum möglichst wenig berührt werden, um Temperaturschwankungen zu vermindern. Des Weiteren ist eine Überprüfung der Temperatur des Verschweißgerätes zu empfehlen. Spezifische Gerätekonfigurationen für die Präparation von Nanostraws existieren gegenwärtig nicht. Das genutzte Gerät „Ultraseal $21 \mathrm{TM}^{\prime \prime}$ ist für handelsübliche $0,25 \mathrm{ml}$ und $0,5 \mathrm{ml}$ Pailletten entwickelt. Das Verschweißen eines Straws mit einem so geringen Durchmesser könnte zu Veränderungen in der Struktur des Kunststoffs und somit in der Durchlässigkeit des Materials führen. Innerhalb des Versuches konnte teilweise ein Kondenswassereintritt in die Nanostraws beobachtet werden, da die Spermien in der späteren morphologischen Untersuchung aufgerollte Schwänze aufzeigten, was 
bedingt durch die Veränderung des $\mathrm{pH}$-Wertes im Verdünnermedium zu einer herabgesetzten Befruchtungsfähigkeit der Spermien führen kann. Nach WOELDERS (1997) liegt die optimale Einfriergeschwindigkeit für Bullensperma bei $100^{\circ} \mathrm{C} / \mathrm{min}$. ROBBINS ET AL. (1976) empfehlen eine Einfriergeschwindigkeit von $26,3^{\circ} \mathrm{C} / \mathrm{min}$. Im vorliegenden Versuch wurde mit einer am Institut für Nutztiergenetik gängigen Einfrierkurve Kurve $A$ begonnen (Kapitel 3.2). Nach einer Anpassungszeit von 2 Stunden bei $5^{\circ} \mathrm{C}$ wurden die Straws im Einfrierautomaten mit einer Gefriergeschwindigkeit von $3^{\circ} \mathrm{C} / \mathrm{min}$ auf $-8^{\circ} \mathrm{C}$ heruntergekühlt. Es folgte ein einminütiger Haltepunkt bei $-8^{\circ} \mathrm{C}$. Daraufhin wurde das Sperma erst in Schritten von $20^{\circ} \mathrm{C} / \mathrm{min}$ und ab $-120^{\circ} \mathrm{C}$ in Schritten von $10^{\circ} \mathrm{C} / \mathrm{min}$ auf $-140^{\circ} \mathrm{C}$ heruntergekühlt. Anschließend erfolgte eine Überführung in flüssigen Stickstoff. Nach dem Auftauen zeigte sich, dass die Qualitätsparameter Motilität, Membranintegrität und Morphologie des Spermas im Nanostraw nach dem Auftauen nicht den Qualitätsanforderungen entsprachen. Der Anteil motiler Spermien nach dem Auftauen aus dem Kontrollstraw lag um 27,8\% über dem des Nanostraws. Da der Kontrollstraw über ein Volumen von $230 \mu \mathrm{l}$ je Straw verfügte, wurde vermutet, dass das geringe Volumen der Spermasuspension in dem $\mathrm{Na}-$ nostraw zu schnell gefriert und es hierdurch zu einer verfrühten Kapazitation der Spermien kommt. Die verfrühte Kapazitation hatte WATSON (2000) in seiner Versuchsanordnung postuliert. Eine zu schnelle Gefriergeschwindigkeit führt dazu, dass das intrazelluläre Wasser die Zelle nicht schnell genug entsprechend ihres Gradienten verlassen kann und es somit zur einer intrazellulären Eiskristallbildung kommt (SWELUM ET AL., 2011).

Durch eine erste Reduzierung der Gefriergeschwindigkeit aus Kurve $A$ ab $-8^{\circ} \mathrm{C}$ in $10^{\circ} \mathrm{C}$-Schritten pro Minute auf $-120^{\circ} \mathrm{C}$ entstand Kurve B. Der Anteil motiler Spermien aus dem Nanostraw verbesserte sich um 23,3\% auf 45,4 \% nach dem Auftauen. Der Anteil motiler Spermien aus dem Kontrollstraw verbesserte sich ebenfalls auf $62 \%$. Betrachtet man alle Gefrierkurven in Abbildung 7 , so beobachtet man eine deutliche Verlangsamung der Einfriergeschwindigkeit entlang der Kurven. Bei der Kurve $\mathrm{C}$ erfolgte eine weitere Verlangsamung ab $-8^{\circ} \mathrm{C}$ in $5^{\circ} \mathrm{C}$-Schritten pro Minute. Die Folge war wieder eine leichte, jedoch nicht signifikante, Verbesserung des Anteils motiler Spermien sowie des Anteils morpho- 
logisch- und akrosomintakter Spermien. Der Anteil membranintakter Spermien überstieg aber $50 \%$ nicht.

Da der Nanostraw lediglich einen sehr kleinen Innendurchmesser besitzt und dadurch über ein deutlich vermindertes Oberflächen-Volumenverhältnis verfügt, hat der Nanostraw ein anderes Wärmeleitfähigkeitsverhalten. Daher kam die Vermutung auf, dass die Verringerung des Durchmessers des Straws sowie die Verminderung der Spermasuspension im Straw eine Veränderung des Kristallisationspunktes nach sich zieht. Um den Kristallisationspunkt des Nanostrawmediums festzustellen, wurde ein Temperaturfühler PT-100 im Nanostraw eingesetzt und ein Testprogramm zur Feststellung der probenspezifischen Kristallisationstemperatur eingesetzt. Der Kristallisationspunkt konnte nicht gefunden werden, da das Medium durch den Fühler aus dem Nanostraw verdrängt und lediglich die Umgebungstemperatur gemessen wurde. Erfahrungswerte haben gezeigt, dass die Kristallisation bei Bullensperma zwischen $-7^{\circ}$ und $-15^{\circ} \mathrm{C}$ liegt. Da das Sperma im Nanostraw im Bereich von $5^{\circ}$ bis $-8^{\circ} \mathrm{C}$ vermutlich zu schnell gekühlt wurde, wurde dieser Schritt von $-3^{\circ} \mathrm{C}$-Schritten auf $1^{\circ} \mathrm{C}$ pro Minute heruntergesetzt (Kurve D). Der Anteil motiler Spermien verbesserte sich daraufhin von $48,4 \%$ auf $50,4 \%$ im Nanostraw und im Kontrollstraw von $64,1 \%$ auf $71,9 \%$. Eine ähnliche Steigerung war im Anteil morphologisch und akrosomintakter Spermien zu verzeichnen.

Der Anteil membranintakter Spermien verbesserte sich mit der Verringerung der Einfriergeschwindigkeit beim Sperma aus dem Nanostraw von Kurve A mit $41,5 \%$ auf $45,7 \%$ in Kurve B. Der Anteil membranintakter Spermien aus dem Kontrollstraw verbesserte sich von $57,5 \%$ auf $59,3 \%$. Kurve D zeigte eine kleine Erhöhung des Anteils membranintakter Spermien aus dem Nanostraw.

Der Einfrierautomat „Ice Cube 14 S“ bläst den Stickstoff aus einem Schacht, der seitlich am Boden angebracht ist, in den Automaten ein. Über einen Ventilator wird dieser dann in der Kammer verteilt. Bei jeder Temperaturstufe ist ein starker Stickstoffeinstrom zu beobachten. Der Behälter mit den Nanostraws befindet sich unmittelbar vor dem Schacht durch den der Stickstoff eintritt. Ein starker Einstrom führt dabei vermutlich zu einem plötzlichen Gefrieren bzw. einer starken Kühlung der Spermasuspension im Nanostraw mit anschließender Er- 
wärmung bei Verringerung des Stickstoffeinstroms. Es kommt zu Temperaturschwankungen im Nanostraw. Dieser ist zwar durch eine weitere handelsübliche $0,5 \mathrm{ml}$ Paillette vor geringen Temperaturschwankungen etwas geschützt. Die schlechten Ergebnisse der Membranintegrität sprachen jedoch nicht für eine ausreichende Isolierung. Daher wurde ein Windschutznetz für den Einfrierautomaten entwickelt (Abbildung 6). Dieses sollte den phasenweise auftretenden Stickstoffeinstrom besser verteilen und einen direkten Einstrom des Stickstoffs auf die Nanostraws verhindern, um ein gleichmäßige Kühlung des Nanostraws zu gewährleisten. Ein gleichmäßiger Stickstoffeinstrom in den Einfrierautomaten ist die Voraussetzung für ein konstantes Abkühlen und Gefrieren des Spermas (WOELDERS, 1997). Tabelle 18 zeigt die Verbesserung des Anteils membranintakter Spermien im Nanostraw durch den Einsatz des Stickstoffgitters. Da der Automat den Haltepunkt bei $-8^{\circ} \mathrm{C}$ mit dem Stickstoffgitter nicht konstant halten konnte, wurde dieser aus der Kurve herausgenommen. Der Haltepunkt bei $-8^{\circ} \mathrm{C}$ dient dazu, den Inhalt des gesamten Straws annähernd auf eine konstante Temperatur zu kühlen und der Kristallisationswärme entgegenzuwirken und den Aggregatzustand nicht wieder in den flüssigen Bereich zu überführen.

Die Kristallisationswärme entsteht, wenn sich der Aggregatzustand von flüssig zu fest ändert. Durch die Zugabe von 6,4\% Glyzerin im Verdünner wurde der Gefrierpunkt des Mediums herabgesetzt. Die Senkung des Gefrierpunktes führte zu einem höheren Anteil nicht gefrorener Fraktionen in der Verdünnerlösung. Die Hyperosmolariät wurde herabgesetzt und somit Zellschäden reduziert. Versuche, die Glyzerinkonzentration im Verdünnermedium des Nanostraws auf 5\% herabzusetzen, um die toxische Wirkung des Glyzerins nach dem Auftauen zu mindern und osmotische Schwankungen, die zu einer verminderten Motilität führen, zu verhindern, führten zu keinem Erfolg. Eine Erhöhung der Glyzerinkonzentration auf $7 \%$ und $7,5 \%$ sollte theoretisch die Schutzwirkung während des Einfrierprozesses verbessern. Da der Nanostraw mit nur wenigen Mikrolitern Spermasuspension gefüllt ist, sollte die Erhöhung der Glyzerinkonzentration die Hyperosmolarität im Medium vermindern und die Spermien vor dem Gefrieren schützen. Eine Erhöhung verbesserte die Motilität und die Membranintegrität der Spermien nicht. 


\subsubsection{Auftauen der Nanostraws}

Das Auftauen der Nanostraws erfolgte bei Raumtemperatur. Die meisten Studien empfehlen ein Auftauen der handelsüblichen in der Praxis eingesetzten Pailletten mit einem Fassungsvermögen von $230 \mu \mathrm{im}$ Wasserbad bei $33-37^{\circ} \mathrm{C}$ für einen Zeitraum von 30-45 Sekunden (SENGER ET AL., 1983; CHANDLER ET AL., 1984). Andere Autoren sehen keine Verschlechterung der NRR und somit keine Einbußen in den Spermaqualitätsparametern nach dem Auftauen der Straws bei Raumtemperatur (KAPROTH ET AL., 2005).

Gegen ein Auftauen im Wasserbad sprechen die dabei möglicherweise auftretenden Temperaturschwankungen in der weiteren Verarbeitung des Spermas. Nach dem Auftauen bei $37^{\circ} \mathrm{C}$ würde das Sperma beim Abfüllen in die Eppendorfgefäße wieder leicht an die Raumtemperatur angepasst werden. Es käme zu Temperaturschwankungen, welche eine hyperosmotische Belastung nach sich ziehen könnten (SENGER ET AL., 1983). Zudem führte das Auftauen des Nanostraws im Wasserbad bei $37^{\circ} \mathrm{C}$ zu unzureichenden Spermaqualitätsparametern. Grund dafür ist vermutlich die noch nicht ausgereifte Verpackung bzw. das Verschweißen des Nanostraws. Nach dem Auftauen im Wasserbad, waren teilweise $70 \%$ morphologische Veränderungen in Form von aufgerollten Schwänzen der Spermien zu erkennen, die einen Eintritt des Wassers in die Spermasuspension und somit eine zu starke Veränderung der Osmolarität vermuten ließen.

Da sich in jedem Nanostraw lediglich ca. $20 \mu$ Spermasuspension befand, erfolgte das Auftauen bei Raumtemperatur. Durch die Veränderung des Oberflächen-Volumen-Verhältnisses taute das Sperma so bereits nach wenigen Sekunden auf und konnte sofort verarbeitet werden. Zudem erleichterte das Auftauen an der Luft den späteren Einsatz in der Praxis. 


\subsubsection{Versuch 2: Qualitätsüberprüfung der in Versuch 1 entwickelten Kühlkurve und der tiefgefrorenen Spermien im Nanostraw mittels etablierter Laborverfahren}

Ausgehend von den Ergebnissen des ersten Versuchsabschnitts erschien die Gefrierkurve D+ am ehesten geeignet. Im folgenden Thermoresistenztest sollte die Langlebigkeit und Belastbarkeit der Spermien getestet werden. Dabei zeigte der Faktor Bulle einen signifikanten Effekt $(p \leq 0,01)$ auf den Anteil motiler und progressiver Spermien sowie den Anteil PI-negativer Spermien. Dieses Ergebniss wurde durch mehrere Arbeitsgruppen bestätigt, die einen Bulleneffekt auf die Qualität und Befruchtungsfähigkeit der Spermien nach dem Auftauen zeigten (JANUSKAUSKAS ET AL., 1996; KATHIRAVAN ET AL., 2011). Die bei diesem Versuch verwendeten Bullen gehören der Rasse Deutsch Holstein an. Der Bulle A war noch jung und verfügte lediglich über einen genomischen Zuchtwert. Der Bulle B konnte bereits Töchter- bzw. Nachkommenleistungen aufweisen (Tabelle 5).

Der Anteil motiler Spermien des Bullen A aus dem Nanostraw lag nach dem Auftauen im Durchschnitt bei $51,1 \%$, der des Bullen B bei 48,5\%. Dies entspricht den Minimalanforderungen von mindestens 50\% an die Einzelspermienbeweglichkeit (RATH ET AL., 2009). Die Qualitätsanforderungen nach RATH ET AL. (2009) gelten für geschlechtsspezifisch differenzierte Spermien. Sie dienten in dieser Arbeit lediglich als Anhaltspunkt für die Qualitätsanforderungen der Spermien aus dem Nanostraw. Die geforderten 30\% motile Spermien im Thermotoleranztest nach drei Stunden konnten mit den Spermien aus dem Nanostraw beider Bullen erfüllt werden. Bei beiden Tieren war jedoch ein signifikant höherer Anteil motiler Spermien aus den Kontrollstraws zu verzeichnen. HALLAP ET AL. (2006) erzielten 67,2\% motile Spermien nach dem Auftauen bei Bullen der Rasse Deutsch Holstein. Dieses Ergebnis ist vergleichbar mit dem Anteil motiler Spermien aus den Kontrollstraw in diesem Versuch.

Die Linearität (LIN) der Spermien nahm bei beiden Bullen nach drei Stunden ab und stieg dann wieder an. Die Linearität ist ein Parameter der mittels CASA gemessen wird. Er beschreibt das Verhältnis der kürzesten Distanz (VSL), die das Spermium während der Messung zurücklegt und der kurvolinearen Ge- 
schwindigkeit (VCL) des Spermiums in Prozent (KATHIRAVAN ET AL., 2011). Auffällig war, dass dieser prozentuale Anteil bei beiden Bullen nach drei Stunden auf dem Wärmeblock abfällt, um dann nach sechs Stunden wieder anzusteigen. Dies ist ebenfalls bei der Straightness (STR) (VSL/NAP x 100) zu beobachten. Spermien, die den Eileiter erreichen sind nicht sofort befruchtungsfähig. Sie durchlaufen zunächst den Prozess der Kapazitation. Es kommt zur Entfernung der schützenden Proteinschicht (Dekapazitationsfaktoren), was die Zellmembran zugänglich für die lipidbindenden Proteine des Eileiters macht. Diese bewirken einen Cholesterinefflux. Kalzium-Ionen strömen durch aktivierte lonenkanäle in die Zelle. Es kommt zur Phosphorylierung von Proteinen und zu einer Destabilisierung der Zellmembran und Erschöpfung des Spermiums. Unterstützt wird die Kapazitation durch eine Hyperaktivierung der Spermien, um der Eizelle entgegen zu schwimmen (TÖPfER-PETERSEN, 2007). Nach MORTIMER UND MORTIMER (1990) ist die Kopfbewegung des Spermiums abhängig von der Krümmung und dem Bewegungsmuster des Flagellums. Die Arbeitsgruppe untersuchte das Bewegungsmuster humaner kapazitierter Spermien und stellte einen Anstieg der Werte VCL und ALH in Kombination mit einem Abfall der Linearität als einen Indikator für eine Hyperaktivierung der Spermien fest. Andere Arbeitsgruppen machten sich diesen Indikator zur Nutze und bestätigten eine Hyperaktivierung mit Abfall der LIN und Anstieg der Werte VCL und ALH (MARQUEZ Und SuAREZ, 2007; KaTHIRAVAN ET AL., 2011). Verbunden mit dem Abfall der LIN der Spermien aus dem Nanostraw ist in dieser Arbeit ein erhöhter VCL-Wert sowie eine Erhöhung des ALH-Wertes zu sehen. Dieses könnte für eine frühzeitige Kapazitation der Spermien nach drei Stunden auf dem Thermoblock und somit für eine verfrühte Hyperaktivierung der Spermien sprechen. So sind vermutlich die Spermien durch den Prozess der Kryokonservierung geschädigt worden und beginnen daher teilweise innerhalb von drei Stunden mit der Kapazitation gefolgt von einer Akrosomreaktion. Nach sechs Stunden kommt es wieder zu einem Anstieg der Linearität. Übrig geblieben sind vermutlich die Spermien, die den Einfrierprozess ohne Schäden an der Kopfkappe überstanden haben und nun durch normale physiologische Belastungen ihre Motilität bzw. ihre Kopfkappe verlieren. Dafür spricht der Wert des Anteils membranintakter Spermien des Bullen B, der nach drei Stunden 9\% verliert, wohingegen der Anteil PI-negativer Spermien nach sechs Stunden sich nur 
noch um 2,5\% verringert. Der Anteil membranintakter Spermien aus dem Kontrollstraw verringert sich beim Bullen A um 2\% und beim Bullen B um 0,9\% nach drei Stunden auf dem Wärmeblock. Dies stellt ebenso einen möglichen Beweis für die starken Belastungen der Kryokonservierung im Nanostraw und die möglicherweise verfrühte Kapazitation dar.

Nach RATH ET AL. (2009) sollten die gesamtmorphologischen Veränderungen direkt nach dem Auftauen unter 20\% liegen. Die Spermien des Bullen A entsprechen diesen Qualitätsanforderungen unmittelbar nach dem Auftauen aus dem Nanostraw mit 18\% Veränderungen sowie aus der Kontrolle mit 17\% morphologischen Veränderungen. Nach sechs Stunden auf dem $37^{\circ} \mathrm{C}$ Wärmeblock fällt der Anteil morphologisch veränderter Spermien nicht unter 30\%. Der Bulle B liegt mit 23\% morphologischen Veränderungen der Spermien aus dem Nanostraw über dem Grenzwert von 20\% (RATH ET AL. 2009). Nach sechs Stunden wiesen die Spermien aus dem Nanostraw zu 35\% morphologische Veränderungen auf. Die Spermien der Kontrolle erfüllen jedoch die Anforderungen der Spermaqualitätsparameter. Im Anteil akrosomintakter Spermien lagen beide Bullen über den geforderten $10 \%$ sowohl beim Nanostraw als auch bei der Kontrolle. Hierbei ist aufzuführen, dass der Bulle A bessere Qualitätsparameter in der Morphologie vor dem Einfrieren als Bulle B aufwies. Insgesamt bestätigen diese Ergebnisse die Vermutung einer verfrühten Kapazitation der Spermien aus dem Nanostraw.

Während des Einfrierens und Auftauens entstehen freie Sauerstoffradikale (ROS). Bei einem Überschuss dieser Radikale kommt es zu Lipidoxidationen an der Zellmembran der Spermien. Die Folge sind morphologische Veränderungen sowie eine reduzierte Motilität der Spermien (SIKKA, 1996; BILODEAU ET AL., 2000; BUCAK ET AL., 2010). Um dies zu verhindern, wurde in den eigenen Versuchen dem Verdünnungsmedium das Antioxidans Katalase zugegeben. Antioxidantien wirken als Radikalfänger für die ROS und schützen die Spermien vor morphologischen Veränderungen. Bei Radikalen handelt es sich um Moleküle mit ungepaarten Elektronen, die sich beispielsweise aus Wasserstoffperoxid bilden können (WHITE, 1993). Da ungepaarte Elektronen quantenchemisch ungünstig sind, sind diese Substanzen hochreaktiv. Folglich können Radikale 
wichtige DNA-, Protein- und Kohlenhydratstrukturen verändern. Das bei der Lipidoxidation entstehende Wasserstoffperoxid wird dabei in Sauerstoff und Wasser umgesetzt und auf diese Weise eine Radikalbildung vermieden. Die Zugabe von Katalase verbessert die Motilität und die Membranintegrität der Spermien nach dem Auftauen (WHITE, 1993). Um die Qualitätsparameter aus dem Nanostraw weiter zu optimieren, besteht die Möglichkeit, den Anteil an Antioxidantien oder ähnlichen Zusätzen im Verdünnungsmedium zu erhöhen bzw. zu verändern. Eine Möglichkeit wäre das Antioxidans Licopen, das zur Klasse der Karotinoide gehört. Karotinoide sind eine bedeutende Gruppe von natürlichen Antioxidantien (KRINSKY, 1989). MANGIAGALLI ET AL. (2007) setzten zur Verbesserung der Haltbarkeit von Geflügelsperma $500 \mu \mathrm{g}$ Licopen/ml dem Verdünnungsmedium zu. Die Ergebnisse zeigten eine erhöhte Lebensfähigkeit nach 6 - bis 24 -stündiger Lagerung der Spermien im Wasserbad bei $14^{\circ} \mathrm{C}$. Eine weitere Möglichkeit, die Spermaqualitätsparameter nach dem Einfrieren zu verbessern, ist die Zugabe von VitaminB 12 zum Verdünnungsmedium. In einer Studie konnte die Arbeitsgruppe HU ET AL. (2011) zeigen, dass eine Zugabe von 2,50 mg/ml Vitamin B12 zum Verdünner die Motilität, die Membranintegrität und den Anteil akrosomintakter Spermien signifikant verbessern kann. Sie kamen zu dem Ergebnis, dass Vitamin $B_{12}$ den oxidativen Stress, der durch das Einfrieren verursacht wird, vermindert und die Lebensfähigkeit der Spermien verbessert.

\subsubsection{Beurteilung Nanostraw}

Der Strawtyp wirkt sich während des gesamten Thermoresistenztests signifikant $(p \leq 0,001)$ auf den Anteil motiler, progressiver, membranintakter und den Anteil morphologisch und akrosomintakter Spermien aus. Dieses Ergebnis bestätigt den signifikanten Unterschied zwischen den Qualitätsparametern aus dem Nanostraw und der Kontrolle über den gesamten Zeitraum. Jedoch entsprechen die Ergebnisse der Motilität und Morphologie des Nanostraws den Qualitätsanforderungen einer künstlichen Besamungsportion nach RATH ET AL. (2009). Der Anteil motiler Spermien liegt bei beiden Bullen nach drei Stunden Inkubation bei $37^{\circ} \mathrm{C}$ über $30 \%$. Gleiches gilt für den Anteil morphologisch veränderter Spermien, der bei beiden Bullen nach dem Auftauen weniger als $20 \%$ betrug. 
Nach CURRY (2000) überleben trotz eines guten Einfrierprotokolls nur 50\% der kryokonservierten Spermien nach dem Auftauen. In der vorliegenden Arbeit überlebte mehr als die Hälfte der kryokonservierten Spermien aus dem Nanostraw. Eine übliche Besamungsportion enthält $15 \times 10^{6}$ Spermien pro Straw im Gegensatz zu 0,5 × $10^{6}$ Spermien aus dem Nanostraw. Nach HOLt (2000B) verlieren Spermien, die durch die Kryokonservierung beschädigt wurden, nicht ihre Befruchtungsfähigkeit. Sie sind lediglich nicht mehr in der Lage, die physiologische Passage durch den Uterus zu vollziehen. Veränderungen an den Spermien durch Kryokonservierung sind meist kompensierbar, da häufig nur ihre Vorwärtsbeweglichkeit eingeschränkt ist (BEßELING, 2001). Eine Verkürzung des von den Spermien zurückzulegenden Weges, z.B. durch laparoskopische Besamung, kann nach HOLT (2000B) zu besseren Befruchtungsergebnissen führen. Somit könne auch die Gefahr der Abwehr- und Immunreaktionen des Uterus als Reaktion auf kapazitierte Spermien umgangen werden (ZERBE ET AL., 2003). Umso wichtiger ist daher eine möglichst nahe Übertragung der Spermien an den Ort der Befruchtung zum richtigen Besamungszeitpunkt.

Insgesamt erfüllten die Spermien aus dem Nanostraw die Mindestanforderungen an die Spermaqualität. Bei einer Weiterentwicklung des Nanostraws sollte die bereits erwähnte Abfüllung automatisiert werden, um Temperaturschwankungen zu vermeiden.

Im Anteil motiler, progressiver und membranintakter Spermien ist ein signifikanter Effekt $(p \leq 0,05)$ des Bullen im Thermoresistenztest zu erkennen. Somit scheinen nicht alle Bullen für die Tiefgefrierung in kleinen Volumina geeignet zu sein. Dabei ist jedoch darauf hinzuweisen, dass die Qualitätsparameter des Bullen B nicht als schlecht für die Besamung anzusehen sind. Eine Erhöhung der Spermien pro Paillette könnte hierbei die Spermamängel hinsichtlich der Motilität und der Membranintegrität in vivo kompensieren (BEßELING, 2001). Dabei ist darauf hinzuweisen, dass die auch bei der Kryokonservierung in den handelsüblichen Pailletten nicht alle Bullen TG-tauglich sind (KATHIRAVAN ET AL., 2011). 


\subsection{Einsatz von Sperma aus Nanostraws für SIFT ${ }^{\circledR}$}

\subsubsection{Versuch 3: Besamungsversuch SIFT ${ }^{\circledR}$ - Frischsamen (gesext)}

Die mit dem CASA-System ausgewerteten Daten ermöglichen eine Einschätzung der Bewegungsfähigkeit der Spermien. Das CASA übermittelt eine Vielzahl von Qualitätsparametern. Inwieweit diese eine Aussage über die potentielle Befruchtungskompetenz erlauben, ist jedoch nicht bekannt. Nach JANUSKAUSKAS ET AL. (2001) und CONTRI ET AL. (2010) ist der prozentuale Anteil motiler Spermien der am aussagekräftigste Parameter. Sämtliche im Versuch verwendeten Ejakulate wurden daher unmittelbar vor der Besamung erneut unter dem Mikroskop subjektiv auf ihren Anteil motiler Spermien hin untersucht.

In einem ersten Versuchsabschnitt wurden 16 Färsen, nach vorheriger hormoneller Brunstinduktion, mit Frischsperma der zwei leistungsgeprüften Bullen besamt. Die Ergebnisse zeigten, dass ein Fruchtbarkeitsunterschied zwischen den verwendeten Bullen bestand. Bulle $\mathrm{C}$ erzielte eine Trächtigkeitsrate von $57 \%$, Bulle D eine von 22\%. Dieses Ergebnis bestätigte Untersuchungen andere Autoren, die einen starken Einfluss des Bullen auf den Trächtigkeitserfolg bei sortiertem Sperma sehen (SEIDEL AND SCHENK, 2008; DeJARnetTe et AL., 2008). MÖNCH-TEGEDER (2011) konnte im Gegensatz dazu keinen signifikanten Fruchtbarkeitsunterschied durch den Einsatz von geschlechtsdifferenziertem Sperma vier geprüfter Bullen sehen. Er begründete dies durch die in seinem Versuch eingesetzten Bullen, die zuvor auf ihre Fruchtbarkeit geprüft wurden und einer strengen Vorauswahl aufgrund spermatologischer Untersuchungen unterlagen. FRIJTERS ET AL. (2009) stellten fest, dass die Bullen sich nicht nur unterschiedlich sortieren lassen, sondern eine Verringerung der Besamungsportion einen bullenindividuellen Effekt nach sich ziehen kann und somit kleinere Besamungsportionen die Trächtigkeitsrate negativ beeinflussen. Die Verwendung von fruchtbaren Bullen, die sich zudem noch gut sortieren lassen, ist daher Voraussetzung für gute Trächtigkeitsraten (FRIJTERS ET AL., 2009). Für den SIFT ${ }^{\circledR}$ Versuch wurden daher zwei leistungsgeprüfte Bullen verwendet. Entsprach ein Ejakulat jedoch nicht den Mindestanforderungen nach RATH ET AL. (2009), so wurde es nicht für die Übertragung in den Eileiter verwendet. 
Insgesamt zehn Kühe wurden zusätzlich mit gesextem Sperma des Bullen D mittels SIFT ${ }^{\circledR}$ besamt. Es wurde eine Trächtigkeitsrate von 33\% erzielt. Dabei zeigte die Verwendung der unterschiedlichen Besamungsdosen einen Effekt auf die Fruchtbarkeit. Die Hälfte der Tiere wurde mit 500.000 Samenzellen pro Portion tragend und $16 \%$ der Tiere mit 250.000 Samenzellen. Dies spricht für die Aussage von FRIJTERS ET AL. (2009), die den Einfluss der Größe der Besamungsportion als bullenabhängig und fruchtbarkeitsrelevant ansahen. Auch wenn reduzierte Spermienzahlen nicht zwangsläufig zu schlechteren Besamungsportionen führen, wird bei einigen Autoren ein dosisabhängiger Fruchtbarkeitserfolg beschrieben (ANDERSSON ET AL., 2004). Die besseren Trächtigkeitsergebnisse mit einer höheren Besamungsdosis sprechen zudem für kompensierbare Schädigungen an den Spermien durch den Sortiervorgang. Gegen nicht kompensierbare Spermamängel an geschlechtsdifferenziertem Sperma spricht zudem eine Arbeit von KLINC (2005). In seinen Untersuchungen waren die Trächtigkeitsraten zwischen der Kontrollgruppe, die mit konventionellem Sperma besamt wurde, und der Gruppe, die gesexte Besamungsdosen erhielten, vergleichbar (KLINC, 2005).

In beiden Besamungsversuchen wurden nur geringe Tierzahlen verwendet. Der bullen- und dosisabhängige Effekt ist daher nicht statistisch zu untermauern. Ein Trend lässt sich jedoch damit aufzeigen. Alle tragenden Tiere hatten 24 Stunden nach der Übertragung der Spermien in den Eileiter ovuliert. Die Überlebensfähigkeit der Eizelle beträgt 6-7 Stunden. Da Alterungsvorgänge der Eizelle eine erhöhte embryonale Mortalität zur Folge haben, sollten die Spermien daher auf die Eizelle „warten“. Eine befruchtungsfähige Spermienpopulation hat sich jedoch erst 6-7 Stunden nach künstlicher Besamung im Eileiter etabliert (SAACKE ET AL., 2000; SAACKE, 2008). Durch die Übertragung der Spermien in den Eileiter durch SIFT $^{\circledR}$ verringert sich der Weg der Spermien. Sie gelangen direkt in das Spermienreservoir und können sich auf die Akrosomreaktion und somit die Penetration der Eizelle vorbereiten. Nach Untersuchungen von SAACKE ET AL. (2000) führten konventionelle Besamungen zu Beginn der Brunst bzw. Duldung zu geringen Trächtigkeitsraten. Die Embryonen sind dabei jedoch als qualitativ gut einzustufen, da die Spermien bei Eintreffen der Eizelle bereits im Spermienreservoir gereift sind und sofort für die Befruchtung bereit stehen. 
Die Besamung muss durch die Methode SIFT ${ }^{\circledR}$ vermutlich später als bei einer künstlichen Besamung in den Uterus erfolgen. Somit wird die Wahrscheinlichkeit erhöht, dass sich möglichst viele vitale Spermien im Eileiter befinden und die Eizelle kurz nach ihrem Eintreffen im Eileiter befruchtet wird. Eine Besamung zum Zeitpunkt der Ovulation wäre dabei von Vorteil.

Die geringen Trächtigkeitsraten von 33\% lassen sich möglicherweise durch die vorherige Nutzung der Tiere in anderen reproduktionsbiotechnischen Versuchen begründen. Fast alle Kühe wurden zuvor mehrfach für OPU oder Embryospülungen genutzt. Die Tiere wurden hierfür hormonell behandelt. Aufgrund der mehrfachen Nutzung und dem Einsatz von Hormonpräparaten kann es zu Zyklusstörungen kommen, die den späteren Fruchtbarkeitserfolg negativ beeinflussen.

\subsubsection{Versuch 4: Besamungsversuch SIFT ${ }^{\circledR}$ TG- Sperma}

Nach SIFT ${ }^{\circledR}$ mit TG-Sperma des Bullen A wurden $40 \%$ der fünf besamten Färsen tragend. TG-Sperma des Bullen B wurde nur für die Besamung eines Tieres verwendet. Die durchschnittliche Trächtigkeitsrate bei Kühen betrug für beide Bullen $33 \%$.

Wie bereits in dem Frischsamenversuch festgestellt, wurden nur die Tiere tragend, die nach 24 Stunden ovuliert hatten. Die Besamung erfolgte mindestens 24 Stunden nachdem die Techniker vor Ort anhand der Brunstanzeichen diese als „brünstig“ eingestuft hatten, um die Insemination möglichst nah an dem Ovulationspunkt auszurichten. Die Befruchtungsfähigkeit der Spermien aus dem Nanostraw wurde anhand der Trächtigkeiten bestätigt. Es konnte kein bullenindividueller Effekt gezeigt werden. Dies widerspricht den Ergebnissen von GROSSFELD ET AL. (2011B), die bei 103 Milchkühen Sperma in den Eileiter übertrugen und von einem starken Einfluss des Bullen auf den Trächtigkeitserfolg berichteten.

Bulle A zeigte einen um 8\% höheren Trächtigkeitserfolg beim Vergleich der konventionellen Besamung mit SIFT ${ }^{\circledR}$. Bulle $\mathrm{B}$ führte bei Verwendung von $\mathrm{SIFT}^{\circledR}$ 
und somit bei einer Volumen- und Mengenreduzierung zu knapp 20\% schlechteren Fertilitätsraten im Vergleich zur konventionellen Besamung. Dies bestätigt auch hier die Aussage mehrerer Autoren, die von einem dosisabhängigen und bullenabhängigen Befruchtungserfolg, sprechen (ANDERSSON ET AL., 2004; FRIJTERS ET AL., 2009).

Für die Besamung der Tiere wurden jeweils zwei Nanostraws gepoolt. Ziel war es, Spermamängel zu kompensieren, die möglicherweise durch den Kryokonservierungsprozess auftraten. Empirisch wurde dies jedoch nicht festgestellt. Kompensierbare Schädigungen der Spermien können durch die direkte Übertragung der Spermien in den Eileiter mittels SIFT ${ }^{\circledR}$ umgangen werden. Pro Besamungsportion wurden in diesem Versuch ca. 1 Mio. Spermien übertragen. Für spätere Versuche sollte die Besamungsdosis auf 1,5 Mio. Spermien leicht erhöht werden, um kompensierbare Schädigungen der Spermien bedingt durch die Kryokonservierung auszuschließen.

\subsection{Abschließende Beurteilung SIFT ${ }^{\circledR}$}

Für den effektiven Einsatz von Spitzengenetik ist der Einsatz einer reduzierten Spermienzahl interessant (DEN DAAS ET AL., 1998). Durch die neu entwickelte Methode $\mathrm{SIFT}^{\circledR}$ lassen sich die Besamungsportionen ohne Einbußen im Besamungserfolg durchschnittlich auf 1 Mio. oder weniger Samenzellen pro Portion minimieren (GROSSFELD ET AL., 2011B). Die Qualitätsparameter der Spermien aus dem Nanostraw entsprachen den Mindestanforderungen von RATH ET AL. (2009). Im Anteil motiler, progressiver und membranintakter Spermien war ein signifikanter Effekt $(p \leq 0,05)$ des Bullen im Thermoresistenztest zu erkennen. Somit scheinen nicht alle Bullen für die Tiefgefrierung in kleinen Volumina geeignet zu sein. Für den Einsatz des Nanostraws in der Praxis wäre daher ein vorangehender Test der Bullen auf die Kryokonservierbarkeit im Nanostraw unerlässlich. Eine statistische Analyse des Befruchtungspotentials der Spermien in Korrelation zu den erhobenen Daten im Labor war aufgrund der kleinen Tierzahl in dieser Arbeit nicht möglich. Viele Autoren sehen die Motilität (FARRELL ET AL., 1998; JAnUSKauskas ET AL., 2001), andere die Morphologie (PhiLliPS ET AL., 
2004) oder die Membranintegrität (CHRISTENSEN ET AL., 2005) als wichtigen Laborparameter zur Vorhersehbarkeit der Befruchtungsfähigkeit des Ejakulates. Die Befruchtungsfähigkeit der kryokonservierten Spermien aus dem Nanostraw konnte anhand der positiven Trächtigkeiten bestätigt werden. Um die Fertilität der Spermien aus dem Nanostraw in vivo statistisch zu belegen, sollte ein groß angelegter Feldversuch folgen. Dieser könnte in Zusammenarbeit mit einer Besamungsstation erfolgen. Auf einem großen Milchviehbetrieb mit mindestens 2000 Kühen in Laktation sollte jede zweite Kuh aus erster und zweiter Laktation, die zur Besamung ansteht, mit SIFT ${ }^{\circledR}$-Nanostrawspermien übertragen werden. Die anderen Tiere aus erster und zweiter Laktation könnten als Kontrollgruppe dienen. Ein einheitliches Fütterungsmanagement ist hierbei Voraussetzung. Auch das Personal sollte für die Durchführung der Besamung nicht wechseln.

Weitere Untersuchungen bezüglich des optimalen Besamungszeitpunktes bei Verwendung der Besamungsmethode $\mathrm{SIFT}^{\circledR}$ sind unabdingbar. Die Ergebnisse dieser Arbeit haben gezeigt, dass die Übertragung der Spermien möglichst nah am Ovulationspunkt mit minimalen Spermaportionen erfolgreich ist. Wie bereits erwähnt, sollten jedoch die Abfüllung und Handhabung des Nanostraws optimiert und automatisiert werden, um sich in der Laborarbeit zu etablieren.

Die neu entwickelte Methode $\mathrm{SIFT}^{\circledR}$ stellt eine revolutionäre Entwicklung in der Rinderzucht dar. Die Besamungsportionen können um bis zu $90 \%$ reduziert und Jungbullen sowie geschlechtsdifferenziertes Sperma kann effizient eingesetzt werden. Mit dem Nanostraw lassen sich die Spermienzahlen in tiefgefrorenen Besamungsportionen ohne Einbußen im Besamungserfolg deutlich reduzieren und nach den Qualitätsanforderungen für eine Besamungsportion nach RATH ET AL. (2009) kryokonservieren. 


\section{$6 \quad$ Zusammenfassung}

Bislang wurden Bullen in der Milchrinderzucht anhand des Töchterleistungsvergleiches bewertet, was zur Folge hatte, dass die Zuchtwertschätzung erst nach fünf Jahren vorlag (REENTS UND REINHARDT, 2007). Durch die 2010 eingeführte genomische Zuchtwertschätzung werden Bullenkälber bereits in den ersten Lebensmonaten geprüft und die erfolgreichen Bullen ab einem Alter von 12 Monaten zur Spermaproduktion von den Besamungsstationen eingesetzt. Zu bedenken ist dabei, dass Jungbullen unter 2 Jahren lediglich ein durchschnittliches Ejakulatvolumen von 2-4 $\mathrm{ml}$ aufweisen und die Spermienkonzentration deutlich unter der von Altbullen liegt. Es müssen daher entweder mehr Jungbullen zum Einsatz kommen oder die Besamungsportionen müssen in ihrer Spermienkonzentration reduziert werden. Eine am Institut für Nutztiergenetik Mariensee entwickelte Methode, der Sperm-Intra-Fallopian-Transfer (SIFT ${ }^{\circledR}$ ), ermöglicht es, minimal dosierte Spermaportionen unchirurgisch in den Eileiter zu übertragen (GROSSFELD ET AL., 2011B). Ein wesentlicher Vorteil dieser Methode ist die Reduzierung des Besamungsvolumens unter Beibehaltung des Volumen/Mengenverhältnisses.

Zielsetzung dieser Arbeit war es, eine in Volumen und Spermienzahl reduzierte Spermaportion neu zu konfektionieren und ein angepasstes Kühl- sowie Gefrierprotokoll zu entwickeln. Hierbei sollten vergleichbare Auftauqualitäten wie in einer üblichen Besamungsportion erreicht werden. Die Qualität des Spermas wurde dabei sowohl unter Laborbedingungen als auch in Testbesamungen an zufällig ausgewählten Färsen und Kühen evaluiert.

In ersten Screeningversuchen wurde zunächst ein Tiefgefrierverfahren für gering dosierte Verpackungssysteme (Nanostraw) mit einem Volumen bis $50 \mu \mathrm{l}$ entwickelt. Dabei sollten vergleichbare Auftauqualitäten üblicher Besamungsportionen erreicht werden. Es wurden sechs verschiedene Kühlkurven (A-D, D+ und E) entwickelt. Dabei zeigte sich, dass aufgrund der Stickstoffvolumeneinströme ein Haltepunkt bei $-8^{\circ} \mathrm{C}$ in keiner der Einfrierkurven für kleine Volumina zu etablieren war. Dies ist u.a. auf die bauartbedingten Vorgaben des verwendeten Einfrierautomaten zurückzuführen. Ebenso wurde der Zusatz von 
7,5\% Glyzerin im Verdünner bei dem Gefrierprotokoll D+ aufgrund der Datenlage des Vorversuchs für den Hauptversuch verworfen. Die Proben wurden bullenindividuell erhoben, zur besseren statistischen Absicherung jedoch für die Auswertung zusammengefasst. Aus den Screeningversuchen erschien das Kryokonservierungsprotokoll $D+$ für den Nanostraw unter Laborbedingungen am geeignetsten und wurde im Thermoresistenztest, der den Bedingungen im Hinblick auf die Temperatur im Uterus bzw. Eileiter ähnlich ist, getestet. Weiterhin fand ein Vergleich der spermatologischen Qualitätsparameter nach dem Auftauen zwischen der Kontroll- und der Nanostrawgruppe mit der Kühlkurve D+ im Thermoresistenztest statt.

Im praktischen Teil der Arbeit wurde die Methode SIFT ${ }^{\circledR}$ zunächst anhand eines Versuchs mit geschlechtsdifferenziertem Frischsamen praktiziert. Dabei wurden 20 Färsen mittelseiner Prid ${ }^{\circledR} \alpha 1,55 \mathrm{~g}$ Progesteron-Spirale und zehn Kühe mit einem Ovsynch Programm synchronisiert. In einem weiteren Besamungsversuch konnte das Sperma aus den Nanostraws verwendet werden, das vorher kryokonserviert worden ist. Es wurden nur spontan brünstige Färsen und Kühe in den Eileiter besamt.

Die Untersuchungen führten zu folgenden Ergebnissen:

1) In den Screeningversuchen zeigte sich, dass der Anteil motiler Spermien signifikant $(p \leq 0,05)$ abhängig von der Gefriergeschwindigkeit der Kühlkurve war. Der höchste Anteil motiler Spermien aus dem Nanostraw war in Kühlkurve D+ mit einem Anteil von 52,9\% zu verzeichnen. Eine signifikante Zunahme des Anteils membranintakter Spermien von Kurve $A$ zu B und D zu D+ war zu beobachten. Die Hälfte der Nanostrawspermien zeigten in der Kühlkurve D+ eine intakte Membranintegrität. Die Kontrollspermien lagen bei 56,9\%. In Kurve D+ zeigten $66,6 \%$ der Spermien aus dem Nanostraw keine morphologischen Veränderungen, in der Kontrollgruppe waren dies 75,4\%. Die Änderung der Glyzerinkonzentration im Verdünnungsmedium zeigte keine signifikante Verbesserung der Spermaqualitätsparameter nach dem Auftauen.

2) Im Thermoresistenztest erreichten die Spermien aus dem Nanostraw in allen gemessenen Parametern die Mindestanforderungen an die Spermaquali- 
tät nach Rath et al. (2009). So belief sich der Anteil membranintakter Spermien aus dem Nanostraw nach dreistündiger Inkubation bei $37^{\circ} \mathrm{C}$ auf $56,4 \%$, die Kontrollstrawspermien lagen bei einem Anteil von 67,2\%. Dabei zeigte der Faktor Bulle einen signifikanten Effekt $(p \leq 0,01)$ auf den Anteil motiler und progressiver Spermien sowie den Anteil PI-negativer Spermien. Mögliche Effekte des Bullen auf die Qualität und Befruchtungsfähigkeit der Spermien nach dem Auftauen zeigten andere Versuchsanstellungen und Forschungshypothesen (JANUSKAUSKAS ET AL., 1996, KATHIRAVAN ET AL., 2011).

3) In dem ersten Besamungsversuch wurden 20 Färsen und zehn Kühen geschlechtsdifferenziertes Sperma mit der Methode $\mathrm{SIFT}^{\circledR}$ in den Eileiter übertragen. 37,5\% der Färsen und 33\% der Kühe wurden tragend. Dabei konnte ein bullenindividueller dosisabhängiger Effekt festgestellt werden. 50\% der Kühe, die mit 500.000 Samenzellen inseminiert wurden und 16\% der Kühe, die mit 250.000 Samenzellen besamt wurden, wurden tragend.

4) Im Besamungsversuch mit dem kryokonservierten Sperma aus dem Nanostraw wurden sechs spontan brünstige Rinder mittels SIFT ${ }^{\circledR}$-Spermien in den Eileiter übertragen. Alle Tiere wurden als Kälber für die Follikelpunktion in einem anderen Versuch verwendet. Fünf Tiere wurden mit dem Bullen A besamt. 40\% der Tiere wurden tragend. Lediglich ein Tier wurde mit dem Bullen $B$ besamt. Das Trächtigkeitsergebnis war negativ. Die Kühe wurden mit dem Bullen $A$ besamt, dieser erzielte eine Trächtigkeitsrate von $33 \%$. 


\section{$7 \quad$ Summary}

To date in dairy cow breeding, bulls have been assessed by offspring performance, which resulted in estimated breeding values only after five years (REENTS AND REINHARDT, 2007). By introducing the so called genomic breeding value established in 2010, bull calves are now tested within their first months of living and successful bulls can be used for semen production at Al centres from 12 months of age on. It has to be considered that pubertal bulls only have an average ejaculate volume of $2-4 \mathrm{ml}$ and that the sperm concentration is much lower than in adult bulls. Therefore either more pubertal bulls need to be collected for semen or the concentration in Al portions needs to be reduced. A method established at the Institute of Farm animal Genetics in Mariensee, Germany, Sperm-Intra-Fallopian-Tube $\left(\mathrm{SIFT}^{\circledR}\right)$ enables us to transfer minimal sperm dosages non-surgically into the oviduct (GROSSFELD ET AL., 2011B). A crucial part of this method is the reduction of the insemination volume perpetuating the volume: quantity ratio.

The aim of this study was to develop a new method for packaging a volume and sperm number reduced insemination portion and to establish an adapted cooling and deep freezing protocol. Comparable thawing quality to conventional insemination portions was to be gained. The sperm quality was assessed under laboratory as well as under field conditions in test inseminations with randomly assigned heifers and cows.

A deep freezing procedure for low dosage confection systems (Nanostraw) with a volume of up to $50 \mu \mathrm{l}$ was established in initial screening tests. Comparable thawing qualities to conventional insemination portions should be accomplished. Six different freezing curves (A-D, D+ und E) were developed. Thereby was shown that due to the nitrogen influx into the cooling chamber, a holding point at $-8^{\circ} \mathrm{C}$ could not be established in any of the curves. This may arise from the construction of the applied automatic freezer. Further the addition of $7.5 \%$ glycerol to the extender, using protocol $\mathrm{D}+$, was dismissed in the main trial due to the data generated in the pretest. Samples were analyzed individually, but were pooled for better statistical support. From the results of the screening test the 
protocol D+ appeared as suitable under laboratory conditions and was tested with the thermo tolerance test, which simulates the temperature in the uterus or the oviduct, respectively. The spermatological quality parameters between the control and the Nanostraw group were analyzed after cryopreservation with the protocol D+ and thawing.

For the practical part of the study, the SIFT ${ }^{\circledR}$ method was implemented with fresh sexed semen. Twenty heifers were synchronized for ovulation using a Prid $^{\circledR} \alpha 1,55 \mathrm{~g}$ Progesterone spiral and ten cows using an ovsynch program, respectively. In a further trial the semen from cryopreserved and thawed Nanostraws was used. Only spontaneous ovulating heifers and cows were inseminated into the fallopian tube.

In summary the investigations lead to the following results:

1) The screening trials showed that the fraction of motile spermatozoa significantly $(p \leq 0.05)$ depended on the freezing speed of the respective protocol. The highest fraction of motile sperm (52.9\%) from the Nanostraw was gained from cooling curve $\mathrm{D}+$. A significant increase in membrane integrity could be seen between curve $A$ and $B$ as well as curve $D$ to $D+.50 \%$ of the Nanostraw sperm showed intact membranes after freezing with curve $D+$. The control group featured $56.9 \%$ membrane intact sperm. $66.6 \%$ of the Nanostraw sperm frozen with protocol $\mathrm{D}+$ showed no morphological changes. The control group showed $75.4 \%$ morphological intact spermatozoa. The modification of the glycerol concentration in the extender showed no significant improvement of the sperm vitality parameters after thawing.

2) In the thermo tolerance test all sperm from the Nanostraw reached the minimum standards for all measured parameters defined by Rath et al (2009). Thus the fraction of membrane intact sperm added up to $56.4 \%$ for the Nanostraw after three hours of incubation at $37^{\circ} \mathrm{C}$ and $67.2 \%$ for the control straw, respectively. Hereby the factor "bull" had a significant effect $(p \leq 0.01)$ on motility and progressiveness as well as the number of PI negative sperm. Putative effects of the bull on quality and fertility after thawing were shown in other trials and research hypotheses (JANUSKAUSKAS ET AL., 1996; KATHIRAVAN ET AL., 2011). 
3) In the first insemination trial sexed semen was deposited by SIFT ${ }^{\circledR}$ method into the oviduct of 20 heifers and ten cows. $37.7 \%$ of the heifers and $33 \%$ of the cows became gravid. A bull dependent, dose response effect was identified. $50 \%$ of the cows, which were inseminated with 500,000 spermatozoa and $16 \%$ of the cows, inseminated with 250,000 spermatozoa respectively, were fertilized.

4) In the insemination trial with cryopreserved semen, six spontaneously ovulating cows were inseminated by $\mathrm{SIFT}^{\circledR}$ into the oviduct with semen from the Nanostraw. All animals had been used in trials for ovum collection by OPU technique beforehand. Five animals were inseminated with semen from bull $A$. Only one animal was inseminated with bull $B$ and did not become gravid. The group of animals inseminated with bull A yielded in a pregnancy rate of $33 \%$. 


\section{$8 \quad$ Literaturverzeichnis}

AAMDAL, J., LYNGSET, O. \& FILSETH, O. (1969):

Insemination experiment with a new type of insemination equipment for straws. Anim. Breed. Abstr. 37:56

ADLER, H. C., JESPERSEN, C., MEDING, J. H. \& RASBECH, N. O. (1968): Fertilising efficiency of bull semen frozen in straws or in pellet form.

Anim. Breed. Abstr., 36:229

AITKEN, R. J. (1995):

Free radicals, lipid peroxidation and sperm function.

Reprod. Fertil. Dev. 7, 659-668

AITKEN, R. J., CLARKSON, J. S. \& FISHEL, S. (1989):

Generation of reactive oxygen species, lipid peroxidation, and human sperm function.

Biol. Reprod. 41, 183-197

AITKEN, R. J., IRVINE, D. S. \& WU, F. C. (1991):

Prospective analysis of sperm-oocyte fusion and reactive oxygen species generation as criteria for the diagnosis of infertility.

Am. J. Obstet. Gynecol. 164, 542-551

ALMQUIST, J. O. \& WIGGIN, H. B. (1973):

Survival of bull spermatozoa frozen and thawed by different methods in plastic straws.

A.I. Digest. 21, 12

AMBROGI DE, M., SPINACI, M., GALEATI, G. \& TAMANINI, C. (2006):

Viability and DNA fragmentation in differently sorted boar spermatozoa.

Theriogenology 66, 1994-2000

ANDERSSON, M., TAPONEN, J., KOSKINEN, E. \& DAHLBOM, M. (2004):

Effect of insemination with doses of 2 or 15 million frozen-thawed spermatozoa and semen deposition site on pregnancy rate in dairy cows.

Theriogenology 61, 1583-1588

ANDRABI, S. M. (2009):

Factors affecting the quality of cryopreserved buffalo (Bubalus bubalis) bull spermatozoa.

Reprod. Domest. Anim. 44, 552-569

AUSTIN, C. R. (1951):

Observation of the penetration of sperm into the mammalian egg.

Aust. J. Sci. Res 4, 581-596

AUSTIN, C. R. (1960):

Capacitation and the release of hyaluronidase from spermatozoa.

J. Reprod. Fertil. 3, 310-311 
BAILEY, J. L., BILODEAU, J. F. \& CORMIER, N. (2000):

Semen cryopreservation in domestic animals: a damaging and capacitating phenomenon.

J. Androl. 21, 1-7

BANSAL, A. K. \& BILASPURI, G. S. (2010):

Impacts of oxidative stress and antioxidants on semen functions.

Vet. Med. Int. 686137

BART, A. D., BOWMAN, P. A., BO, G. A. \& MAPLETOFT, R. J. (1992):

Effect of narrow sperm head shape on fertility in cattle.

Can. Vet. J. 33, 31-39

BEDFORD, J. M. (1970):

Sperm capacitation and fertilization in mammals.

Biol. Reprod. 2 (Suppl. 2), 128-158

BEHRENDT, D. M. R. (2009):

Versuche zur Vitrifikation equiner Spermatozoen im Vergleich zur konventionellen Tiefgefrierung mit und ohne Verwendung von Kryoprotektiva.

Dissertation, Tierärztliche Hochschule Hannover

BERGMANN, A. (2010):

Einfluss von verschiedenen Lagertemperaturen und Natriumflourid auf die Lagerungsqualität von gesextem Bullensperma.

Masterarbeit, Fakultät für Agrarwissenschaften, Georg-August-Universität Göttingen

BERRY, D. P., EVANS, R. D. \& MC PARLAND, S. (2011):

Evaluation of bull fertility in dairy and beef cattle using cow field data.

Theriogenology $75,172-181$

BESENFELDER, U. \& BREM, G. (1998):

Tubal transfer of bovine embryos: a simple endoscopic method reducing longterm exposure of in vitro produced embryos.

Theriogenology 50, 739-745

BESENFELDER, U., HAVLICEK, V., KUZMANY, A. \& BREM, G. (2010):

Endoscopic approaches to manage in vitro and in vivo embryo development:

use of the bovine oviduct.

Theriogenology 73, 768-776

BEßELING, M. (2001):

Tiefgefrierung von flowzytometrisch gesextem Ebersperma: Verbesserung der

Tiefgefrierfähigkeit durch Crossflowfiltration.

Dissertation, Tierärztliche Hochschule Hannover

BIELANSKI, A., NADIN-DAVIS, S., SAPP, T. \& LUTZE-WALLACE, C. (2000):

Viral contamination of embryos cryopreserved in liquid nitrogen.

Cryobiology 40, 110-116 
BILODEAU, J. F., CHATTERJEE, S., SIRARD, M. A. \& GAGNON, C. (2000): Levels of antioxidant defenses are decreased in bovine spermatozoa after a cycle of freezing and thawing.

Mol. Reprod. Dev. 55, 282-288

BJÖRKMAN, N. (1959):

The ultrastructural organization and the alkaline Phosphatase activity of the epithelial surface of the bovine fallopian tube.

Z. Zellforsch. 589-596

BRAHMKSHTRI, B. P., EDWIN, M. J., JOHN, M. C., NAINAR, A. M. \& KRISHNAN, A. R. (1999):

Relative efficacy of conventional sperm parameters and sperm penetration bioassay to assess bull fertility in vitro.

Anim. Reprod. Sci. 54, 159-168

BREITBART, H. (2003):

Signaling pathways in sperm capacitation and acrosome reaction.

Cell. Mol. Biol. 49, 321-327

BUCAK, M. N., TUNCER, P. B., SARIOZKAN, S., BASPINAR, N., TASPINAR, M., COYAN, K., BILGILI, A., AKALIN, P. P., BUYUKLEBLEBICI, S., AYDOS, S., ILGAZ, S., SUNGUROGLU, A. \& OZTUNA, D. (2010):

Effects of antioxidants on post-thawed bovine sperm and oxidative stress parameters: antioxidants protect DNA integrity against cryodamage.

Cryobiology 61, 248-253

BUSCH, W. (2007):

Insemination. In: Busch, W. und Waberski D. (Hrsg.)

Künstliche Besamung bei Haus- und Nutztieren.

1. Auflage, Schattauer, Stuttgart, 99-106; ISBN:978-3-7945-2410-5

CHANDLER, J. E., ADKINSON, R. W. \& NEBEL, R. L. (1984):

Thawing optimums for bovine spermatozoa processed by three methods and packaged in continental and french straws.

J. Dairy Sci., 67, 398-404

CHRISTENSEN, P., STENVANG, J. P. \& GODFREY, W. L. (2004):

A flow cytometric method for rapid determination of sperm concentration and viability in mammalian and avian semen.

J. Androl. 25, 255-264

CHRISTENSEN, P., BOELLING, D., PEDERSEN, K. M., KORSGAARD, I. R. \& JENSEN, J. (2005):

Relationship between sperm viability as determined by flow cytometry and nonreturn rate of dairy bulls.

J. Androl. 26, 98-106 
CHRISTENSEN, P., LABOURIAU, R., BIRCK, A., BOE-HANSEN, G. B., PEDERSEN, J. \& BORCHERSEN, S. (2011):

Relationship among seminal quality measures and field fertility of young dairy bulls using low-dose inseminations.

J. Dairy Sci. 94, 1744-1754

CONTRI, A., VALORZ, C., FAUSTINI, M., WEGHER, L. \& CARLUCCIO, A. (2010):

Effect of semen preparation on CASA motility results in cryopreserved bull spermatozoa.

Theriogenology $74,424-435$

CRAMER, H., DIRNBERGER, M., ONKEN, F., RÖSSNER, M., SCHÄFER, C. S., WEIDEL, M. \& WUTKE, M. (2009):

Rinderproduktion in Deutschland 2008, Bonn, Arbeitsgemeinschaft Deutscher Rinderzüchter e.V.

CURRY, M. R. (2000):

Cryopreservation of semen from domestic livestock.

Rev. Reprod. 5, 46-52

DEJARNETTE, J. M. \& MARSHALL, C. E. (2005):

Straw-thawing method interacts with sire and extender to influence sperm motility and conception rates of dairy cows.

J. Dairy Sci. 88, 3868-3875

DEJARNETTE, J. M., NEBEL, R. L., MARSHALL, C. E., MORENO, J. F., MCCLEARY, C. R. \& LENZ, R. W. (2008):

Effect of sex-sorted sperm dosage on conception rates in Holstein heifers and lactating cows.

J. Dairy Sci. 91, 1778-1785

DEJARNETTE, J. M., MCCLEARY, C. R., LEACH, M. A., MORENO, J. F., NEBEL, R. L. \& MARSHALL, C. E. (2010):

Effects of 2.1 and $3.5 \times 10^{6}$ sex-sorted sperm dosages on conception rates of Holstein cows and heifers.

J. Dairy Sci. 93, 4079-4085

DEJARNETTE, J. M., LEACH, M. A., NEBEL, R. L., MARSHALL, C. E., MCCLEARY, C. R. \& MORENO, J. F. (2011):

Effects of sex-sorting and sperm dosage on conception rates of Holstein heifers: is comparable fertility of sex-sorted and conventional semen plausible?

J. Dairy Sci. 94, 3477-3483

DEN DAAS, J. H., DE JONG, G., LANSBERGEN, L. M. \& VAN WAGTENDONK-DE LEEUW, A. M. (1998):

The relationship between the number of spermatozoa inseminated and the reproductive efficiency of individual dairy bulls.

J. Dairy Sci. 81, 1714-1723 
DESNOYERS, L. \& MANJUNATH, P. (1992):

Major proteins of bovine seminal plasma exhibit novel interactions with phospholipid.

J. Biol. Chem. 267, 10149-10155

DHAMI, A. J., SAHNI, K. L. \& MOHAN, G. (1992):

Effect of various cooling rates (from 30 degrees to 5 degrees) and thawing temperatures on the deep-freezing of Bos Taurus and Bos Bubalis semen.

Theriogenology $38,565-574$

ELLINGTON, J. E. (1991):

The bovine oviduct and its role in reproduction: a review of the literature.

Cornell. Vet. 81, 313-328

FARRELL, P. B., PRESICCE, G. A., BROCKETT, C. C. \& FOOTE, R. H. (1998): Quantification of bull sperm characteristics measured by computer-assisted sperm analysis (CASA) and the relationship to fertility.

Theriogenology 49, 871-879

FAYRER-HOSKEN, R. A., YOUNIS, A. I., BRACKETT, B. G., MCBRIDE, C. E., HARPER, K. M., KEEFER, C. L. \& CABANISS, D. C. (1989):

Laparoscopic oviductal transfer of in vitro matured and in vitro fertilized bovine oocytes.

Theriogenology $32,413-420$

FAZELI, A., HAGE, W. J., CHENG, F. P., VOORHOUT, W. F., MARKS, A., BEVERS, M. M. \& COLENBRANDER, B. (1997):

Acrosome-intact boar spermatozoa initiate binding to the homologous zona pellucida in vitro.

Biol. Reprod. 56, 430-438

FILSETH, O. (1970):

Conception rates using the French straw.

Anim. Breed. Abstr. 38: 252

FLESCH, F. M. \& GADELLA, B. M. (2000):

Dynamics of the mammalian sperm plasma membrane in the process of fertilization.

Biochem. Biophys. Acta, 197-235

FOOTE, R. H. \& KAPROTH, M. T. (1997):

Sperm numbers inseminated in dairy cattle and nonreturn rates revisited.

J. Dairy Sci. 80, 3072-3076

FOUNTAIN, D., RALSTON, M., HIGGINS, N., GORLIN, J. B., UHL, L., WHEELER, C., ANTIN, J. H., CHURCHILL, W. H. \& BENJAMIN, R. J. (1997): Liquid nitrogen freezers: a potential source of microbial contamination of hematopoietic stem cell components.

Transfusion 37, 585-591 
FRIJTERS, A. C., MULLAART, E., ROELOFS, R. M., VAN HOORNE, R. P., MORENO, J. F., MORENO, O. \& MERTON, J. S. (2009):

What affects fertility of sexed bull semen more, low sperm dosage or the sorting process?

Theriogenology 71, 64-67

GARNER, D. L. (1997):

Ancillary tests of bull semen quality.

Vet. Clin. North Am. Food Anim. Pract. 13, 313-330

GARNER, D. L., JOHNSON, L. A., YUE, S. T., ROTH, B. L. \& HAUGLAND, R. P. (1994):

Dual DNA staining assessment of bovine sperm viability using SYBR-14 and propidium iodide.

J. Androl. 15, 620-629

GARRIDO, N., MESEGUER, M., SIMON, C., PELLICER, A. \& REMOHI, J. (2004):

Pro-oxidative and anti-oxidative imbalance in human semen and its relation with male fertility.

Asian J. Androl. 6, 59-65

GILMORE, J. A., LIU, J., GAO, D. Y. \& CRITSER, J. K. (1997):

Determination of optimal cryoprotectants and procedures for their addition and removal from human spermatozoa.

Hum. Reprod. 12, 112-128

GROSSFELD, R., SIEG, B., STRUCKMANN, C., FRENZEL, A., MAXWELL, W. M. \& RATH, D. (2008):

New aspects of boar semen freezing strategies.

Theriogenology 70, 1225-1233

GROSSFELD, R., HADELER, K., VELAZQUEZ, M. \& RATH, D. (2011a):

Non-surgical, low dosage semen-intra-fallopian-transfer in cattle (SIFT).

In: RODRIGUES-MARTINEZ, H. (ed.)

Conference of the European Society for Domestic Animal Reproduction

(ESDAR), Antalya, Turkey: Wiley-Blackwell

GROSSFELD, R., STROTHMEYER, M. \& RATH, D. (2011b):

Low-dosage sperm-intra-fallopian-transfer (SIFT) in diary cows.

In: RODRIGUEZ-MARTINEZ, H. (ed.) Conference of the European Society for Domestic Animal Reproduction (ESDAR). Antalya, Turkey: Wiley-Blackwell

GWATHMEY, T. M., IGNOTZ, G. G. \& SUAREZ, S. S. (2003):

PDC-109 (BSP-A1/A2) promotes bull sperm binding to oviductal epithelium in vitro and may be involved in forming the oviductal sperm reservoir.

Biol. Reprod. 69, 809-815 
GWATHMEY, T. M., IGNOTZ, G. G., MUELLER, J. L., MANJUNATH, P. \& SUAREZ, S. S. (2006):

Bovine seminal plasma proteins PDC-109, BSP-A3, and BSP-30-kDa share functional roles in storing sperm in the oviduct.

Biol. Reprod. 75, 501-507

HALLAP, T., JAAKMA, U. \& RODRIGUEZ-MARTINEZ, H. (2006):

Changes in semen quality in Estonian Holstein Al bulls at 3,5 and 7 years of age.

Reprod. Domest. Anim. 41, 214-218

HAWK, H. W. (1983):

Sperm survival and transport in the female reproductive tract.

J. Dairy Sci. 66, 2645-2660

HAWK, H. W. (1987):

Transport and fate of spermatozoa after insemination of cattle.

J. Dairy Sci. 70, 1487-1503

HOLT, W. V. (2000a):

Basic aspects of frozen storage of semen.

Anim. Reprod. Sci. 62, 3-22

HOLT, W. V. (2000b):

Fundamental aspects of sperm cryobiology: the importance of species and individual differences.

Theriogenology $53,47-58$

HU, J. H., TIAN, W. Q., ZHAO, X. L., ZAN, L. S., XIN, Y. P. \& LI, Q. W. (2011): The cryoprotective effects of vitamin B12 supplementation on bovine semen quality.

Reprod. Domest. Anim. 46, 66-73

HUNTER, R. H. (2003):

Advances in deep uterine insemination: a fruitful way forward to exploit new sperm technologies in cattle.

Anim. Reprod. Sci. 79, 157-170

HUNTER, R. H. (2010):

Sperm head binding to epithelium of the oviduct isthmus is not an essential preliminary to mammalian fertilization - review.

Zygote, 1-5

ISACHENKO, V. V., ALABART, J. L., ISACHENKO, E. F., BEZUGLY, N. D. \& MICHELMANN, H. W. (2000):

Ultra-rapid freezing and storage of rat embryos in an electric refrigerator at -130 degree $\mathrm{C}$ without liquid cryo-agents, with ultra-short exposure in the freezing medium and direct rehydration after thawing.

Cryo. Letters 21, 13-18 
ISACHENKO, E., ISACHENKO, V., KATKOV, II, RAHIMI, G., SCHONDORF, T., MALLMANN, P., DESSOLE, S. \& NAWROTH, F. (2004a):

DNA integrity and motility of human spermatozoa after standard slow freezing versus cryoprotectant-free vitrification.

Hum. Reprod. 19, 932-939

ISACHENKO, V., ISACHENKO, E., KATKOV, II, MONTAG, M., DESSOLE, S., NAWROTH, F. \& VAN DER VEN, H. (2004b):

Cryoprotectant-free cryopreservation of human spermatozoa by vitrification and freezing in vapor: effect on motility, DNA integrity, and fertilization ability.

Biol. Reprod. 71, 1167-1173

ISHITSUKA, R., KOJIMA, K., UTSUMI, H., OGAWA, H. \& MATSUMOTO, I. (1998):

Glycosaminoglycan binding properties of annexin IV, V, and VI.

J. Biol. Chem. 273, 9935-9941

JANUSKAUSKAS, A., SODERQUIST, L., HAARD, M. G., HAARD, M. C., LUNDEHEIM, N. \& RODRIGUEZ-MARTINEZ, H. (1996):

Influence of sperm number per straw on the post-thaw sperm viability and fertility of Swedish red and white A.I. bulls.

Acta. Vet. Scand. 37, 461-470

JANUSKAUSKAS, A., JOHANNISSON, A. \& RODRIGUEZ-MARTINEZ, H. (2001):

Assessment of sperm quality through fluorometry and sperm chromatin structure assay in relation to field fertility of frozen-thawed semen from Swedish Al bulls.

Theriogenology 55, 947-961

JANUSKAUSKAS, A., JOHANNISSON, A. \& RODRIGUEZ-MARTINEZ, H. (2003):

Subtle membrane changes in cryopreserved bull semen in relation with sperm viability, chromatin structure, and field fertility.

Theriogenology 60, 743-758

JILLELLA, D., EATON, R. J. \& BAKER, A. A. (1977):

Successful transfer of a bovine embryo through a cannulated fallopian tube.

Vet. Rec. 100, 385-386

JOHNSON, L. A. (1985):

Fertility results of frozen boar spermatozoa.

1st Int. Conference on Deep Freezing of Boar Semen. Uppsala

JOHNSON, L. A., WELCH, G. R. \& RENS, W. (1999):

The Beltsville sperm sexing technology: high-speed sperm sorting gives improved sperm output for in vitro fertilization and Al.

J. Anim. Sci. 77 (Suppl. 2), 213-220 
JOHNSON, M. S., SENGER, P. L., ALLEN, P. C., HANCOCKT, D. D., ALEXANDEL, B. M. \& SASSERG, R. G. (1995):

Fertility of bull semen packaged in 0.25 - and $0.5-$ Milliliter french straws. J. Anim. Sci. 73, 1914-1919

JONDET, R. (1964):

Congelation rapide du sperme de taureau conditionne en paillettes.

5th Intern. Congr. Animal Reprod. and Artif. Insem. Trento IV, 463-468

KAPROTH, M. T., RYCROFT, H. E., GILBERT, G. R., ABDEL-AZIM, G., PUTNAM, B. F., SCHNELL, S. A., EVERETT, R. W. \& PARKS, J. E. (2005):

Effect of semen thaw method on conception rate in four large commercial dairy heifer herds.

Theriogenology 63, 2535-2549

KATHIRAVAN, P., KALATHARAN, J., KARTHIKEYA, G., RENGARAJAN, K. \& KADIRVEL, G. (2011):

Objective sperm motion analysis to assess dairy bull fertility using computeraided system--a review.

Reprod. Dom. Anim. 46, 165-172

KILLIAN, G. J., CHAPMAN, D. A. \& ROGOWSKI, L. A. (1993):

Fertility-associated proteins in Holstein bull seminal plasma.

Biol. Reprod. 49, 1202-1207

KJAESTAD, H., ROPSTAD, E. \& BERG, K. A. (1993):

Evaluation of spermatological parameters used to predict the fertility of frozen bull semen.

Acta Vet. Scand. 34, 299-303

KLEWITZ, J. (2009):

Durchflusszytometrische und computervideomikrographische Untersuchungen zur Kapazitation, Akrosomenreaktion und Chromatinintegrität equine Spermatozoen.

Promotion, Tierärztliche Hochschule Hannover

KLINC, P. (2005):

Improved fertility of flow cytometrically sex selected bull spermatozoa.

Dissertation, Tierärztliche Hochschule Hannover

KLINC, P. \& RATH, D. (2007):

Reduction of oxidative stress in bovine spermatozoa during flow cytometric sorting.

Reprod. Dom. Anim. 42, 63-67

KNIGHT, C. W., PATRICK, T. E., ANDERSON, H. W. \& CECIL, B. (1951):

The relation of site of semen deposit to breeding efficiency of dairy cattle.

J. Dairy Sci. 34, 199-202 
KOZUMPLIK, J. \& SOSNOVA, J. (1985):

The thermoresistance test of spermatozoa and fertility in bulls.

Vet. Med. (Praha) 30, 385-392

KRINSKY, N. I. (1989):

Antioxidant functions of carotenoids.

Free Radic. Biol. Med. 7, 617-635

KURYKIN, J., JAAKMA, U., MAJAS, L., JALAKAS, M., AIDNIK, M., WALDMANN, A. \& PADRIK, P. (2003):

Fixed time deep intracornual insemination of heifers at synchronized estrus.

Theriogenology 60, 1261-1268

KURYKIN, J., JAAKMA, U., JALAKAS, M., AIDNIK, M., WALDMANN, A. \& MAJAS, L. (2007):

Pregnancy percentage following deposition of sex-sorted sperm at different sites within the uterus in estrus-synchronized heifers.

Theriogenology 67, 754-759

LARSSON, B. (1988):

Distribution of spermatozoa in the bovine genital tract after artificial insemination.

Dissertation, Swedish University of Agriculture Sciences, Umea

LICHTNER, C. (2010):

Samengewinnung am stehenden Bullen ohne Aufsprung unter besonderer Berücksichtigung des Sexualverhaltens und der Samenqualität.

Dissertation, Tierärztliche Hochschule Hannover

LIEBERMANN, J. (2003):

Die Vitrifikation: Eine Alternative zum traditionellen Kryokonservierungsverfahren.

Dissertation, Universitäts-Frauenklinik und Poliklinik Würzburg

LOPEZ-GATIUS, F. (1995):

Intraperitoneal insemination in repeat-breeder cows: a preliminary report.

Theriogenology 44, 153-158

LOPEZ-GATIUS, F. (1996):

Side of gestation in dairy heifers affects subsequent sperm transport and pregnancy rates after deep insemination into one uterine horn.

Theriogenology 45, 417-425

LOPEZ-GATIUS, F. \& CAMON-URGEL, J. (1988):

Increase of pregnancy rate in dairy cattle after preovulatory follicle palpation and deep cornual insemination.

Theriogenology 29, 1099-1103 
MACPHERSON, J. W. \& PENNER, P. (1972):

A modified straw technique for frozen semen.

A.I. Digest. 20, 6

MAMMOTO, A., MASUMOTO, N., TAHARA, M., IKEBUCHI, Y., OHMICHI, M., TASAKA, K. \& MIYAKE, A. (1996):

Reactive oxygen species block sperm-egg fusion via oxidation of sperm sulfhydryl proteins in mice.

Biol. Reprod. 55, 1063-1068

MANGIAGALLI, M. G., MARELLI, S. P. \& CALVACHINI, L. G. (2007):

Effect of lycopene on fowl sperm characteristics during in vitro storage.

Arch.Geflügelk. 71, 25-29

MANJUNATH, P., MARCEL, Y. L., UMA, J., SEIDAH, N. G., CHRETIEN, M. \& CHAPDELAINE, A. (1989):

Apolipoprotein A-I binds to a family of bovine seminal plasma proteins.

J. Biol. Chem. 264, 16853-16857

MARQUEZ, B. \& SUAREZ, S. S. (2007):

Bovine sperm hyperactivation is promoted by alkaline-stimulated $\mathrm{Ca} 2+$ influx.

Biol. Reprod. 76, 660-665

MAZUR, P. (1984):

Freezing of living cells: mechanisms and implications.

Am J. Physiol. 247, C125-142

MCKENNA, T., LENZ, R. W., FENTON, S. E. \& AX, R. L. (1990):

Nonreturn rates of dairy cattle following uterine body or cornual insemination.

J. Dairy Sci. 73, 1779-1783

MOCE, E., GRAHAM, J. K. \& SCHENK, J. L. (2006):

Effect of sex-sorting on the ability of fresh and cryopreserved bull sperm to undergo an acrosome reaction.

Theriogenology 66, 929-936

MOMONT, H. W., SEGUIN, B. E., SINGH, G. \& STASIUKYNAS, E. (1989):

Does intrauterine site of insemination in cattle really matter?

Theriogenology 32, 19-26

MÖNCH-TEGEDER, G. (2011):

Einfluss verschiedener Ejakulatbehandlungen auf die Lebensfähigkeit und das Befruchtungspotential geschlechtsspezifisch differenzierter Bullenspermien.

Dissertation, Georg-August-Universität Göttingen

MORTIMER, S. T. \& MORTIMER, D. (1990):

Kinematics of human spermatozoa incubated under capacitating conditions.

J. Androl. 11, 195-203 
MOUSSA, M., MARINET, V., TRIMECHE, A., TAINTURIER, D. \& ANTON, M. (2002):

Low density lipoproteins extracted from hen egg yolk by an easy method: cryoprotective effect on frozen-thawed bull semen.

Theriogenology 57, 1695-1706

MUKAIDA, T., NAKAMURA, S., TOMIYAMA, T., WADA, S., KASAI, M. \& TAKAHASHI, K. (2001):

Successful birth after transfer of vitrified human blastocysts with use of a cryoloop containerless technique.

Fertil. Steril. 76, 618-620

MÜLLER, C. H. (2000):

Rationale, interpretation, validation, and uses of sperm function tests.

J. Androl. 21, 10-30

NAGASE, H., NIWA, T., YAMASHITA, S. \& IRIE, S. (1964):

Deep freezing bulle semen in concentrated pellet form. II. Protective action of sugars.

5th Intern. Congr. Animal Reprod. and Artif. Insem. Trento, IV, 498-502

PHILLIPS, N. J., MCGOWAN, M. R., JOHNSTON, S. D. \& MAYER, D. G. (2004):

Relationship between thirty post-thaw spermatozoal characteristics and the field fertility of 11 high-use Australian dairy Al sires.

Anim. Reprod. Sci. 81, 47-61

PHILLIPS, P. H. (1939):

The preservation of bull semen.

J. Biol. Chem. 130, 415

PICKETT, B. W. \& BERNDTSON, W. E. (1974):

Preservation of bovine spermatozoa by freezing in straws: a review.

J. Dairy Sci. 57, 1287-1301

PICKETT, B. W. \& BERNDTSON, W. E. (1978):

Influence of seminal additives and packaging systems on fertility of frozen bovine spermatozoa.

J.Animal Sci. 47 (Suppl 2), 12-47

POLGE, C., SMITH, A. U. \& PARKES, A. S. (1949):

Revival of spermatozoa after vitrification and dehydration at low temperatures.

Nature 164, 666

PURSEL, V. G., SCHULMAN, L. L. \& JOHNSON, L. A. (1978):

Effect of glycerol concentration on frozen boar sperm.

Theriogenology 9, 305-312 
RALL, W. F. \& FAHY, G. M. (1985):

Ice-free cryopreservation of mouse embryos at -196 degrees $C$ by vitrification. Nature 313, 573-575

RATH, D. \& JOHNSON, L. A. (2008):

Application and commercialization of flow cytometrically sex-sorted semen. Reprod. Domest. Anim. 43, 338-346

RATH, D., MOENCH-TEGEDER, G., TAYLOR, U. \& JOHNSON, L. A. (2009): Improved quality of sex-sorted sperm: A prerequisite for wider commercial application.

Theriogenology $71,22-29$

RATHI, R., COLENBRANDER, B., STOUT, T. A., BEVERS, M. M. \& GADELLA, B. M. (2003):

Progesterone induces acrosome reaction in stallion spermatozoa via a protein tyrosine kinase dependent pathway.

Mol. Reprod. Dev. 64, 120-128

REED, M. L., LANE, M., GARDNER, D. K., JENSEN, N. L. \& THOMPSON, J. (2002):

Vitrification of human blastocysts using the cryoloop method: successful clinical application and birth of offspring.

J. Assist. Reprod. Genet. 19, 304-306

REENTS, R. \& REINHARDT, F. (2007):

Use of molecular genetic information to supplement population genetics.

Züchtungskunde 79, 41-45

ROBBINS, R. K., SAACKE, R. G. \& CHANDLER, P. T. (1976):

Influence of freeze rate, thaw rate and glycerol level on acrosomal retention and survival of bovine spermatozoa frozen in french straws.

J. Anim. Sci. 42, 145-154

RODRIGUEZ-MARTINEZ, H., NICANDER, L., VIRING, S., EINARSSON, S. \& LARSSON, K. (1990):

Ultrastructure of the uterotubal junction in preovulatory pigs.

Anat. Histol. Embryol. 19, 16-36

SAACKE, R. G. (2008):

Insemination factors related to timed $\mathrm{Al}$ in cattle.

Theriogenology 70, 479-484

SAACKE, R. G., DALTON, J. C., NADIR, S., NEBEL, R. L. \& BAME, J. H. (2000):

Relationship of seminal traits and insemination time to fertilization rate and embryo quality.

Anim. Reprod. Sci. 60-61, 663-677 
SALISBURY, G. W. \& VANDENMARK, N. L. (1951):

The Effect of Cervical, Uterine and Cornual Insemination on Fertility of the Dairy Cow.

J. Dairy Sci. 34, 68-74

SCHENK, J. L., CRAN, D. G., EVERETT, R. W. \& SEIDEL, G. E., JR. (2009):

Pregnancy rates in heifers and cows with cryopreserved sexed sperm: effects of sperm numbers per inseminate, sorting pressure and sperm storage before sorting.

Theriogenology $71,717-728$

SCHWARTZ, D., MACDONALD, P. D. \& HEUCHEL, V. (1981):

On the relationship between the number of spermatozoa and the probability of conception.

Reprod. Nutr. Dev. 21, 979-988

SEIDEL, G. E., JR. \& SCHENK, J. L. (2008):

Pregnancy rates in cattle with cryopreserved sexed sperm: effects of sperm numbers per inseminate and site of sperm deposition.

Anim. Reprod. Sci. 105, 129-138

SENGER, P. L., MITCHELL, J. R. \& ALMQUIST, J. O. (1983):

Influence of cooling rates and extenders upon post-thaw viability of bovine spermatozoa packaged in 0.25 - and $0.5-\mathrm{ml}$ French straws.

J. Anim. Sci. 56, 1261-1268

SENGER, P. L., BECKER, W. C., DAVIDGE, S. T., HILLERS, J. K. \& REEVES, J. J. (1988):

Influence of cornual insemination on conception in dairy cattle.

J. Anim. Sci. 66, 3010-3016

SHAFFNER, C. S. (1942):

Longevity of fowl spermatozoa in frozen condition.

Science 96, 337

SHANNON, P. \& VISHWANATH, R. (1995):

The effect of optimal and suboptimal concentrations of sperm on the fertility of fresh and frozen bovine semen and a theoretical model to explain the fertility differences.

Anim. Reprod. Sci. 39, 1-10

SIKKA, S. C. (1996):

Oxidative stress and role of antioxidants in normal and abnormal sperm function.

Front Biosci. 1, 78-86

SIMMET, L. (1972):

A fully automatic method of packaging bull semen in plastic tubes according to the Landshut method.

VII Inter. Congr. Anim. Reprod. Artif. Insem. II, 1357 
SIRARD, M. A. \& LAMBERT, R. D. (1986):

Birth of calves after in vitro fertilisation using laparoscopy and rabbit oviduct incubation of zygotes.

Vet. Rec. 119, 167-169

SKJERVEN, O. (1954):

Conception in a heifer after deposition of semen in the abdominal cavity.

Fertil. Steril. 6, 66-67

SODERQUIST, L., RODRIGUEZ-MARTINEZ, H. \& JANSON, L. (1991):

Post-thaw motility, ATP content and cytochrome $\mathrm{C}$ oxidase activity of A.I. bull spermatozoa in relation to fertility.

Zentralbl. Veterinarmed. A. 38, 165-174

SØRENSEN, E. (1940):

Overforing of gelatineret sperma: parafinerede cellophanror.

Member BI Danish Veterinary Forren 23, 166

SPINACI, M., VALLORANI, C., BUCCI, D., BERNARDINI, C., TAMANINI, C., SEREN, E. \& GALEATI, G. (2010):

Effect of liquid storage on sorted boar spermatozoa.

Theriogenology $74,741-748$

STÅLHAMMAR, E. M., JANSON, L. \& PHILIPSSON, J. (1994):

The impact of sperm motility on non-return rate in preselected dairy bulls.

Reprod. Nutr. Dev. 34, 37-45

SUAREZ, S. S. (2002):

Formation of a reservoir of sperm in the oviduct.

Reprod. Domest. Anim. 37, 140-143

SUAREZ, S. S. (2007):

Interactions of spermatozoa with the female reproductive tract: inspiration for assisted reproduction.

Reprod. Fertil. Dev. 19, 103-110

SUKHATO, P., THONGSODSEANG, S., UTHA, A. \& SONGSASEN, N. (2001): Effects of cooling and warming conditions on post-thawed motility and fertility of cryopreserved buffalo spermatozoa.

Anim. Reprod. Sci. 67, 69-77

SWELUM, A. A., MANSOUR, H. A., ELSAYED, A. A. \& AMER, H. A. (2011):

Comparing ethylene glycol with glycerol for cryopreservation of buffalo bull semen in egg-yolk containing extenders.

Theriogenology 76, 833-842

TALEVI, R. \& GUALTIERI, R. (2010):

Molecules involved in sperm-oviduct adhesion and release.

Theriogenology $73,796-801$ 
TAYLOR, U., RATH, D., ZERBE, H. \& SCHUBERTH, H. J. (2008): Interaction of intact porcine spermatozoa with epithelial cells and neutrophilic granulocytes during uterine passage.

Reprod. Domest. Anim. 43, 166-175

TEDDER, R. S., ZUCKERMAN, M. A., GOLDSTONE, A. H., HAWKINS, A. E., FIELDING, A., BRIGGS, E. M., IRWIN, D., BLAIR, S., GORMAN, A. M., \& PATTERSON, K. G. (1995):

Hepatitis B transmission from contaminated cryopreservation tank. Lancet. 346, 137-140

TÖPFER-PETERSEN, E. (2007):

Spermienreifung, Transport und Befruchtung. In: Busch, W. und Waberski D. (Hrsg) Künstliche Besamung bei Haus und Nutztieren.

1. Auflage, Schattauer, Stuttgart, 84-93; ISBN: 978-3-7945-2410-5

TÖPFER-PETERSEN, E. \& WABERSKI, D. (2001):

Spermienreifung und Befruchtung.

In: Busch, W. und A. Holzmann (Hrsg) Veterinärmedizinische Andrologie.

1. Auflage, Schattauer, Stuttgart, 67-82; ISBN:3-7945-1955-8

THOMSON, A. (2011):

"Animal Science Lab" in: News from Ithaca (März, 2011) unter

http://alexanderthomson.wordpress.com/2011/03/10/animal-science-lab/

(abgerufen am 30.02.2013)

VAZQUEZ, J. M., ROCA, J., GIL, M. A., CUELLO, C., PARRILLA, I., VAZQUEZ, J. L. \& MARTINEZ, E. A. (2008):

New developments in low-dose insemination technology.

Theriogenology $70,1216-1224$

VERBERCKMOES, S., VAN SOOM, A., DE PAUW, I., DEWULF, J., VERVAET, C. \& DE KRUIF, A. (2004):

Assessment of a new utero-tubal junction insemination device in dairy cattle.

Theriogenology $61,103-115$

VERBERCKMOES, S., VAN SOOM, A., DEWULF, J., THYS, M. \& DE KRUIF, A. (2005):

Low dose insemination in cattle with the Ghent device.

Theriogenology 64, 1716-1728

VIANNA, F. P., PAPA, F. O., ZAHN, F. S., MELO, C. M. \& DELL'AQUA, J. A., JR. (2009):

Thermoresistance sperm tests are not predictive of potential fertility for cryopreserved bull semen.

Anim. Reprod. Sci. 113, 279-282

VISHWANATH, R. (2003):

Artificial insemination: the state of the art.

Theriogenology 59, 571-584 
VISHWANATH, R. \& SHANNON, P. (2000):

Storage of bovine semen in liquid and frozen state.

Anim. Reprod. Sci. 62, 23-53

WABERSKI, D. \& PETRUNKINA A.M. (2007):

Arbeits- und Untersuchungsmethoden- Spermatologie.

In: Busch, W. und Waberski D. (Hrsg.) Künstliche Besamung bei Haus- und Nutztieren.

1. Auflage, Schattauer, Stuttgart, 99-106; ISBN: 978-3-7945-2410-5

WABERSKI, D., SOARES, J. A. G., BANDEIRA, DE ARRUDA, E. \& WEITZE, K. F. (1996):

Effect of a transcervical infusion of seminal plasma prior to insemination on the fertilising competence of low numbers of boar spermatozoa at controlled Alovulation intervals.

Anim. Reprod. Sci. 44, 165-173

WABERSKI, D., A., P., WEITZE, K. F. \& TÖPFER-PETERSEN, E. (1999):

In-vitro Beurteilung von Sperma zur Vorhersage der Fertilität.

Tierärztliche Praxis 27, 1-7

WATSON, P. F. (1995):

Recent developments and concepts in the cryopreservation of spermatozoa and the assessment of their post-thawing function.

Reprod. Fertil. Dev. 7, 871-891

WATSON, P. F. (2000):

The causes of reduced fertility with cryopreserved semen.

Anim. Reprod. Sci. 60-61, 481-492

WEITZE, K.F. (2001):

Prinzipien der andrologischen Untersuchung.

In: Busch, W. und Holzmann, A. 1. Auflage, Schattauer, Stuttgart, 87-118;

ISBN:3-7945-1955-8

WEITZE, K.F. \& PETRUNKINA, A.M. (2001):

Samenkonservierung, biochemische Grundlagen und Prinzipien der Einfrierund Auftautechniken.

In: Busch, W. und Waberski, D.

1. Auflage, Schattauer, Stuttgart, 119-145; ISBN:978-3-7945-2410-5

WENDT, H. (2007):

Interaktionen von Spermatozoen mit Immunzellen des Rinderuterus.

Hannover, Tierärztliche Hochschule, Dissertation 
WETSCHER, F., HAVLICEK, V., HUBER, T., GILLES, M., TESFAYE, D., GRIESE, J., WIMMERS, K., SCHELLANDER, K., MULLER, M., BREM, G. \& BESENFELDER, U. (2005):

Intrafallopian transfer of gametes and early stage embryos for in vivo culture in cattle.

Theriogenology $64,30-40$

WHITE, I. G. (1993):

Lipids and calcium uptake of sperm in relation to cold shock and preservation: a review.

Reprod. Fertil. Dev. 5, 639-658

WILLIAMS, B. L., GWAZDAUSKAS, F. C., WHITTIER, W. D., PEARSON, R. E. \& NEBEL, R. L. (1988):

Impact of site of inseminate deposition and environmental factors that influence reproduction of dairy cattle.

J. Dairy Sci. 71, 2278-2283

WOELDERS, H. (1997):

Fundamentals and recent development in cryopreservation of bull and boar semen.

Vet. Q. 19, 135-138

WOLF, F. R., J. O. ALMQUIST, E. B. HALE (1965):

Prepuberal behavior and puberal characteristics of beef bulls on high nutrient allowance.

J. Anim. Sci. 24, 761-765

YANIZ, J. L., LOPEZ-GATIUS, F., SANTOLARIA, P. \& MULLINS, K. J. (2000): Study of the functional anatomy of bovine oviductal mucosa.

Anat. Rec. 260, 268-278

ZERBE, H., SCHUBERTH, H. J., ENGELKE, F., FRANK, J., KLUG, E. \& LEIBOLD, W. (2003):

Development and comparison of in vivo and in vitro models for endometritis in cows and mares.

Theriogenology 60, 209-223

ZHANG B.R., LARSSON B., LUNDEHEIM N. \& RODRIQUEZ-MARTINEZ H. (1998):

Sperm characteristics and zona pellucida binding in relation to field fertility of frozen-thawed semen from dairy Al bulls.

Int. J. Androl. 21, 207-216 


\section{$9 \quad$ Anhang}

\subsection{Materialien}

Alle Chemikalien wurden, wenn nicht anders ausgeführt, durch die Carl Roth $\mathrm{GmbH}+\mathrm{CO}$ (Karlsruhe, Deutschland) bezogen .

\subsection{Zusammensetzung der Verdünner}

TRIS-Sample: 199,98 mM Tris-Hydroxymethyl-Aminomethan, 64,72 mM Zitronensäure-Monohydrat, 95,5 mM D-Fruktose und 50 mg/l Gentamicin-Sulfat verdünnt in zweifach destilliertem Wasser.

TRIS-Trägerflüssigkeit: 197,13 mM Tris-Hydroxymethyl-Aminomethan, 55,34 mM Zitronensäure-Monohydrat, 47,46 mM D-Fruktose, 0,058 g Penicillin G und $0,05 \mathrm{~g} / \mathrm{l}$ Streptomycin-Sulfat verdünnt in zweifach destilliertem Wasser $(\mathrm{pH} 6,8)$.

TEST-TRIS-Eigelb-Puffer: $\quad 188,73 \quad \mathrm{mM} \quad \mathrm{N}$-Tris-Hydromethyl-Methyl-2Aminomethan (TEST), 84,78 mM Tris-Hydroxymethyl-Aminomethan, 11,1 mM Glukose, 0,05 g/l Gentamicin-Sulfat und $25 \mathrm{~g} / \mathrm{l}$ Eigelb in zweifach destilliertem Wasser. Nach Zentrifugation bei $850 \mathrm{~g}$ für $10 \mathrm{~min}$, wurde der Überstand vorsichtig entfernt und wenn nötig mit Tris-Hydroxymethyl-Aminomethan auf $\mathrm{pH}$ 7,4 eingestellt.

TRIS-Eigelb Einfrierverdünner Komponente I: Mischung aus $672,0 \mathrm{ml}$ Stammlösung (297,59 mM Tris-hydroxymethyl-aminomethan, 96,32 mM Zitronensäure-Monohydrat, 82,59 mM D-Fruktose, 0,606 g/l Penicillin und 1,48 g/l Streptomycin-Sulfat verdünnt mit zweifach destilliertem Wasser), 200,0 ml Eigelb und 128,0 ml zweifach-destilliertem Wasser (End-pH 6,75). 
TRIS-Eigelb Einfrierverdünner Komponente II: es handelt sich hierbei um die gleiche Aufbereitung wie bei Komponente I, jedoch wurden die 128,0 ml zweifach destilliertes Wasser mit 128,0 ml 87 \% Glyzerin ersetzt (End-pH 6,85).

Lebensmittelfarbstoff: $25 \mathrm{mg}$ Food dye FD\&C\#40 in $1 \mathrm{ml}$ zweifach destilliertem Wasser.

Hancock-Medium: 2,784 g Tri-Natriumzitrat-Dihydrat, $4 \mathrm{ml}$ 37\%iges Formaldehyd-Lösung in zweifach destilliertem Wasser auf $100 \mathrm{ml}$ 


\title{
9.3 Parametereinstellungen CASA (Version 12 IVOS, Hamilton Thorne Biosciences, Berverly, USA)
}

Untersuchung im Thermoresistenztest (mit Fluoreszenzmessung)

Inst. f. Nutztiergenetik, FLI

22/05/2012

08:46:58

Setup Report

Analysis Setup

ANALYSIS SETUP \#7: Hoechst

\author{
Apply Sort: 0 \\ Frames Acquired: 60 \\ Frame Rate: $50 \mathrm{~Hz}$ \\ Minimum Contrast: 40 \\ Minimum Cell Size: 5 Pixel \\ Minimum Static Contrast: 30 \\ Straightness (STR), Threshold: 50,0\% \\ Vap Cutoff: $20,0 \mu \mathrm{m} / \mathrm{s}$ \\ Prog. Min VAP: $35,0 \mu \mathrm{m} / \mathrm{s}$ \\ VSL Cutoff: $12,0 \mu \mathrm{m} / \mathrm{s}$ \\ Cell size: 5 Pixel \\ Cell Intensity: 100 \\ Static Head Size: 0,33 to 3,96 \\ Static Head Intensity: 0,13 to 1,75 \\ Static Elongation: 16 to 97 \\ Slow Cells Motil: NO \\ Magnification: 1,87 \\ Video Frequency: 60 \\ Bright Field: NO \\ LED Illumination Intensity: 2050 \\ IDENT Illumination Intensity: 4095 \\ Temperature, Set: $38,1^{\circ} \mathrm{C}$ \\ Chamber depth: $10,0 \mu \mathrm{m}$ \\ Chamber position: $15,3 \mathrm{~mm}$ \\ Chamber position B: $15,3 \mathrm{~mm}$ \\ Chamber position C: $15,3 \mathrm{~mm}$ \\ Chamber position D: $15,3 \mathrm{~mm}$ \\ Chamber type: Makler \\ Field Selection Mode: AUTO \\ IDENT Fluorescent Option: FULL \\ Integrating Time: 1 Frames
}

IVOS 
9.4 Parametereinstellungen Durchflusszytometer (FACScan $\odot$, Becton, Dickinson, Biosciences, Heidelberg, Deutschland)

a) Syber14/PI-Messung

Compensation:

FL1 - 0,8\% FL2

FL2 - 28\% FL1

FL2 - 0\% FL3

FL3 - 12\% FL2

Threshold:

FSC-H 113

Detections/Amps:

ParameterDetector Voltage Amp Gain Mode

$\begin{array}{llll}\text { P1 } & \text { FSC } & \text { E00 } & 1,32\end{array}$

$\begin{array}{lllll}\text { P2 } & \text { SSC } & 412 & 1,00 & \text { LIN }\end{array}$

$\begin{array}{llll}\text { P3 } & \text { FL1 } & 504 & \text { LOG }\end{array}$

$\begin{array}{llll}\text { P4 } & \text { FL2 } & 612 & \text { LOG }\end{array}$

$\begin{array}{llll}\text { P5 } & \text { FL3 } & 597 & \text { LOG }\end{array}$ 


\subsection{Tabellen}

a) Darstellung der Gefrierprogramme aus Kapitel 4.1.

Tabelle 39: Detaillierte Darstellung in ${ }^{\circ} \mathrm{C}$ pro Minute der Gefrierkurve B

\begin{tabular}{|cccc|}
\hline Segment & Endtemperatur $\left({ }^{\circ} \mathbf{C}\right)$ & Rel. Zeit (min.) & Rampe $\left({ }^{\circ} \mathbf{C} / \mathbf{m i n}\right)$ \\
\hline 0 & 5 & 0,00 & 0 \\
\hline 1 & -8 & 4,33 & -3 \\
\hline 2 & -8 & 1,00 & 0 \\
\hline 3 & -120 & 11,20 & -10 \\
\hline 4 & -140 & 2,00 & -10 \\
\hline
\end{tabular}

Tabelle 40: Detaillierte Darstellung in ${ }^{\circ} \mathrm{C}$ pro Minute der Gefrierkurve $\mathrm{C}$

\begin{tabular}{|cccc|}
\hline Segment & Endtemperatur $\left({ }^{\circ} \mathbf{C}\right)$ & Rel. Zeit (min.) & Rampe $\left({ }^{\circ} \mathbf{C} / \mathbf{m i n}\right)$ \\
\hline 0 & 5 & 0,00 & 0 \\
\hline 1 & -8 & 4,33 & -3 \\
\hline 2 & -8 & 1,00 & 0 \\
\hline 3 & -120 & 22,40 & -5 \\
\hline
\end{tabular}

Tabelle 41: Detaillierte Darstellung in ${ }^{\circ} \mathrm{C}$ pro Minute der Gefrierkurve D

\begin{tabular}{|cccc|}
\hline Segment & Endtemperatur $\left({ }^{\circ} \mathbf{C}\right)$ & Rel. Zeit (min.) & Rampe ( $\left.{ }^{\circ} \mathbf{C} / \mathbf{m i n}\right)$ \\
\hline 0 & 5 & 0,00 & 0 \\
\hline 1 & -8 & 13,00 & -1 \\
\hline 2 & -8 & 1,00 & 0 \\
\hline 3 & -35 & 5,40 & -5 \\
\hline 4 & -120 & 8,50 & -10 \\
\hline 5 & -140 & 2,00 & -10 \\
\hline
\end{tabular}

Tabelle 42: Detaillierte Darstellung in ${ }^{\circ} \mathrm{C}$ pro Minute der Gefrierkurve D+

\begin{tabular}{|cccc|}
\hline Segment & Endtemperatur $\left({ }^{\circ} \mathbf{C}\right)$ & Rel. Zeit (min.) & Rampe $\left({ }^{\circ} \mathbf{C} / \mathbf{m i n}\right)$ \\
\hline 0 & 5 & 0,00 & 0 \\
\hline 1 & -8 & 13,00 & -1 \\
\hline 2 & -35 & 5,40 & -5 \\
\hline 3 & -120 & 8,50 & -10 \\
\hline 4 & -140 & 2,00 & -10 \\
\hline
\end{tabular}


b) Durch das CASA System erfasste Qualitätsparameter der Bullen A und B aus dem Thermoresistenztest in Kapitel 4.2.

Bulle A

Tabelle 43: Anteil vorwärtsbeweglicher Spermien ( $\bar{x} \pm$ SEM \%) des Bullen A unmittelbar nach dem Auftauen sowie nach drei- und sechsstündiger Inkubation bei $37^{\circ} \mathrm{C}$

\begin{tabular}{|c|c|c|c|c|}
\hline Gruppe & & $\begin{array}{c}\text { O Std. } \\
\bar{x} \pm \text { SEM }\end{array}$ & $\begin{array}{c}3 \text { Std. } \\
\bar{x} \pm \text { SEM }\end{array}$ & $\begin{array}{c}6 \text { Std. } \\
\bar{x} \pm \text { SEM }\end{array}$ \\
\hline Nanostraw & $(n=24)$ & $30,3 \pm 1,3^{\mathrm{a}, \mathrm{A}}$ & $21,0 \pm 1,2^{\mathrm{a}, \mathrm{B}}$ & $11,7 \pm 1,1^{\mathrm{a}, \mathrm{C}}$ \\
\hline Kontrollstraw & $(n=24)$ & $40,5 \pm 1,6^{\mathrm{b}, \mathrm{A}}$ & $28,1 \pm 1,4^{\mathrm{b}, \mathrm{B}}$ & $15,0 \pm 1,6^{\mathrm{a}, \mathrm{C}}$ \\
\hline
\end{tabular}

Tabelle 44: Kürzeste zurückgelegte Distanz der Spermien zwischen Anfangs- und Endpunkt (VSL; $\bar{x} \pm$ SEM $\mu \mathrm{m} /$ Sek.) des Bullen A unmittelbar nach dem Auftauen sowie nach drei- und sechsstündiger Inkubation bei $37^{\circ} \mathrm{C}$

\begin{tabular}{lccc}
\hline Gruppe & $\begin{array}{c}\text { 0 Std. } \\
\bar{x} \pm \text { SEM }\end{array}$ & $\begin{array}{c}\text { 3 Std. } \\
\bar{x} \pm \text { SEM }\end{array}$ & $\begin{array}{c}\text { 6 Std. } \\
\bar{x} \pm \text { SEM }\end{array}$ \\
\hline Nanostraw $\quad(\mathbf{n = 2 4 )}$ & $34,8 \pm 0,7^{\mathrm{A}}$ & $31,7 \pm 0,7^{\mathrm{B}}$ & $27,9 \pm 0,6^{\mathrm{C}}$ \\
Kontrollstraw (n=24) & $36,0 \pm 0,9^{\mathrm{A}}$ & $32,8 \pm 0,9^{\mathrm{B}}$ & $28,9 \pm 1,1^{\mathrm{C}}$ \\
$\begin{array}{l}\mathrm{A}, \mathrm{B}, \mathrm{C}: \text { Werte mit unterschiedlichen Indizes unterscheiden sich innerhalb einer Gruppe bei Betrachtung aller } \\
\text { Untersuchungszeitpunkte signifikant }(\mathrm{p} \leq 0,05) .\end{array}$
\end{tabular}

Tabelle 45: Volle zurückgelegte Distanz (VCL; $\bar{x} \pm$ SEM $\mu \mathrm{m} /$ Sek.) des Bullen A unmittelbar nach dem Auftauen sowie nach drei- und sechsstündiger Inkubation bei $37^{\circ} \mathrm{C}$

\begin{tabular}{|c|c|c|c|}
\hline Gruppe & $\begin{array}{c}0 \text { Std. } \\
\bar{x} \pm \text { SEM }\end{array}$ & $\begin{array}{c}3 \text { Std. } \\
\bar{x} \pm \text { SEM }\end{array}$ & $\begin{array}{c}6 \text { Std. } \\
\bar{x} \pm \text { SEM }\end{array}$ \\
\hline Nanostraw $\quad(n=24)$ & $99,6 \pm 1,8^{A}$ & $102 \pm 3,5^{\mathrm{A}}$ & $86,7 \pm 3,3^{\mathrm{B}}$ \\
\hline Kontrollstraw ( $n=24)$ & $100,6 \pm 2,5^{\mathrm{A}}$ & $99,1 \pm 3,6^{A}$ & $84,0 \pm 3,7^{\mathrm{B}}$ \\
\hline
\end{tabular}


Tabelle 46: Geglättete zurückgelegte Distanz (VAP; $\bar{x} \pm$ SEM $\mu \mathrm{m} /$ Sek.) des Bullen A unmittelbar nach dem Auftauen sowie nach drei- und sechsstündiger Inkubation bei $37^{\circ} \mathrm{C}$

\begin{tabular}{lccc}
\hline Gruppe & $\begin{array}{c}\text { 0 Std. } \\
\bar{x} \pm \text { SEM }\end{array}$ & $\begin{array}{c}\text { 3 Std. } \\
\bar{x} \pm \text { SEM }\end{array}$ & $\begin{array}{c}6 \text { Std. } \\
\bar{x} \pm \text { SEM }\end{array}$ \\
\hline Nanostraw $\quad(\mathbf{n = 2 4 )}$ & $53,0 \pm 1,0^{\mathrm{A}}$ & $54,9 \pm 2,2^{\mathrm{A}}$ & $44,7 \pm 2,0^{\mathrm{B}}$ \\
Kontrollstraw ( $\mathbf{n = 2 4 )}$ & $54,4 \pm 1,4^{\mathrm{A}}$ & $53,5 \pm 2,2^{\mathrm{A}}$ & $44,1 \pm 2,0^{\mathrm{B}}$ \\
$\begin{array}{l}\mathrm{A}, \mathrm{B}, \mathrm{C}: \text { Werte mit unterschiedlichen Indizes unterscheiden sich innerhalb einer Gruppe bei Betrachtung aller } \\
\text { Untersuchungszeitpunkte signifikant }(p \leq 0,05) .\end{array}$
\end{tabular}

Tabelle 47: Seitlich Auslenkung der Spermienköpfe (ALH; $\bar{x} \pm$ SEM $\mu \mathrm{m})$ des Bullen A unmittelbar nach dem Auftauen sowie nach drei- und sechsstündiger Inkubation bei $37^{\circ} \mathrm{C}$

\begin{tabular}{|c|c|c|c|}
\hline Gruppe & $\begin{array}{c}\text { O Std. } \\
\bar{x} \pm \text { SEM }\end{array}$ & $\begin{array}{c}3 \text { Std. } \\
\bar{x} \pm \text { SEM }\end{array}$ & $\begin{array}{c}6 \text { Std. } \\
\bar{x} \pm \text { SEM }\end{array}$ \\
\hline Nanostraw $\quad(n=24)$ & $6,5 \pm 0,1^{\mathrm{a}, \mathrm{A}}$ & $7,1 \pm 0,1^{\mathrm{a}, \mathrm{B}}$ & $6,9 \pm 0,1^{a}$ \\
\hline Kontrollstraw $(n=24)$ & $6,3 \pm 0,1^{\mathrm{a}, \mathrm{A}}$ & $7,0 \pm 0,1^{\mathrm{a}, \mathrm{B}}$ & $6,5 \pm 0,1^{b}$ \\
\hline
\end{tabular}

Tabelle 48: Frequenz der Pendelbewegung (BCF; $\bar{x} \pm$ SEM Hz) des Bullen A unmittelbar nach dem Auftauen sowie nach drei- und sechsstündiger Inkubation bei $37^{\circ} \mathrm{C}$

\begin{tabular}{|c|c|c|c|}
\hline Gruppe & $\begin{array}{c}\text { 0 Std. } \\
\bar{x} \pm \text { SEM }\end{array}$ & $\begin{array}{c}3 \text { Std. } \\
\bar{x} \pm \text { SEM }\end{array}$ & $\begin{array}{c}6 \text { Std. } \\
\bar{x} \pm \text { SEM }\end{array}$ \\
\hline Nanostraw $\quad(n=24)$ & $21,0 \pm 0,4^{\mathrm{a}, \mathrm{A}}$ & $19,2 \pm 0,5^{\mathrm{a}, \mathrm{B}}$ & $20,4 \pm 0,6^{\mathrm{a}, \mathrm{A}}$ \\
\hline Kontrollstraw ( $n=24)$ & $21,3 \pm 0,4^{\mathrm{a}, \mathrm{A}}$ & $20,1 \pm 0,4^{a, B}$ & $22,0 \pm 0,5^{\mathrm{b}, \mathrm{A}}$ \\
\hline
\end{tabular}


Tabelle 49: Straightness (STR; $\bar{x} \pm$ SEM \%) der Spermien des Bullen A unmittelbar nach dem Auftauen sowie nach drei- und sechsstündiger Inkubation bei $37^{\circ} \mathrm{C}$

\begin{tabular}{lccc}
\hline & 0 Std. & 3 Std. & 6 Std. \\
Gruppe & $\bar{x} \pm$ SEM & $\bar{x} \pm$ SEM & $\bar{x} \pm$ SEM \\
\hline Nanostraw $\quad(\mathbf{n = 2 4 )}$ & $68,0 \pm 0,7^{\mathrm{A}}$ & $62,5 \pm 1,3^{\mathrm{B}}$ & $65,5 \pm 1,5^{\mathrm{A}}$ \\
Kontrollstraw $(\mathbf{n = 2 4})$ & $68,4 \pm 0,7^{\mathrm{A}}$ & $64,0 \pm 1,0^{\mathrm{B}}$ & $67,7 \pm 1,3$
\end{tabular}

$A, B, C$ : Werte mit unterschiedlichen Indizes unterscheiden sich innerhalb einer Gruppe bei Betrachtung aller Untersuchungszeitpunkte signifikant $(p \leq 0,05)$.

Tabelle 50: Linearity (LIN; $\bar{x} \pm$ SEM \%) der Spermien des Bullen A unmittelbar nach dem Auftauen sowie nach drei- und sechsstündiger Inkubation bei $37^{\circ} \mathrm{C}$

\begin{tabular}{|c|c|c|c|}
\hline & 0 Std. (\%) & 3 Std. (\%) & 6 Std. (\%) \\
\hline Gruppe & $\bar{x} \pm$ SEM & $\bar{x} \pm$ SEM & $\bar{x} \pm$ SEM \\
\hline Nanostraw $\quad(n=24)$ & $37,1 \pm 0,6^{\mathrm{a}, \mathrm{A}}$ & $33,8 \pm 1,5^{\mathrm{a}, \mathrm{B}}$ & $34,4 \pm 0,7^{\mathrm{a}, \mathrm{B}}$ \\
\hline Kontrollstraw $(n=24)$ & $38,0 \pm 0,6^{\mathrm{a}, \mathrm{A}}$ & $35,4 \pm 0,6^{b, B}$ & $37,2 \pm 0,9^{b}$ \\
\hline
\end{tabular}

Bulle B

Tabelle 51: Anteil vorwärtsbeweglicher Spermien ( $\bar{x} \pm$ SEM \%) des Bullen B unmittelbar nach dem Auftauen sowie nach drei- und sechsstündiger Inkubation bei $37^{\circ} \mathrm{C}$

\begin{tabular}{|c|c|c|c|}
\hline Gruppe & $\begin{array}{c}0 \text { Std. } \\
\bar{x} \pm \mathrm{SEM}\end{array}$ & $\begin{array}{c}3 \text { Std. } \\
\bar{x} \pm \text { SEM }\end{array}$ & $\begin{array}{c}6 \text { Std. } \\
\bar{x} \pm \text { SEM }\end{array}$ \\
\hline Nanostraw $\quad(n=24)$ & $29,3 \pm 1,7^{\mathrm{a}, \mathrm{A}}$ & $15,0 \pm 1,6^{\mathrm{a}, \mathrm{B}}$ & $7,3 \pm 0,9^{\mathrm{a}, \mathrm{C}}$ \\
\hline Kontrollstraw $(n=24)$ & $38,8 \pm 2,1^{\mathrm{b}, \mathrm{A}}$ & $24,2 \pm 1,9^{b, B}$ & $11,9 \pm 1,9^{\mathrm{a}, \mathrm{C}}$ \\
\hline
\end{tabular}


Tabelle 52: Kürzeste zurückgelegte Distanz der Spermien zwischen Anfangs- und Endpunkt (VSL; $\bar{x} \pm$ SEM $\mu \mathrm{m} /$ Sek.) des Bullen B unmittelbar nach dem Auftauen sowie nach drei- und sechsstündiger Inkubation bei $37^{\circ} \mathrm{C}$

\begin{tabular}{|c|c|c|c|}
\hline Gruppe & $\begin{array}{c}\text { O Std. } \\
\bar{x} \pm \text { SEM }\end{array}$ & $\begin{array}{c}3 \text { Std. } \\
\bar{x} \pm \text { SEM }\end{array}$ & $\begin{array}{c}6 \text { Std. } \\
\bar{x} \pm \text { SEM }\end{array}$ \\
\hline Nanostraw $\quad(n=24)$ & $37,1 \pm 0,9^{A}$ & $32,9 \pm 0,9^{B}$ & $30,0 \pm 1,0^{C}$ \\
\hline Kontrollstraw $(\mathrm{n}=24)$ & $37,8 \pm 1,4^{\mathrm{A}}$ & $32,9 \pm 0,9^{B}$ & $28,2 \pm 0,8^{C}$ \\
\hline
\end{tabular}

Tabelle 53: Volle zurückgelegte Distanz (VCL; $\bar{x} \pm$ SEM $\mu \mathrm{m} /$ Sek.) des Bullen B unmittelbar nach dem Auftauen sowie nach drei- und sechsstündiger Inkubation bei $37^{\circ} \mathrm{C}$

\begin{tabular}{lccc}
\hline Gruppe & $\begin{array}{c}\mathbf{0} \text { Std. } \\
\bar{x} \pm \text { SEM }\end{array}$ & $\begin{array}{c}\text { 3 Std. } \\
\bar{x} \pm \text { SEM }\end{array}$ & $\begin{array}{c}6 \text { Std. } \\
\bar{x} \pm \text { SEM }\end{array}$ \\
\hline Nanostraw $\quad(\mathbf{n = 2 4})$ & $107,2 \pm 2,8^{\mathrm{A}}$ & $108,6 \pm 3,9^{\mathrm{A}}$ & $87,4 \pm 3,2^{\mathrm{B}}$ \\
Kontrollstraw $(\mathbf{n = 2 4})$ & $108,9 \pm 3,6^{\mathrm{A}}$ & $101,7 \pm 3,4^{\mathrm{A}}$ & $81,0 \pm 3,4^{\mathrm{B}}$
\end{tabular}

$A, B, C$ : Werte mit unterschiedlichen Indizes unterscheiden sich innerhalb einer Gruppe bei Betrachtung aller Untersuchungszeitpunkte signifikant $(p \leq 0,05)$.

Tabelle 54: Geglättete zurückgelegte Distanz (VAP; $\bar{x} \pm$ SEM $\mu \mathrm{m} /$ Sek.) des Bullen B unmittelbar nach dem Auftauen sowie nach drei- und sechsstündiger Inkubation bei $37^{\circ} \mathrm{C}$

\begin{tabular}{lccc}
\hline Gruppe & $\begin{array}{c}\text { 0 Std. (\%) } \\
\bar{x} \pm \text { SEM }\end{array}$ & $\begin{array}{c}\text { 3 Std. (\%) } \\
\bar{x} \pm \text { SEM }\end{array}$ & $\begin{array}{c}\text { 6 Std. (\%) } \\
\bar{x} \pm \text { SEM }\end{array}$ \\
\hline Nanostraw $\quad(\mathbf{n = 2 4 )}$ & $55,7 \pm 0,9^{\mathrm{A}}$ & $57,2 \pm 2,4^{\mathrm{A}}$ & $48,5 \pm 2,5^{\mathrm{B}}$ \\
Kontrollstraw (n=24) & $57,9 \pm 1,9^{\mathrm{A}}$ & $55,8 \pm 2,1^{\mathrm{A}}$ & $45,1 \pm 2,4^{\mathrm{B}}$ \\
$\begin{array}{l}\mathrm{A}, \mathrm{B}, \mathrm{C}: \text { Werte mit unterschiedlichen Indizes unterscheiden sich innerhalb einer Gruppe bei Betrachtung aller } \\
\text { Untersuchungszeitpunkte signifikant }(\mathrm{p} \leq 0,05) .\end{array}$
\end{tabular}


Tabelle 55: Seitlich Auslenkung der Spermienköpfe (ALH; $\bar{x} \pm$ SEM $\mu \mathrm{m}$ ) des Bullen B unmittelbar nach dem Auftauen sowie nach drei- und sechsstündiger Inkubation bei $37^{\circ} \mathrm{C}$

\begin{tabular}{|c|c|c|c|}
\hline & 0 Std. (\%) & 3 Std. (\%) & 6 Std. (\%) \\
\hline Gruppe & $\bar{x} \pm$ SEM & $\bar{x} \pm$ SEM & $\bar{x} \pm \mathrm{SEM}$ \\
\hline Nanostraw $\quad(n=24)$ & $6,2 \pm 0,1$ & $7,0 \pm 0,2$ & $7,1 \pm 0,2^{a}$ \\
\hline Kontrollstraw $(n=24)$ & $6,2 \pm 0,2$ & $6,6 \pm 0,2^{A}$ & $5,8 \pm 0,4^{b, B}$ \\
\hline
\end{tabular}

Tabelle 56: Frequenz der Pendelbewegung (BCF; $\bar{x} \pm$ SEM Hz) des Bullen B unmittelbar nach dem Auftauen sowie nach drei- und sechsstündiger Inkubation bei $37^{\circ} \mathrm{C}$

\begin{tabular}{|c|c|c|c|}
\hline & 0 Std. (\%) & 3 Std. (\%) & 6 Std. (\%) \\
\hline Gruppe & $\bar{x} \pm \mathrm{SEM}$ & $\bar{x} \pm \mathrm{SEM}$ & $\bar{x} \pm \mathrm{SEM}$ \\
\hline Nanostraw $\quad(n=24)$ & $22,7 \pm 0,4^{\mathrm{a}, \mathrm{A}}$ & $21,6 \pm 0,3$ & $20,8 \pm 0,6^{B}$ \\
\hline Kontrollstraw $(n=24)$ & $21,3 \pm 0,3^{b}$ & $21,1 \pm 0,4$ & $22,1 \pm 0,5$ \\
\hline
\end{tabular}

Tabelle 57: Straightness (STR; $\bar{x} \pm$ SEM \%) der Spermien des Bullen B unmittelbar nach dem Auftauen sowie nach drei- und sechsstündiger Inkubation bei $37^{\circ} \mathrm{C}$

\begin{tabular}{|c|c|c|c|}
\hline & 0 Std. (\%) & 3 Std. (\%) & 6 Std. (\%) \\
\hline Gruppe & $\bar{x} \pm$ SEM & $\bar{x} \pm \mathrm{SEM}$ & $\bar{x} \pm \mathrm{SEM}$ \\
\hline Nanostraw $\quad(n=24)$ & $67,3 \pm 1,3^{A}$ & $60,5 \pm 1,6^{\mathrm{B}}$ & $65,0 \pm 2,0^{A}$ \\
\hline Kontrollstraw $(n=24)$ & $66,7 \pm 1,0^{A}$ & $61,8 \pm 1,5^{\mathrm{B}}$ & $67,4 \pm 1,8^{A}$ \\
\hline
\end{tabular}


Tabelle 58: Linearity (LIN; $\bar{x} \pm$ SEM \%) der Spermien des Bullen B unmittelbar nach dem Auftauen sowie nach drei- und sechsstündiger Inkubation bei $37^{\circ} \mathrm{C}$

\begin{tabular}{|c|c|c|c|}
\hline & 0 Std. (\%) & 3 Std. (\%) & 6 Std. (\%) \\
\hline Gruppe & $\bar{x} \pm$ SEM & $\bar{x} \pm \mathrm{SEM}$ & $\bar{x} \pm \mathrm{SEM}$ \\
\hline Nanostraw $\quad(n=24)$ & $37,2 \pm 1,1^{\mathrm{A}}$ & $32,4 \pm 0,8^{B}$ & $36,6 \pm 1,8^{A}$ \\
\hline Kontrollstraw ( $n=24)$ & $37,6 \pm 0,6$ & $35,8 \pm 1,6$ & $38,0 \pm 1,5$ \\
\hline
\end{tabular}

$A, B, C$ : Werte mit unterschiedlichen Indizes unterscheiden sich innerhalb einer Gruppe bei Betrachtung aller Untersuchungszeitpunkte signifikant $(p \leq 0,05)$. 


\subsection{Tabellenverzeichnis}

Tabelle 1: Beschreibung der Beurteilung der Spermienbewegung (KATHIRAVAN ET AL., 2011).

Tabelle 2: Korrelation der am CASA bzw. subjektiv unter dem Mikroskop gemessenen Motilität und der Fruchtbarkeit in vivo

Tabelle 3: Morphologische Untersuchungsklassifikation (WEITZE, 2001) 13

Tabelle 4: Grenzwerte für die Qualität sortierter Spermien (RATH ET AL. 2009). 16

Tabelle 5: Geburtsjahr, Gesamtzuchtwert (RZG), Relativzuchtwert Milch (RZM), Relativzuchtwert Exterieur (RZE), Relativzuchtwert Nutzungsdauer (RZN) und der Relativzuchtwert Kalbeverlauf (KV) der in den Versuchen eingesetzten Bullen

Tabelle 6: Detaillierte Darstellung in ${ }^{\circ} \mathrm{C}$ pro Minute der Gefrierkurve $\mathrm{A}$

Tabelle 7: Darstellung der angewandten Kühlkurven unter Verwendung unterschiedlicher Glyzerinkonzentrationen

Tabelle 8: Anzahl besamter Färsen je Bulle sowie die Aufteilung nach $\mathrm{X}$ - und Ychromosomal verwendeten Spermaportionen

Tabelle 9: Anzahl besamter Kühe des Bullen $D$, aufgeteilt nach unterschiedlichen Besamungsdosen.

Tabelle 10: Anteil motiler Spermien (in \%) aus den Gefrierkurven A, B, C, D und D+ unmittelbar nach dem Auftauen.

Tabelle 11: Anteil motiler Spermien (in \%) der Gefrierkurve D+ mit einem Anteil von $5 \%$ und $7 \%$ Glyzerin unmittelbar nach dem Auftauen 58

Tabelle 12: Anteil vorwärtsbeweglicher Spermien (in \%) der Gefrierkurven A, B, $\mathrm{C}, \mathrm{D}$ und $\mathrm{D}+$ unmittelbar nach dem Auftauen. 59

Tabelle 13: VSL der Spermien (in \%) der Gefrierkurven A, B, C, D und D+ unmittelbar nach dem Auftauen. 60

Tabelle 14: VCL der Spermien (in \%) der Gefrierkurven A, B, C, D und D+ unmittelbar nach dem Auftauen.

Tabelle 15: VAP der Spermien (in \%) der Gefrierkurven A, B, C, D und D unmittelbar nach dem Auftauen.

Tabelle 16: ALH der Spermien (in \%) der Gefrierkurven A, B, C, D und D+ unmittelbar nach dem Auftauen. 
Tabelle 17: BCF der Spermien (in \%) der Gefrierkurven A, B, C, D und D+ unmittelbar nach dem Auftauen.

Tabelle 18: STR der Spermien (in \%) der Gefrierkurven A, B, C, D und D+

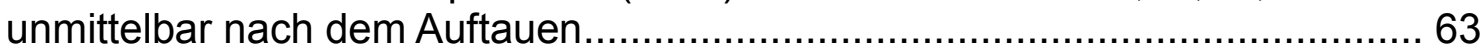

Tabelle 19: LIN der Spermien (in \%) der Gefrierkurven A, B, C, D und D+ unmittelbar nach dem Auftauen

Tabelle 20: Anteil membranintakter Spermien (PI-negativ; in \%) der Kurven A, B, $C, D$ und $D+$ unmittelbar nach dem Auftauen

Tabelle 21: Anteil membranintakter Spermien (PI-negativ; in \%) der Kurve D+ mit einem Anteil von 5\% und 7\% Glyzerin (GLY) unmittelbar nach dem Auftauen

Tabelle 22: Anteil morphologisch intakter Spermien (in \%) der Kurven A, B, C, $\mathrm{D}, \mathrm{D}+$ unmittelbar nach dem Auftauen

Tabelle 23: Anteil morphologisch intakter Spermien (in \%) der Kurve D+ mit einem Anteil von 5\% bzw. 7\% Glyzerin (GLY) unmittelbar nach dem Auftauen 66

Tabelle 24: Anteil Spermien (in \%) mit einem intakten Akrosom der Kurven A, B, C, D, D+ unmittelbar nach dem Auftauen. 66

Tabelle 25: Anteil Spermien ( $\bar{x} \pm$ SEM \%) mit einem intakten Akrosom der Kurve D+ mit einem Anteil von 5\% und 7\% Glyzerin (GLY) unmittelbar nach dem Auftauen.

Tabelle 26: Einfluss der fixen Effekte Bulle, Strawtyp und Zeit (Thermoresistenztest) sowie deren Interaktionen auf die Merkmale der Spermaqualität. 69

Tabelle 27: Anteil motiler Spermien (in \%) des Bullen A unmittelbar nach dem Auftauen sowie nach drei- und sechsstündiger Inkubation bei $37^{\circ} \mathrm{C}$. 70

Tabelle 28: Anteil motiler Spermien (in \%) des Bullen B unmittelbar nach dem Auftauen sowie nach drei- und sechsstündiger Inkubation bei $37^{\circ} \mathrm{C}$. 71

Tabelle 29: Anteil membranintakter Spermien (PI-negativ; in \%) des Bullen A unmittelbar nach dem Auftauen sowie nach drei- und sechsstündiger Inkubation bei $37^{\circ} \mathrm{C}$

Tabelle 30: Anteil membranintakter Spermien (PI-negativ; in \%) des Bullen B unmittelbar nach dem Auftauen sowie nach drei- und sechsstündiger Inkubation bei $37^{\circ} \mathrm{C}$

Tabelle 31: Anteil morphologisch intakter Spermien (in \%) des Bullen A unmittelbar nach dem Auftauen sowie nach drei- und sechsstündiger Inkubation bei $37^{\circ} \mathrm{C}$ 
Tabelle 32: Anteil morphologisch intakter Spermien (in \%) des Bullen B unmittelbar nach dem Auftauen sowie nach drei- und sechsstündiger Inkubation bei $37^{\circ} \mathrm{C}$

Tabelle 33: Anteil Spermien mit intaktem Akrosom (in \%) des Bullen A unmittelbar nach dem Auftauen sowie nach drei- und sechsstündiger Inkubation bei $37^{\circ} \mathrm{C}$

Tabelle 34: Anteil Spermien mit intaktem Akrosom (in \%) des Bullen B unmittelbar nach dem Auftauen sowie nach drei- und sechsstündiger Inkubation bei $37^{\circ} \mathrm{C}$

Tabelle 35: Überblick über die vorherige Behandlung der Färsen sowie deren Follikelgrößen unmittelbar vor und $24 \mathrm{~h}$ nach der Samenübertragung sowie die Trächtigkeitsergebnisse nach der Übertragung von X- und Y- chromosmal sortierten Spermien der Bullen C und D durch SIFT ${ }^{\circledR}$

Tabelle 36: Überblick über die vorherige Behandlung der Kühe sowie deren Follikelgrößen unmittelbar vor und $24 \mathrm{~h}$ nach der Samenübertragung.... 81

Tabelle 37: Überblick über die vorherige Behandlung der Rinder sowie deren Follikelgrößen unmittelbar vor und $24 \mathrm{~h}$ nach der Samenübertragung mit dem Sperma aus dem Nanostraw.

Tabelle 38: Überblick über die vorherige Behandlung der Kühe sowie deren Follikelgrößen unmittelbar vor und $24 \mathrm{~h}$ nach der Samenübertragung mit dem Sperma aus dem Nanostraw 84

Tabelle 39: Detaillierte Darstellung in ${ }^{\circ} \mathrm{C}$ pro Minute der Gefrierkurve $\mathrm{B}$....... 130 Tabelle 40: Detaillierte Darstellung in ${ }^{\circ} \mathrm{C}$ pro Minute der Gefrierkurve $\mathrm{C}$....... 130 Tabelle 41: Detaillierte Darstellung in ${ }^{\circ} \mathrm{C}$ pro Minute der Gefrierkurve D....... 130 Tabelle 42: Detaillierte Darstellung in ${ }^{\circ} \mathrm{C}$ pro Minute der Gefrierkurve $D+\ldots . .130$ Tabelle 43: Anteil vorwärtsbeweglicher Spermien ( $\bar{x} \pm$ SEM \%) des Bullen A unmittelbar nach dem Auftauen sowie nach drei- und sechsstündiger Inkubation bei $37^{\circ} \mathrm{C}$ 131

Tabelle 44: Kürzeste zurückgelegte Distanz der Spermien zwischen Anfangsund Endpunkt (VSL; $\bar{x} \pm$ SEM $\mu \mathrm{m} / \mathrm{sek}$ ) des Bullen A unmittelbar nach dem Auftauen sowie nach drei- und sechsstündiger Inkubation bei $37^{\circ} \mathrm{C}$ 131

Tabelle 45: Volle zurückgelegte Distanz (VCL; $\bar{x} \pm$ SEM $\mu \mathrm{m} / \mathrm{sek}$ ) des Bullen A unmittelbar nach dem Auftauen sowie nach drei- und sechsstündiger Inkubation bei $37^{\circ} \mathrm{C}$ 131 
Tabelle 46: Geglättete zurückgelegte Distanz (VAP; $\bar{x} \pm$ SEM $\mu \mathrm{m} / \mathrm{sek}$ ) des Bullen A unmittelbar nach dem Auftauen sowie nach drei- und sechsstündiger Inkubation bei $37^{\circ} \mathrm{C}$ 132

Tabelle 47: Seitlich Auslenkung der Spermienköpfe $(\mathrm{ALH} ; \bar{x} \pm \mathrm{SEM} \mu \mathrm{m})$ des Bullen A unmittelbar nach dem Auftauen sowie nach drei- und sechsstündiger Inkubation bei $37^{\circ} \mathrm{C}$

Tabelle 48: Frequenz der Pendelbewegung (BCF; $\bar{x} \pm \mathrm{SEM} \mathrm{Hz)}$ des Bullen $\mathrm{A}$ unmittelbar nach dem Auftauen sowie nach drei- und sechsstündiger Inkubation bei $37^{\circ} \mathrm{C}$

Tabelle 49: Straightness (STR; $\bar{x} \pm$ SEM \%) der Spermien des Bullen A unmittelbar nach dem Auftauen sowie nach drei- und sechsstündiger Inkubation bei $37^{\circ} \mathrm{C}$

Tabelle 50: Linearity (LIN; $\bar{x} \pm$ SEM \%) der Spermien des Bullen A unmittelbar nach dem Auftauen sowie nach drei- und sechsstündiger Inkubation bei $37^{\circ} \mathrm{C}$

Tabelle 51: Anteil vorwärtsbeweglicher Spermien ( $\bar{x} \pm$ SEM \%) des Bullen B unmittelbar nach dem Auftauen sowie nach drei- und sechsstündiger Inkubation bei $37^{\circ} \mathrm{C}$

Tabelle 52: Kürzeste zurückgelegte Distanz der Spermien zwischen Anfangsund Endpunkt (VSL; $\bar{x} \pm$ SEM $\mu \mathrm{m} / \mathrm{sek}$ ) des Bullen B unmittelbar nach dem Auftauen sowie nach drei- und sechsstündiger Inkubation bei $37^{\circ} \mathrm{C}$. 134

Tabelle 53: Volle zurückgelegte Distanz (VCL; $\bar{x} \pm$ SEM $\mu \mathrm{m} / \mathrm{sek}$ ) des Bullen B unmittelbar nach dem Auftauen sowie nach drei- und sechsstündiger Inkubation bei $37^{\circ} \mathrm{C}$

Tabelle 54: Geglättete zurückgelegte Distanz (VAP; $\bar{x} \pm$ SEM $\mu \mathrm{m} / \mathrm{sek}$ ) des Bullen $B$ unmittelbar nach dem Auftauen sowie nach drei- und sechsstündiger Inkubation bei $37^{\circ} \mathrm{C}$ 134

Tabelle 55: Seitlich Auslenkung der Spermienköpfe (ALH; $\bar{x} \pm$ SEM $\mu \mathrm{m})$ des Bullen $B$ unmittelbar nach dem Auftauen sowie nach drei- und sechsstündiger Inkubation bei $37^{\circ} \mathrm{C}$

Tabelle 56: Frequenz der Pendelbewegung (BCF; $\bar{x} \pm \mathrm{SEM} \mathrm{Hz)}$ des Bullen B unmittelbar nach dem Auftauen sowie nach drei- und sechsstündiger Inkubation bei $37^{\circ} \mathrm{C}$ 135

Tabelle 57: Straightness (STR; $\bar{x} \pm$ SEM \%) der Spermien des Bullen B unmittelbar nach dem Auftauen sowie nach drei- und sechsstündiger Inkubation bei $37^{\circ} \mathrm{C}$ 
Tabelle 58: Linearity (LIN; $\bar{x} \pm$ SEM \%) der Spermien des Bullen B unmittelbar nach dem Auftauen sowie nach drei- und sechsstündiger Inkubation bei $37^{\circ} \mathrm{C}$ 136 


\subsection{Abbildungsverzeichnis}

Abbildung 1: Übersicht über den Versuchsablauf........................................... 36

Abbildung 2: Besamungskatheter (SIFT ${ }^{\circledR}$-Sonde) ........................................ 42

Abbildung 3: Aufsaugen des Inseminatvolumens in den Innenkatheter ........... 43

Abbildung 4: Graphische Darstellung der einzelnen Schritte des Besamungsvorgangs SIFT $^{\circledR}$ anhand von endoskopischen Aufnahmen der Zervix, Bifurkation und der uterotubalen Verbindung im Uterus ....................... 44

Abbildung 5: Darstellung des Nanostraws in seinen Einzelbestandteilen, dem Innenkatheter sowie der Endversion in der ein handelsüblicher Straw zum Schutz vor Temperaturschwankungen und zur besseren Kennzeichnung über den Innenkatheter gezogen wird (siehe oben im Bild). Zum Größenvergleich ist eine handelsübliche Wäscheklammer dargestellt. 45

Abbildung 6: Modifizierung des Ice Cube 14S mittels eines Schutzgitters (roter Pfeil) aus Metall 49

Abbildung 7: Darstellung der fünf entwickelten Kühlkurven in ${ }^{\circ} \mathrm{C}$ pro Minute... 57 Abbildung 8: Linearität (\%) der Spermien des Bullen A und B im Thermoresistenztest........................................................................ 72

Abbildung 9: Straightness (\%) der Spermien der Bullen A und B im Thermoresistenztest. 73

Abbildung 10: Darstellung eines Fetus ca.30 Tage nach SIFT ${ }^{\circledR}$ von Tier 9786.85 


\subsection{Eidesstattliche Erklärung}

Hiermit erkläre ich, dass diese Arbeit weder in gleicher noch in ähnlicher Form bereits anderen Prüfungsbehörden vorgelegen hat.

Weiter erkläre ich, dass ich mich an keiner anderen Hochschule um einen Doktorgrad beworben habe.

Göttingen, den

(Unterschrift)

Hiermit erkläre ich eidesstattlich, dass diese Dissertation selbständig und ohne unerlaubte Hilfe angefertigt wurde.

Göttingen, den

(Unterschrift) 


\section{Lebenslauf}

Marlene-Sophie Strothmeyer

geb. am 16.01.1984 in Göttingen

\section{Studium}

03/2010-05/2013

Promotionsstudiengang der Agrarwissenschaften an der Georg-August-Universität Göttingen .

Anfertigung der Dissertation am Institut für Nutztiergenetik, Friedrich-Löffler-Institut (FLI), Bundesforschungsinstitut für Tiergesundheit, Mariensee und der Abteilung Reproduktion und Biotechnologie landwirtschaftlicher Nutztiere der Georg-AugustUniversität Göttingen.

Studium der Agrarwissenschaften an der ChristianAlbrechts-Universität Kiel.

Studienschwerpunkt: Nutztierwissenschaften.

Anfertigung der Masterarbeit am Institut für Tierzucht und Tierhaltung der Christian-Albrechts-Universität zu Kiel.

Thema: Ursachen und Häufigkeit von operativen Therapien beim Pferd.

Abschluss: Master of Science.

08/1996-05/2003

Goethegymnasium, Einbeck, Germany Abschluss: Abitur 


\section{Danksagung}

Die vorliegende Arbeit wurde am Institut für Nutztiergenetik, Friedrich-LoefflerInstitut (FLI), Bundesforschungsinstitut für Tiergesundheit, Mariensee sowie dem Department für Nutztierwissenschaften, Abteilung Reproduktion und Biotechnologie landwirtschaftlicher Nutztiere der Georg-August Universität Göttingen, geschrieben. Unterstützt wurde die Arbeit von der German Genetics International $\mathrm{GmbH}(\mathrm{GGI})$.

Daher möchte ich mich insbesondere bei der GGI für die gute Zusammenarbeit und die Finanzierung meiner Arbeit bedanken.

Ein großer Dank gilt Herrn Prof Dr. Rath, der mir dieses interessante Thema überlassen hat. Vielen Dank für Ihr großes Vertrauen, die ständige Unterstützung und den Einblick in die Forschung. Sie haben mich gelehrt die Dinge auch mal aus einem anderen Blickwinkel zu betrachten.

Ein weiterer Dank geht an Herrn Prof. Dr. Knorr der mir besonders in den letzten zwei Monaten meiner Arbeit mit Rat und Tat zu Seite stand. Vielen Dank für Ihre große Geduld, Unterstützung und konstruktive Kritik.

Einen großen Anteil an dem Gelingen meiner Arbeit haben die Mitarbeiter aus dem Versuchsstall des FLI, Mariensee. Ein riesiges Dankeschön gilt daher Rolf Poppenga und Hans-Georg Sander, die mich bei der Durchführung der Besamungsversuche unterstützt haben. Ihr habt mir die Grundlagen der Besamung, Trächtigkeitsuntersuchungen und den Umgang mit kleinen wilden Färsen beigebracht. Vom ersten Tag an habt ihr das Projekt mit guten Tipps, viel Geduld und der nötigen Ruhe begleitet. Eure lieben Worte in zum Teil schwieriger Situation haben mich immer wieder aufgebaut. Vielen Dank, auch an den Rest der Stallmannschaft!

Ein weiterer Dank gilt den fleißigen Helfern aus dem Labor des Instituts für Nutztiergenetik sowie aus dem Labor der Masterrind $\mathrm{GmbH}$. Vielen Dank an Birgit Sieg, Patrick Aldag, Antje Frenzel, Christina Struckmann, Christiane von Tils, Andre Mittag, Lothar Schindler und das gesamte Laborteam der Masterrind $\mathrm{GmbH}$. Ihr hattet einen großen Anteil am Gelingen meiner Arbeit, dafür möchte 
ich mich recht herzlich bei Euch bedanken. Zudem möchte ich mich bei der Masterrind für die Bereitstellung der Besamungsportionen für den Laborversuch bedanken. Ebenfalls danken möchte ich Andres und Mike für die Durchführung der Ovarpunktionen.

Dr. Christine Ehling hat mich während meiner Arbeit in Mariensee immer unterstützt und mir zahlreiche Tipps gegeben. Vielen Dank !

Vielen Dank auch an Dr. Ulrich Baulein, der mir eine große Hilfe bei der Ausführung der statistischen Auswertung war.

Ein riesen Dank geht an Annabel Bergmann, die von Anfang an meiner Seite stand. Die Zeit in Mariensee ist mit Dir wie im Flug vergangen. Danke für die tolle Zeit (Tür an Tür), die ständige Unterstützung und deine fröhliche Art. Ich hoffe wir verlieren uns nicht aus den Augen und treffen uns demnächst mal wieder beim alkoholfreien Imbiss.

Vielen Dank auch an meine weiteren Bürokollegen Dr. Ulrike Taylor, Dr. Rudolph Grossfeld, Dr. Gerd Mönch-Tegeder, Dr. Sonja Junge und Stephanie Thebille. Es war eine spannende und gute Zeit mit Euch. Dabei möchte ich mich bei Rudolph Grossfeld für die Einführung in SIFT ${ }^{\circledR}$ und den Feldversuch in Dedelow bedanken.

Desweitern danke ich meiner Kollegin und Freundin Dr. Kerstin Reiners, die mir in den letzten Monaten mit vielen nützlichen Tipps zur Seite stand. Ich hoffe wir bleiben weiterhin in Kontakt.

Ein großer Dank geht an Heinrich Luttmann. Ich kann immer auf dich zählen und du unterstützt mich wo du nur kannst. Danke!

Nicht zu vergessen Katharina Zühlsdorf. Du bist die Beste!

Zum Schluss noch ein riesen Dankeschön an meine Familie! Meinen Eltern Hannelore und Gerd Strothmeyer sowie meinen Geschwistern Sina und Isabell, die mich von Anfang an mit guten Tipps unterstützt haben. Das war spitze. Es ist schön zu wissen, dass ich immer auf Euch zählen kann. 